\title{
Guidelines for the management of patients with Crohn's disease. Recommendations of the Polish Society of Gastroenterology and the Polish National Consultant in Gastroenterology
}

\author{
Michał Łodyga ${ }^{1}$, Piotr Eder ${ }^{2}$, Magdalena Gawron-Kiszka ${ }^{3}$, Agnieszka Dobrowolska², Maciej Gonciarz ${ }^{4}$, \\ Marek Hartleb ${ }^{3}$, Maria Kłopocka5 ${ }^{5}$ Ewa Małecka-Wojciesko ${ }^{6}$, Piotr Radwan7, Jarosław Reguła, \\ Edyta Zagórowicz ${ }^{8,9}$, Grażyna Rydzewska ${ }^{1,10}$
}

\begin{abstract}
${ }^{1}$ Department of Gastroenterology with the Inflammatory Bowel Disease Subdivision, Central Clinical Hospital of the Ministry of the Interior and Administration, Warsaw, Poland

${ }^{2}$ Department of Gastroenterology, Dietetics and Internal Medicine, Poznan University of Medical Sciences, Heliodor Święcicki University Hospital, Poznan, Poland

${ }^{3}$ Department of Gastroenterology and Hepatology, Medical University of Silesia, Katowice, Poland

${ }^{4}$ Department of Gastroenterology and Internal Medicine, Military Institute of Medicine, Warsaw, Poland

${ }^{5}$ Department of Gastroenterology and Nutritional Disorders, Collegium Medicum in Bydgoszcz, Nicolaus Copernicus University in Torun, Poland

${ }^{6}$ Department of Digestive Tract Diseases, Medical University of Lodz, Lodz, Poland

${ }^{7}$ Department of Gastroenterology, Medical University of Lublin, Lublin, Poland

${ }^{8}$ Department of Gastroenterology, Hepatology and Clinical Oncology, Center of Postgraduate Medical Education, Warsaw,

Poland

${ }^{9}$ Department of Oncological Gastroenterology, Maria Skłodowska-Curie National Research Institute of Oncology, Warsaw, Poland

${ }^{10}$ Collegium Medicum, Jan Kochanowski University, Kielce, Poland
\end{abstract}

Key words: Crohn's disease, endoscopy, thiopurines, biological medicines.

Address for correspondence: Michał todyga, Department of Gastroenterology with the Inflammatory Bowel Disease Subdivision, Central Clinical Hospital of the Ministry of the Interior and Administration, 137 Wołoska St, 02-507 Warsaw, Poland, phone: +4772212 40, e-mail: michal.lodyga@cskmswia.gov.pl

\begin{abstract}
This paper is an update of the diagnostic and therapeutic recommendations of the National Consultant for Gastroenterology and the Polish Society of Gastroenterology from 2012. It contains 46 recommendations for the diagnosis and treatment, both pharmacological and surgical, of Crohn's disease in adults. The guidelines were developed by a group of experts appointed by the Polish Society of Gastroenterology and the National Consultant in the field of Gastroenterology. The methodology related to the GRADE methodology was used to assess the quality and strength of the available recommendations. The degree of expert support for the proposed statement, assessment of the quality of evidence and the strength of the recommendation was assessed on a 6-point Likert scale. Voting results, quality and strength ratings with comments are included with each statement.
\end{abstract}




\section{Introduction}

These guidelines provide an update to the 2012 diagnostic and therapeutic recommendations of the Polish National Consultant in Gastroenterology and the Polish Society of Gastroenterology for the management of adult patients with Crohn's disease (CD), as amended [1-3]. The update was prepared by the Inflammatory Bowel Disease (IBD) Working Group of the Polish Society of Gastroenterology (PTGE).

\section{Objective}

The main objective of this document is to complete the guidelines already in force to include new information, particularly regarding new medicines which have been registered for use in CD since 2012 as well as to popularize and harmonize the rules of conduct in the management of CD to provide patients with better access to diagnostics and treatment as based on current knowledge. At the same time, previous findings were reviewed in terms of substance as well as methodology according to most of the current recommendations of the Agency for Health Technology Assessment and Tariff System (AOTMIT) on the principles for the construction of guidelines.

\section{Health problems addressed in the guidelines}

The recommendations address in detail the following health problems as related to $C D$ :

- the epidemiology of $C D$, including the dynamics of incidence and morbidity rate trends in recent years;

- current knowledge on the etiopathogenesis of CD;

- symptoms and clinical forms of CD;

- diagnostic management of patients with CD suspicion (including differential diagnosis) and diagnostic criteria;

- current recommendations regarding therapeutic management of CD including pharmacotherapy, surgery, nutritional and psychological support, as well as coordinated care of $C D$ patients.

\section{Target population of patients addressed by these guidelines}

These recommendations pertain to the management of adult patients (over 18 years old) with suspected or confirmed diagnosis of CD regardless of the disease form and the severity of symptoms.

\section{Epidemiology, pathogenesis and general characteristics of CD}

$C D$ is a transmural, segmental inflammatory process occurring in any segment of the gastrointestinal tract from the mouth to the anus. The disease is most common in young people, with peak incidence within the age group of 16 to 30 years. Data regarding a second peak between the $5^{\text {th }}$ and the $7^{\text {th }}$ decade of life are somewhat ambiguous. The prevalence of the disease is comparable in male and female patients [4]. No reliable data are available on the incidence and morbidity rates in Poland; however, a systematic rise in these values is evident. It is expected that values similar to those observed in the countries of Western Europe and the USA will be reached within several years. According to most recent studies, IBD is estimated to affect up to $1.3 \%$ of the population in the US and $1.1 \%$ of the population in the UK [5-7].

The etiology of the disease has not been fully elucidated. Chronic inflammation of the inflammatory tract is thought to result from a combination of environmental, immunological, and genetic factors. A key role is attributed to disturbed composition and proportions within the gut microbiota. The intestinal damage starts at the mucosal level. Over time, the disease encompasses the entire intestinal wall and may lead to formation of fistulas, abscesses, and strictures.

$C D$ is characterized by a course with alternating periods of exacerbations and remission of clinical symptoms. Extraintestinal manifestations may occur in addition to gastrointestinal lesions in $20-30 \%$ of patients; most frequently, these include skin and joint lesions.

No method of causal treatment is known for CD. Current pharmacological treatment is aimed at suppressing the activity of the immune system against gastrointestinal tissue. Surgical treatment is also an important part of CD management. The diagnostic and therapeutic management of CD patients is difficult and frequently problematic even for experienced gastroenterologists. In addition to the typical clinical presentation, many patients present with non-specific symptoms and the results of additional investigations may be inconclusive. Long-term treatment, frequently requiring difficult therapeutic decisions, is required in CD patients.

\section{V.1. Definitions}

Active disease - mild, moderate, or severe forms depending on the severity of symptoms. Clinical activity may be assessed by numerous means, with the most reliable indicators being based on clinical signs and simple laboratory parameters. The most popular of these indicators is the Crohn's Disease Activity Index (CDAI) (Table I). Active disease is defined as CDAI of above 150. CDAl score ranges of 150-219, 220-450, and above 450 correspond to mild, moderate, and severe disease, respectively [8].

The CDAI scale consists of many elements and is difficult to use in everyday practice. The Harvey-Brad- 
shaw Index $(\mathrm{HBI})$ is based on clinical parameters alone, is easy to calculate, and does not require symptoms to be logged over a period of a few days while satisfactorily describing the clinical activity of CD (Table II). The $\mathrm{HBI}$ value below 5 is considered to correspond to clinical remission while value ranges of $5-7,8-16$, and above 16 are indicative of mild, moderate, and severe disease, respectively [9].

Clinical remission - the period during which the individual diagnosed with CD remains asymptomatic. In practice, however, it is often difficult or impossible to achieve such remission. Therefore, it is accepted that minor symptoms not affecting the patient's quality of life (CDAl of less than 150, HBI of less than 5) may still be present in remission.

Clinical response - administered treatment leading to a reduction in the CDAl score by at least 100 points.

Exacerbation - symptoms emerging in an individual diagnosed with $C D$ hitherto in remission. Clinical signs of exacerbation should be confirmed by laboratory, imaging and/or endoscopic examinations.

Early exacerbation - exacerbation developing within 3 months from remission being achieved.

Endoscopic remission - condition in which no endoscopic lesions are observed within the gastrointestinal tract sections previously affected by inflammation. In a manner similar to that of clinical remission, complete return to the normal endoscopic image following disease exacerbation(s) is often impossible. Thus, the presence of minor macroscopic lesions is acceptable. However, the exact types of lesions acceptable upon disease remission remain controversial.

Several scales of endoscopic CD activity assessment have been developed to standardize endoscopic evaluations. Of these, the Crohn's Disease Endoscopic Index of Severity (CDEIS) [10] and the Simple Endoscopic Score for Crohn's Disease (SES-CD) are used most frequently [11]. SES-CD is easier to use, repeatable, and provides sufficient information.

Limited disease - pathological lesions located within a section of the bowel not exceeding $30 \mathrm{~cm}$, most frequently in the ileocecal region. The Montreal Classification (Table III) is widely used for simple description of CD phenotypes [12]. The classification system covers the three basic characteristics of the disease: the age at diagnosis, the location of inflammatory lesions, and the clinical behavior of the disease.

Steroid resistance - a clinical situation when remission cannot be achieved despite steroids being administered at full dose for 4 weeks. Steroid resistance is also referred to when only the clinical improvement is achieved without remission.

Steroid dependence - inability to reduce the dose of steroids below the dose equivalent to $10 \mathrm{mg}$
Table I. The CDAI Scale

\begin{tabular}{|c|c|c|}
\hline Variable & Multiplier & Result \\
\hline Number of loose stools/week & Total $\times 2$ & \\
\hline $\begin{array}{l}\text { Abdominal pain as assessed on } \\
\text { a scale of } 0-3 / \text { week }\end{array}$ & Total × 5 & \\
\hline $\begin{array}{l}\text { General wellbeing as assessed on } \\
\text { a scale of 0-4/week }\end{array}$ & Total $\times 7$ & \\
\hline $\begin{array}{l}\text { Extraintestinal symptoms ( } 0 \text { - none, } \\
1 \text { for each symptom) }\end{array}$ & Total $\times 20$ & \\
\hline Antidiarrheal drugs (0 - no, 1 - yes) & $\times 30$ & \\
\hline $\begin{array}{l}\text { Abdominal mass }(0 \text { - none, } \\
1 \text { - questionable, } 5 \text { - present) }\end{array}$ & $\times 10$ & \\
\hline $\begin{array}{l}\text { Hematocrit }(\mathrm{Ht}) \text { (women: } 42-\mathrm{Ht} \text {, } \\
\text { men: } 47-\mathrm{Ht})\end{array}$ & $\times 6$ & \\
\hline \multirow[t]{2}{*}{ Body weight (\% below due) } & $\times 1$ & \\
\hline & Total & \\
\hline
\end{tabular}

Table II. The HBI Scale

\begin{tabular}{ll}
\hline Variable & Result \\
\hline General wellbeing as assessed on a scale of $0-4$ \\
\hline Abdominal pain as assessed on a scale of $0-3$ \\
\hline Number of loose stools \\
\hline Abdominal mass ( 0 - none, 1 - questionable, \\
2 - present, 3 - present, tender) \\
\hline Extraintestinal symptoms (1 for each symptom) \\
\hline Total
\end{tabular}

Table III. The Montreal Classification of Crohn's Disease

\begin{tabular}{lc} 
Age at diagnosis & A1: $<17$ \\
& $A 2: 17-40$ \\
& $A 3:>40$ \\
\hline Location: & L1: ileum \\
L2: colon \\
L3: ileum and colon \\
\hline Behavior: & L4: upper gastrointestinal tract \\
\hline B1: no strictures or fistulas \\
B2: stricturing form \\
B3: fistulasing form \\
p: perianal lesions
\end{tabular}

prednisone or $3 \mathrm{mg}$ of budesonide over a period of 3 months of treatment or exacerbation developing within 3 months from the withdrawal of steroids.

The primary nonresponse is the lack of clinical improvement after the completion of induction treatment $[13,14]$. Most frequently, this definition refers to biological treatment (similarly to the secondary loss of response). 
Table IV. Criteria for assessing the strength (quality) of evidence

Strength (quality) of evidence
$\begin{aligned} & \text { Thigh } \\ & \text { This means that further research is very unlikely to change confidence in the estimate of effect } \\ & \text { (RTs). }\end{aligned}$
$\begin{array}{r}\text { Moderate } \\ \begin{array}{r}\text { Evidence derived from RCTs with important limitations (i.e. study bias, large loss to follow-up, lack of blinding, unex- } \\ \text { plained heterogeneity), indirect evidence derived from similar (but not identical) study populations, and studies with } \\ \text { a very low number of patients or observed events (endpoints) }\end{array} \\ \begin{array}{r}\text { In addition, evidence is available as derived from well-designed, controlled non-randomized studies, well-designed } \\ \text { cohort studies or case-control studies as well as multiple interventional or non-interventional case series. }\end{array} \\ \text { This means that further research is likely to have an important impact on confidence in the estimate of effect and may } \\ \text { change the estimate }\end{array}$
$\begin{array}{r}\text { Observational studies, typically of poor quality due to the risk of errors. } \\ \text { This means that further research is likely to have an important impact on confidence in the estimate of effect and is } \\ \text { likely to change the estimate }\end{array}$
$\begin{array}{r}\text { Levidence is contradictory and/or of poor quality and/or unavailable, and therefore the risk-benefit ratio cannot be } \\ \text { established. }\end{array}$
This means that any estimate of impact is uncertain as evidence, unavailable and/or inconclusive

Table V. Criteria for assessing the strength of recommendations

Recommendation strength
$\begin{gathered}\text { Strong The benefits clearly outweigh the risks and burdens, and vice versa. Typically, a strong recommendation includes the } \\ \text { phrase "we recommend" }\end{gathered}$
$\begin{gathered}\text { Weak } \quad \text { Benefits that are strictly balanced by risk and burdens. Typically, a weak recommendation includes the phrase "we } \\ \text { suggest" }\end{gathered}$

Secondary loss of response - exacerbation developing in the course of maintenance treatment in a patient in whom clinical remission had been previously achieved. This definition is often extended to include patients in whom the dose of the medicine used for maintenance treatment had to be increased in order to maintain the remission [13-15].

\section{V.2. Methodology for drawing up the guidelines}

These guidelines were drawn up by a group of experts appointed by the Polish Society of Gastroenterology and the Polish National Consultant in Gastroenterology. The group had initiated the development of the guidelines by formulating preliminary principles and a list of issues and clinical problems based on the recommendations already in force, which were then updated in line with current knowledge based on the PICO (Patients, Intervention, Comparator, Outcome) protocol. Major updates were required with regard to novel drugs being included in CD treatment algorithms.

At all stages of the drafting, recommendations were developed on the basis of source data as identified from the search of PubMed, Cochrane Library, and Embase electronic databases, as well as guidelines published on the websites of international scientific societies (European Crohn's and Colitis Organization (ECCO), including in particular the latest guidance based on the Grading of Recommendations Assessment, Development, and Evaluation (GRADE) methodology, the American Gastroenterological Association, the American College of Gastroenterology, and the British Society of Gastroenterology, including in particular the latest guidance based on the GRADE methodology) [16-18].

Quality and strength of available therapeutic recommendations were assessed using a GRADE-based methodology. For each recommendation, the quality of the evidence (Table IV: high, moderate, low, very low) and the strength of the recommendation (Table V: strong and weak recommendation) were determined by the experts.

After the recommendations were formulated and their strength and quality of evidence were estimat-

Table VI. The Likert scale

\begin{tabular}{lc} 
Approval rating & \\
\hline 1 & Complete disapproval \\
\hline 2 & Disapproval \\
\hline 3 & Partial disapproval \\
\hline 4 & Partial approval \\
\hline 5 & Approval \\
\hline 6 & Complete approval
\end{tabular}


ed, the final version of each recommendation was analyzed in detail. The degree of experts' approval of the proposed final phrasing of the recommendation, its strength and the quality of supporting evidence was assessed using a 6-point Likert scale, with 1 corresponding to complete disapproval/lack of support, 2 corresponding to disapproval/lack of support, 3 corresponding to partial disapproval/lack of support, 4 corresponding to partial approval/support, 5 corresponding to approval/support, and 6 corresponding to complete approval/support (Table VI).

Recommendations could be revised after voting. A recommendation was considered finally approved if it received a Likert score of $4-6$ from $>75 \%$ of the panelists (high unanimity rate). Unanimity rates of $\leq 75 \%$ were considered low.

The next step involved assessment of the quality of the guidelines using the AGREE II tool pursuant to the AOTMIT guidelines available at www.aotm.gov.pl. All comments were included in the final version of recommendations.

\section{V.3. Interpretation of the guidelines}

Each therapeutic recommendation was provided along with the following information:

- the quality of the evidence defined as high, moderate, low, or very low;

- the strength of the recommendation defined as strong or weak in line with the GRADE methodology; and - expert approval rating (the voting outcome).

\section{Diagnostics}

1. No pathognomonic symptom or combination of symptoms has been identified for Crohn's disease (CD). The diagnosis of CD is based on the overall clinical presentation and the results of additional endoscopic, radiological, and pathomorphological investigations.

(Evidence: low; recommendation: strong)

\begin{tabular}{|c|c|c|c|c|}
\hline \multicolumn{5}{|c|}{ Recommendation \#1 - Approval rating (Likert scale) } \\
\hline $\begin{array}{l}1-\text { Com- } \\
\text { plete dis- } \\
\text { approval }\end{array}$ & $\begin{array}{l}2 \text { - Disap- } \\
\text { proval }\end{array}$ & $\begin{array}{cc}\text { - } 3 \text { - Partial } & 4 \text {-Partial } \\
\text { disap- } & \text { approval } \\
\text { proval } & \end{array}$ & $\begin{array}{l}5-\mathrm{Ap}- \\
\text { proval }\end{array}$ & $\begin{array}{c}6- \\
\text { Complete } \\
\text { approval }\end{array}$ \\
\hline
\end{tabular}

At the moment, no clear criteria are available for the diagnosis of CD. The diagnosis should be based on macroscopic and microscopic evaluation of the gastrointestinal tract. Identification of intestinal sections affected by inflammation is possible by means of physical, endoscopic, and radiological examinations. Microscopic evaluation is performed on endoscopic bi- opsy specimens (being of limited value as they contain only the most superficial layers of intestinal mucosa and submucosa) as well as on postoperative transmural specimens (which are much more reliable). CD is diagnosed after confirmation of segmental, transmural, granulomatous (non-caseating) inflammation of the bowel. It is estimated that histopathological confirmation of CD can be achieved in as few as 30\% of patients with the disease. Lesions limited to the large intestine are particularly difficult. In about 3\% of patients initially diagnosed with ulcerative colitis, the diagnosis has to be changed to $\operatorname{CD}[19,20]$. In some cases, it is not possible to unambiguously differentiate these two nosocomial units despite repeated endoscopic and histopathological examinations. At that time, the disease is referred to as inflammatory bowel disease unclassified (IBDU). The diagnosis of CD may be very difficult due to its rich symptomatology and recurrent character. It is based on the overall clinical presentations and the results of additional investigations.

The most common symptoms of CD include diarrhea, abdominal pain and weight loss. CD should always be suspected if the above symptoms occur in a young individual, or if they present in a persistent or recurring fashion. In addition to gastrointestinal complaints, some patients complain of extraintestinal manifestations which may precede gastrointestinal symptoms. Most frequently, these include articular lesions (manifested as peripheral and axial joint inflammation) and skin lesions (pyoderma gangrenosum, erythema nodosum). In many cases, the diagnosis is confirmed only after complications of the disease have developed (abscesses, fistulas, strictures being observed in $15 \%$ of patients at the time of diagnosis) [21].

2. Ileocolonoscopy, including evaluation of the terminal ileal segment and biopsy collection is the primary endoscopic examination to be used in the diagnostics of CD. Gastroscopy should also be performed in each patient presenting with symptoms originating from the upper gastrointestinal tract.

(Evidence: low; recommendation: strong)

\begin{tabular}{|c|c|c|c|c|}
\hline $\begin{array}{l}1-\text { Com- } \\
\text { plete dis- } \\
\text { approval }\end{array}$ & $\begin{array}{l}\text { 2- Disap- } \\
\text { proval }\end{array}$ & $\begin{array}{cc}\text { 3-Partial } & 4-\text { Partial } \\
\text { disap- } & \text { approval } \\
\text { proval } & \end{array}$ & $\begin{array}{l}5-\mathrm{Ap}- \\
\text { proval }\end{array}$ & $\begin{array}{c}6- \\
\text { Complete } \\
\text { approval }\end{array}$ \\
\hline & & & $11 \%$ & $89 \%$ \\
\hline
\end{tabular}

Colonoscopy including evaluation of the terminal ileal segment and specimen collection is the primary endoscopic tool (with lesions within the terminal ile- 
um being observed in about $40 \%$ of patients and lesions within the large intestine being observed in about $40-50 \%$ of patients). Of particular diagnostic value are the cobblestone appearance of mucosa and segmental lesions within the terminal ileum, and perianal lesions $[22,23]$. In addition, endoscopic examination facilitates the assessment of disease activity. The anatomical criteria for the disease severity include deep ulcerations or extensive erosions and shallow ulcerations. Endoscopic scales, i.e. CDEIS and SES-CD [10, 11], can be helpful in the assessment of the severity of endoscopic lesions. The typical endoscopic presentation is sufficient for the diagnosis of CD and initiation of treatment after all other causes of clinical symptoms have been excluded. With regard to the specimens collected upon endoscopic examinations, histopathological confirmation is obtained in less than one third of the patients. However, CD cannot be excluded from an unremarkable outcome of colonoscopic examination. Full colonoscopy being performed during the active phase of the disease with extensive involvement of the large intestine is associated with a high risk of intestinal perforation and is therefore contraindicated.

Gastroscopic examination should also be performed in each patient with suspected CD and presenting with symptoms within the upper gastrointestinal tract. Pathological changes within the upper part of the gastrointestinal tract are relatively rare as they are observed in up to $13 \%$ of cases; however, their potential presence should always be taken into consideration when making therapeutic decisions. Endoscopic evaluation of the upper section of the gastrointestinal tract should also include the retrobulbar part of the duodenum including the collection of biopsy specimens from that region (for the diagnosis of celiac disease) [24, 25].

In $20-30 \%$ of patients, pathological changes develop only within the small intestine which cannot be assessed by conventional endoscopy. Usually, such lesions can be visualized in an indirect manner using computed tomography (CT) and magnetic resonance imaging (MRI) techniques. In the case of typical clinical symptoms and typical radiological presentation of the small intestine, no endoscopic verification is required for the diagnosis. In dubious cases, capsule endoscopy or enteroscopy is advisable. Ambiguous radiological presentation despite persisting typical clinical symptoms and lack of changes within the sections evaluable by colonoscopy are the typical indications for capsule endoscopy. In patients with confirmed CD, the examination is performed only in exceptional cases. Any strictures within the gastrointestinal tract which might result in capsule trapping should be ruled out prior to capsule endoscopy (passage tests, enterography).
Enteroscopy is rarely used for diagnostic purposes due to its low availability, high costs and lack of a significant advantage in terms of sensitivity and specificity over capsule endoscopy and radiological techniques. However, it facilitates the collection of specimens for histopathological examination in addition to macroscopic evaluation. Therefore, it should be resorted to when histopathological diagnosis is thought to have a significant impact on further treatment. In addition, enteroscopy can be performed as a therapeutic procedure (e.g. for dilatation of strictures).

\section{Magnetic resonance (MRI) enterography or enter-} oclysis is an optimal imaging technique for the assessment of inflammatory lesions, strictures, and fistulas within the small intestine. Computer tomograpgy (CT) examinations should be limited to the necessary minimum.

(Evidence: moderate; recommendation: strong)

\begin{tabular}{|c|c|c|c|c|}
\hline $\begin{array}{l}1-\text { Com- } \\
\text { plete dis- } \\
\text { approval }\end{array}$ & $\begin{array}{l}2 \text { - Disap- } \\
\text { proval }\end{array}$ & $\begin{array}{cc}3 \text { - Partial } & 4 \text { - Partial } \\
\text { disap- } & \text { approval } \\
\text { proval } & \end{array}$ & $\begin{array}{l}5-\text { Ap- } \\
\text { proval }\end{array}$ & $\begin{array}{c}6- \\
\text { Complete } \\
\text { approval }\end{array}$ \\
\hline
\end{tabular}

The diagnostics of small intestinal lesions is challenging as this section of the digestive tract is located outside the range of conventional endoscopic methods, and the availability of capsule endoscopy and enteroscopy is limited. Active inflammatory changes of the intestinal walls can be visualized by means of CT/MRI enterography or enteroclysis. However, these techniques are insufficient for identification of low severity lesions. In addition to enabling diagnostics of the intestines, radiological examinations facilitate the assessment of CD complications including abscesses, fistulas, or strictures. MRI is the preferred method as no risks associated with $X$-ray exposure are involved. The diagnostic value of both imaging techniques is comparable, although some authors emphasize that MRI is better at differentiating inflammatory and fibrotic lesions [26-29].

Ultrasound (US) examination of the abdominal cavity provides a lot of information which is often sufficient to make a diagnosis or identify complications. Ultrasound examinations are widely available, but their quality is largely determined by the skill and experience of the physician performing the examination. In cases of diagnostic ambiguities, an MRI or a CT scan should be used as reference [30-33].

\section{Basic laboratory investigations include peripheral blood count, inflammation markers (CRP, fecal cal- protectin), and markers of the nutritional status}


and absorption disorders (e.g. total protein and albumin levels, iron level).

(Evidence: high; recommendation: strong)

\begin{tabular}{|c|c|c|c|c|c|}
\hline \multicolumn{6}{|c|}{ Recommendation \#4 - Approval rating (Likert scale) } \\
\hline $\begin{array}{l}1 \text {-Com- } \\
\text { plete dis- } \\
\text { approval }\end{array}$ & $\begin{array}{c}2 \text { - Disap- } \\
\text { proval }\end{array}$ & $\begin{array}{c}3 \text { - Partial } \\
\text { disap- } \\
\text { proval }\end{array}$ & $\begin{array}{l}4 \text { - Partial } \\
\text { approval }\end{array}$ & $\begin{array}{l}5-\mathrm{Ap}- \\
\text { proval }\end{array}$ & $\begin{array}{c}6- \\
\text { Complete } \\
\text { approval }\end{array}$ \\
\hline & & & & $22 \%$ & $78 \%$ \\
\hline
\end{tabular}

Laboratory investigations are an important element of $C D$ diagnostics and monitoring. Determination of anti-Saccharomyces cerevisiae (ASCA) and antineutrophil cytoplasmic (ANCA) antibodies may be helpful in diagnosis of the disease in ambiguous cases. These markers are particularly useful for differential diagnostics of individual forms of IBD [34, 35]. The ASCA+, ANCA- configuration is suggestive of CD whereas the ASCA-, ANCA+ configuration is suggestive of ulcerative colitis (UC). The presence of inflammatory changes within the gastrointestinal tract is a characteristic of the active phase of $\mathrm{CD}$. Serum C-reactive protein (CRP) concentration is the most frequent inflammatory marker [36, 37]. Erythrocyte sedimentation rate (ESR) is less specific but may nevertheless be useful in assessing the condition of CD patients [38]. CRP levels remain normal in disease remission and increase in disease exacerbation periods. However, CD cannot be excluded from an unremarkable CRP result. The correlation between the concentration of CRP and the activity of the disease is not satisfactory, and therefore research of other, more sensitive and specific inflammatory markers is being continued. Of special note are the fecal markers (e.g. calprotectin, lactoferrin). Calprotectin levels are well correlated with the activity of inflammatory changes within the gut, particularly if lesions are located within the large intestine; the marker may be useful for monitoring the disease course [39-42]. In addition to the concentration of inflammatory markers, the most primary investigations include the peripheral blood counts. A typical presentation consists in anemia and thrombocythemia. The etiology of CD-associated anemia is complex (blood loss, iron absorption disorders, chronic inflammatory process, dysbiosis). In addition, chronic inflammation of gastrointestinal walls may also lead to absorption problems and, when combined with extensive catabolism, to cachexia. Therefore, the assessment of protein and albumin levels plays an important role in the assessment of patient condition and disease monitoring. Cholestatic markers (particularly alkaline phosphatase) should also be monitored due to concomitant primary sclerosing cholangitis (PSC) being more common in patients with IBD within the large intestine $[43,44]$.

Due to the increased risk of opportunistic infections associated with the disease itself, as well as to the high probability of treatment with immunosuppressive agents, screening tests for HBV, HCV, HIV, and tuberculosis infections should be performed in each patient diagnosed with CD.

Depending on clinical situation, disease activity and complications, other laboratory investigations may be required.

5. Optimal assessment of perianal lesions in CD is provided by MRI scans. Transrectal ultrasound may constitute a valuable preliminary examination.

(Evidence: moderate; recommendation: strong)

Recommendation \#5 - Approval rating (Likert scale)

\begin{tabular}{|c|c|c|c|c|}
\hline $\begin{array}{l}1-\text { Com- } \\
\text { plete dis- } \\
\text { approval }\end{array}$ & $\begin{array}{c}2 \text { - Disap- } \\
\text { proval }\end{array}$ & $\begin{array}{ll}\text { 3-Partial } & 4 \text {-Partial } \\
\text { disap- } & \text { approval } \\
\text { proval } & \end{array}$ & $\begin{array}{l}5-\mathrm{Ap}- \\
\text { proval }\end{array}$ & $\begin{array}{c}6- \\
\text { Complete } \\
\text { approval }\end{array}$ \\
\hline & & & $11 \%$ & $89 \%$ \\
\hline
\end{tabular}

In the case of perianal lesions, magnetic resonance imaging is the optimum tool to assess the fistulas and abscesses. In most cases, identification of fistulas and their complications (abscesses) as well as surgical planning is also facilitated by transrectal ultrasound. Transrectal examination under anesthesia ensures highly accurate tracing of the course of fistulas or identification of abscesses. However, the examination should be performed by an experienced physician, usually prior to surgical treatment. Fistulography may also be useful, particularly for the assessment of fistular patency before the scheduled surgical procedure; however, the quantity of information obtained is lower than that obtained in the MRI or transrectal US scans [45-54].

6. Diagnosis of CD must be preceded by differential diagnostics of other disorders with similar clinical presentation (celiac disease, yersiniosis, tuberculosis, selected bacterial and viral infections, neoplastic diseases).

(Evidence: moderate; recommendation: strong)

\begin{tabular}{|c|c|c|c|c|}
\hline $\begin{array}{l}1 \text { - Com- } \\
\text { plete dis- } \\
\text { approval }\end{array}$ & $\begin{array}{c}2 \text { - Disap- } \\
\text { proval }\end{array}$ & $\begin{array}{cc}\text { 3-Partial } & 4 \text { - Partial } \\
\text { disap- } & \text { approval } \\
\text { proval } & \end{array}$ & $\begin{array}{l}5-\mathrm{Ap}- \\
\text { proval }\end{array}$ & $\begin{array}{c}6- \\
\text { Complete } \\
\text { approval }\end{array}$ \\
\hline & & $33 \%$ & $11 \%$ & $56 \%$ \\
\hline
\end{tabular}

Final diagnosis of $C D$ requires differential diagnostic examinations being carried out to exclude other diseases with similar clinical presentation or diseases that are frequently concomitant with CD. Diagnostics for celiac disease is mandatory in each patient with CD suspicion or diagnosis. A similar clinical presentation (diarrhea, abdominal pain, cachexia, iron deficiency anemia) can lead to diagnostic mistakes. In addition, concomitance of 
celiac disease and CD is quite frequent; untreated celiac disease may lead to a more severe course of $C D$ and lack of response to the treatment [55]. The diagnosis of celiac disease is based on serological tests (anti-endomysial and anti-tissue transglutaminase antibodies) and histopathological specimens collected from the retrobulbar part of the duodenum (as assessed using the Marshall scale). In addition, infections of the digestive tract should be excluded as the cause of symptoms or exacerbation in all patients. Stool culture is the main test to identify aerobic and anaerobic bacteria and fungi. The possibility of infection with strains of Clostridioides difficile and Campylobacter jejuni should also be kept in mind. Infection by Yersinia enterocolitica is also of particular note as it is accompanied by an inflammatory reaction within the ileocecal bowel segment accompanied by abdominal pain, diarrhea, and regional lymphadenopathy. The diagnosis of yersiniosis is based on serological tests (IgM and IgG classes of antibodies). Cytomegalovirus (CMV) infections are most common in patients with immune system impairment as the result of cachexia as well as the use of immunosuppressants. Serological tests are used for screening against these infections. Diagnosis is confirmed by molecular assays (polymerase chain reaction - PCR) targeting the viral genome or by immunohistochemical assays carried out to determine the presence of CMV antigen within the large intestinal tissues. Gastrointestinal tuberculosis is a major diagnostic challenge. Isolated location of the disease within the digestive tract is rare. Diagnosis is confirmed by identification of mycobacterial genetic material within biopsy specimens. A relatively common clinical situation involves a patient with $C D$ within the ileocecal segment being qualified for surgery due to the suspicion of acute appendicitis. Due to the very similar clinical presentation and the results of additional investigations, differentiation between these disorders may be impossible [17, 56-64].

\section{Mucosal healing should be an important parame- ter taken into consideration when monitoring the efficacy of CD treatment in addition to clinical eval- uation.}

(Evidence: high; recommendation: strong)

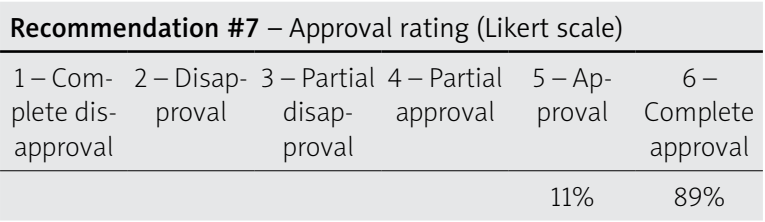

The activity of CD may be expressed at several levels (clinical, biochemical, mucosal, histopathological). Clinical activity is the first level, being most evident and perceptible by the patient. Determination of biochemical parameters (CRP, blood counts, total protein, albumins) facilitates the assessment of the impact of gastrointestinal inflammation on the entire body. The location and extent of inflammatory lesions are determined by radiological and endoscopic examinations. Mucosal healing can be assessed directly by means of endoscopy or indirectly by means of determining calprotectin levels. Finally, microscopic evaluation of inflammation is possible in histopathological examinations $[65,66]$.

The degree of remission can be assessed in a similar manner using the same levels. Based on the available knowledge, the STRIDE II consensus determined the degrees of remission required to minimize the risk of disease recurrence while minimizing the risk of adverse reactions to long-term, intensive treatment. On this basis, the short-, medium- and long-term targets were defined for $C D$ treatment. These are discussed in detail in the recommendations regarding the induction and maintenance treatment [67-71].

The main purpose of the treatment in patients with $C D$ is to inhibit the progressive natural course of disease. Subsequent exacerbations lead to the accumulation of bowel injuries and consequently to complications such as abscesses, fistulas, and strictures. The number of surgical interventions required increases with the duration of the disease. Clinical remission alone is insufficient. As demonstrated, full clinical, biochemical and endoscopic remission may prevent permanent damage to the gastrointestinal tract and reduce the risk of complications in the future. The best assessment of mucosal healing is provided by endoscopic studies (both conventional and capsule endoscopy). Inflammatory markers are also an indirect source of information on the condition of the intestinal mucosa. A good correlation was demonstrated between mucosal healing and fecal calprotectin levels. In many cases, determination of this marker may provide an alternative colonoscopic examination, particularly in the monitoring of the disease course.

\section{Treatment \\ VII.1. General principles}

At present, no causal treatment is available for CD. The treatment is based on the use of immunomodulators to achieve remission (induction treatment) and then to maintain it over a longer period (maintenance treatment). The treatment usually lasts many years, and therefore it should be carefully planned on the basis of medical knowledge and, where possible, the patient's preferences and plans. Patients treated as partners in the treatment process are more willing to accept difficult therapeutic decisions.

The treatment of CD should be delivered on a caseby-case basis according to the clinical form, risk factors 
for severe disease, and the patient's life situation. In general, treatment is based on a step-up strategy (gradual delivery of increasingly aggressive treatments upon the failure of first choice medications). However, if risk factors for severe course of the disease are present, particularly with regard to severe onset of the disease, aggressive treatment is frequently required already upon diagnosis (top-down or accelerated step-up treatment).

Identification of treatment goals is an important step in treatment planning. These goals are different for induction and maintenance treatments and will be discussed in detail in individual recommendations. The long-term objective of the treatment is to inhibit the progressive natural course of disease, which may lead to accumulation of intestinal injuries through repeated exacerbations or persistence of active inflammatory despite the absence of clinical symptoms (clinical remission alone), ultimately resulting in permanent damage and irreversible dysfunction of the intestine.

Proper application of the selected therapeutic strategy requires continuous monitoring of treatment efficacy and rapid modification of the treatment in the event of primary nonresponse or secondary loss of response. Early start of effective therapy increases the chances for a lasting and deep remission. The most common mistake in the management of CD is the prolonged administration of insufficiently effective treatment. This is particularly important in patients treated in outpatient settings. Easy and timely contact between the patient and the attending physician in the event of a nonresponse or recurrence of symptoms is the foundation of good organization at the facility providing care to patients with $C D$.

8. The course of the disease cannot be unambiguously predicted at diagnosis. However, the presence of risk factors for severe disease progression (smoking, young age at diagnosis, stricturing and fistulasing course, extensive intestinal involvement) should always be taken into account when planning treatment strategies.

(Evidence: moderate; recommendation: strong)

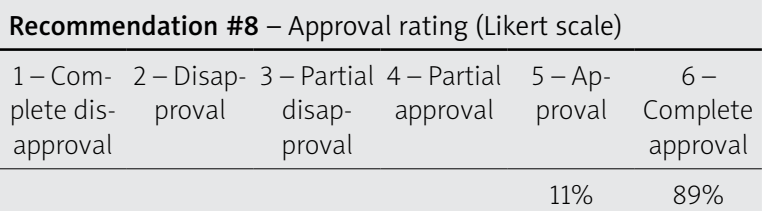

$\mathrm{CD}$ is characterized by alternating exacerbation and remission periods. The frequency of exacerbations, the length of remissions, and the tendency to develop complications may vary between patients. So far, it has not been possible to determine factors which would make it possible to predict the course of the disease after diagnosis. However, studies carried out in large groups of patients with CD allowed the severe course of disease to be linked to certain risk factors. Recognized risk factors include smoking, young age at diagnosis, strictural and fistular course of the disease, and extensive intestinal involvement. The cessation of smoking significantly increases the chance of achieving remission and should be the first step in the treatment of CD. Identification of at least two major risk factors should lead to a more aggressive therapeutic strategy including early inclusion of immunosuppressants (at first onset of the disease) and/or the consideration of earlier biological treatment [72-75].

\section{VII.2. Induction treatment}

Induction treatment is initiated at the time of diagnosis or exacerbation with the aim of achieving remission which would subsequently be maintained by means of maintenance treatment. In some clinical situations, maintenance treatment is not delivered and the patient is followed up for maintained remission after the induction treatment period. Induction treatment should be adjusted on a case-by-case basis depending on the severity of the disease onset, its clinical form, and response to previous treatments. The duration of the induction phase depends on the treatment being applied.

The induction treatment is based on pharmacotherapy; however, surgical treatment may be required at the initial stages of management in some clinical cases. This relates particularly to complications of the disease that may be present at the time of diagnosis, develop during the induction treatment or even be the only symptoms of the disease (e.g. intraoperative diagnosis of CD in patients undergoing procedures for suspected acute appendicitis). When making the decision regarding surgical treatment, one should take into account the overall clinical presentation, the efficacy of previous treatment, as well as the predicted efficacy of the available pharmacotherapy and the possibility of performing an effective, therapeutic resection. In dubious cases, decisions should be made within multidisciplinary teams.

\section{The aim of induction treatment is to achieve clinical remission and mucosal healing.} (Evidence: high; recommendation: strong)

\begin{tabular}{|c|c|c|c|c|}
\hline \multicolumn{5}{|c|}{ Recommendation \#9 - Approval rating (Likert scale) } \\
\hline \multirow[t]{2}{*}{$\begin{array}{l}1 \text {-Com- } \\
\text { plete dis- } \\
\text { approval }\end{array}$} & $\begin{array}{l}2 \text { - Disap- } \\
\text { proval }\end{array}$ & $\begin{array}{cc}\text { - 3-Partial } & 4 \text {-Partial } \\
\text { disap- } & \text { approval } \\
\text { proval } & \end{array}$ & $\begin{array}{l}\text { 5-Ap- } \\
\text { proval }\end{array}$ & $\begin{array}{c}6- \\
\text { Complete } \\
\text { approval }\end{array}$ \\
\hline & & $22 \%$ & $33 \%$ & $45 \%$ \\
\hline
\end{tabular}


The objective of the induction treatment consists in achieving a prompt response followed by clinical remission. Remission may be defined using any of the appropriate clinical scales; however, according to the STRIDE II consensus, resolution of abdominal pain and diarrhea (the PRO2 subscale of the CDAI classification system) is enough. Improvement in biochemical inflammatory markers (CRP) is a predictor of good response to the administered treatment. Mucosal healing takes more time and therefore a lack of mucosal remission is not indicative of failure of the induction treatment. Endoscopy is not recommended for routine evaluation of the efficacy of induction while being reserved for ambiguous cases or cases in which a change in the treatment strategy is required (e.g. surgical treatment). A reduced level of calprotectin in the stool is an indirect indicator of mucosal healing. However, one should keep in mind that the time required for fecal markers to return to normal levels is often longer than the duration of induction treatment [65-71, 76-83].

10. Corticosteroids are the agents of the first choice for induction treatment at the time of diagnosis. In moderate to severe disease, systemic corticosteroids should be administered regardless of the location of inflammatory lesions.

(Evidence: high; recommendation: strong)

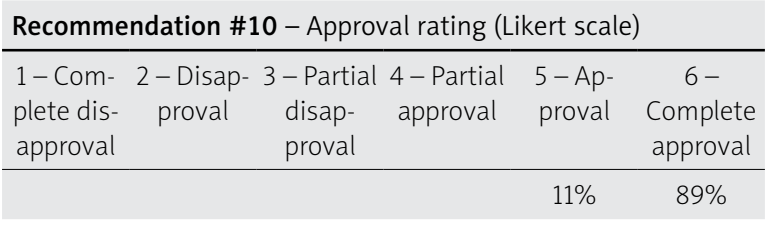

Corticosteroids used in the treatment of CD include systemic corticosteroids (prednisone and methylprednisolone for oral administration and hydrocortisone for intravenous administration) and budesonide (characterized by a large first passage effect involving about 85-95\% being metabolized to minimize the systemic effects and result in a low risk of typical steroid therapy complications). The use of budesonide in CD is limited to mild and moderate disease with lesions located within the ileocecal region and will be discussed in detail in further recommendations.

In other cases, the first line of treatment consists in systemic corticosteroids administered orally (at the initial dose equivalent to $0.75 \mathrm{mg} / \mathrm{kg}$ bw or $40 \mathrm{mg}$ prednisone) or, in selected cases, intravenously (e.g. hydrocortisone at 300-400 mg/day in divided doses). The decision regarding the administration route depends on the general condition of the patient. Due to the serious adverse effects of steroid therapy, including some irreversible effects, the treatment should be administered for the shortest possible period. Treatment with the initial dose should last no longer than 4 weeks and be followed by gradual dose reduction until complete discontinuation. It is recommended that steroid treatment be completed within 12 weeks [84-86].

\section{In case of steroid resistance, steroid dependence or steroid intolerance, the following should be used: immunosuppressants}

11a: (Evidence: very low; recommendation: weak)

or biological therapy (anti-TNF, vedolizumab, ustekinumab), either in monotherapy or in combination with immunosuppressants.

11b: (Evidence: high; recommendation: strong)

Prolonged treatment and suboptimal doses of steroids is not recommended. Surgical treatment should also be taken into consideration at each stage of the treatment.

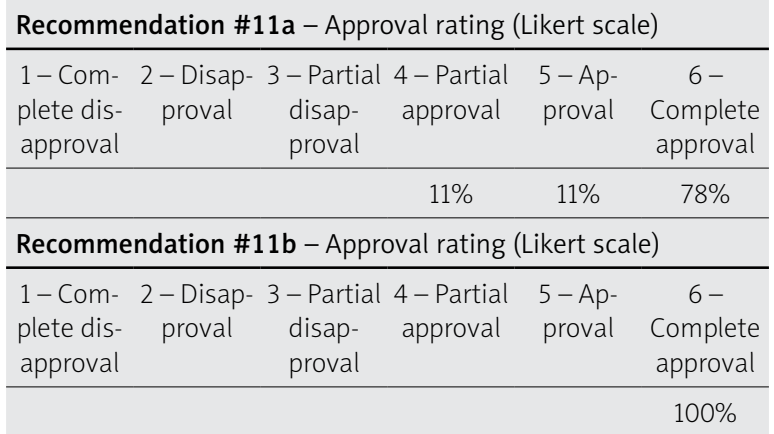

In cases of steroid resistance (no response to corticosteroids), further treatment depends on the severity of the flare. In the case of mild to moderate disease activity, immunosuppressants (thiopurine or methotrexate, whose characteristics will be discussed in Recommendation 18) should be included in the treatment. For moderate to severe disease activity, biological drugs should be used. The delayed action of thiopurines, which are the most commonly used immunosuppressive medicines, should be taken into account when making therapeutic decisions. When the general condition of the patient, for example as being due to long duration of the disease or to the presence of concomitant diseases, does not allow for several weeks' delay until the effect of the immunosuppressant drug is observed, a biological agent should be used already in moderate disease [87-89].

In the case of steroid dependence (i.e. when corticosteroids are effective but dose reduction or withdrawal results in rapid recurrence of symptoms), the next stage of treatment should be planned with the clinical form of the disease being taken into account along with the risk factors for a severe course, concomitant dis- 
eases, and the efficacy of treatment to date. If steroid dependence is observed in a patient who has not hitherto received maintenance treatment, immunosuppressant therapy should be initiated with the corticosteroid dose being increased to the lowest effective dose, until a therapeutic effect of immunosuppressant is achieved, followed by gradual reduction of the steroid dose. Steroid dependence in patients receiving optimum doses of immunosuppressants as well as intolerance and/or adverse effects of immunosuppressants are an indication for biological treatment [90-97].

Combination treatment with an immunosuppressant and an anti-TNF agent is more effective in achieving remission than monotherapy. No interrelation of this type has been demonstrated unambiguously for vedolizumab and ustekinumab.

Long-term treatment with low doses of corticosteroids or prolonged treatment with the initial dose despite the absence of clinical remission is an incorrect approach. Surgical treatment should be considered at each stage of disease management, particularly in the case of lesions confined to a short segment of the bowel and/or the presence of complications (fistulas, strictures, abscesses).

12. First-line biological agents include anti-TNF drugs (infliximab, adalimumab) as well as vedolizumab and ustekinumab. The clinical profile of the patient should be taken into account in drug selection.

(Evidence: high; recommendation: strong)

\begin{tabular}{|c|c|c|c|c|c|}
\hline $\begin{array}{l}1 \text {-Com- } \\
\text { plete dis- } \\
\text { approval }\end{array}$ & $\begin{array}{l}2 \text { - Disap- } \\
\text { proval }\end{array}$ & $\begin{array}{l}\text { 3- Partial } \\
\text { disap- } \\
\text { proval }\end{array}$ & $\begin{array}{l}4-\text { Partial } \\
\text { approval }\end{array}$ & $\begin{array}{l}5-\text { Ap- } \\
\text { proval }\end{array}$ & $\begin{array}{c}6- \\
\text { Complete } \\
\text { approval }\end{array}$ \\
\hline
\end{tabular}

Currently, biological drugs registered for use in $C D$ in Poland include infliximab, adalimumab, vedolizumab and ustekinumab.

Infliximab and adalimumab are monoclonal anti-TNF antibodies of the IgG1 class. Their efficacy in the induction and maintenance of remission in CD patients has been demonstrated in numerous studies [98-101]. Infliximab is given intravenously at a dose of $5-10 \mathrm{mg}$ / $\mathrm{kg}$ bw. Induction treatment involves the administration of 3 doses in a week 0 - week 2 - week 6 schedule. Maintenance therapy is given every 8 weeks. Adalimum$\mathrm{ab}$ is administered subcutaneously at initial doses of $160 \mathrm{mg}$ and $80 \mathrm{mg}$ every 2 weeks, followed by $40 \mathrm{mg}$ every 2 weeks. The remission induction treatment lasts 12 weeks.

Infliximab is a chimeric human/mouse antibody with higher immunogenicity compared to adalimumab.
Combination treatment including thiopurines and infliximab reduces the risk of antibodies being developed against the biological drug and increases the efficacy of treatment. Therefore, thiopurines should always be used in combination with infliximab in the induction treatment provided that they are not contraindicated. The protective effect of thiopurines is reduced over time while the risk of adverse reactions increases; therefore, combination treatment should not be used on a longterm basis. The lack of efficacy of thiopurines in the treatment of CD prior to anti-TNF therapy is not a contraindication for their use as part of combination treatment.

The protective effect of methotrexate is much lower, and therefore the drug should not be routinely used in combined treatment.

Administration of corticosteroids prior to each infliximab infusion in order to reduce the risk of antibody generation is not recommended.

In the case of adalimumab the beneficial effect of combination treatment is much smaller (due to adalimumab being a human antibody with low immunogenicity). However, patients treated with adalimumab in combination with thiopurines were found to have higher levels of the drug and lower risk of antibody formation, particularly in the case of long-term use of biological agents.

Anti-TNF agents are safe medications. Their most common side effects include hypersensitivity to the drug (including anaphylactic reactions to infliximab administration), opportunistic infections (fungal infections, possibility of tuberculosis reactivation) and increased risk of certain cancers. According to studies to date, both agents show similar efficacy in achieving and maintaining remission. The choice of the agent depends primarily on patient preference and on the contraindications for use of thiopurines in combination treatment (patients who cannot be treated with thiopurines due to intolerance or side effects should be treated with adalimumab instead).

Vedolizumab is a monoclonal integrin $\alpha 4 \beta 7$-binding antibody which blocks the migration of lymphocytes to the inflammation site. Vedolizumab was shown to be effective in inducing and maintaining CD remission. In the induction treatment, vedolizumab is given intravenously at a dose of $300 \mathrm{mg}$ in a week 0 - week 2 - week 6 schedule. If no remission is achieved, an additional induction dose is given at week 10 . The maintenance treatment involves intravenous infusions $(300 \mathrm{mg}$ of vedolizumab) being administered every 8 weeks. A subcutaneous formulation of vedolizumab is also available. The first doses of the drug are always administered intravenously, but once two IV infusions have been given, 
a dose of $108 \mathrm{mg}$ administered subcutaneously every 2 weeks is acceptable (the switch is also possible at any moment later in the treatment). Vedolizumab is associated with a much lower risk of severe infection compared to anti-TNF medications. Also, no increased risk was observed for cancer, progressive multifocal leukoencephalopathy (PML), or other neurological complications [102-104].

Ustekinumab is a monoclonal antibody which binds the p40 subunit common to interkeukin 12 (IL-12) and IL-23. Ustekinumab is effective in inducing and maintaining CD remission. A single induction dose is administered intravenously. The maintenance treatment includes doses being administered subcutaneously every 8 or 12 weeks, depending on the assessment of the risk of severe course and the previous treatment. Ustekinumab has a very good safety profile. The risk of severe infection appears to be lower than that of anti-TNF drugs, with no increased risk of cancer being observed $[105,106]$.

All the biological drugs listed above can be used as first line biological drugs. The choice of the agent should be made with consideration of the patient's profile $[91,96,97,100]$.

Anti-TNF drugs, particularly infliximab, are preferred in severe exacerbations, fistular form of the disease, or extraintestinal manifestations. On the other hand, they are characterized by the highest risk of side effects.

Vedolizumab is preferred in inflammatory changes within the large intestine; due to its very good safety profile, it should be used in elderly patients and patients with concomitant diseases.

Contraindications to biological treatment should be ruled out before such a treatment is initiated. These include intraabdominal abscesses and undrained perianal abscesses, latent infections, or recently diagnosed cancer. An interval of at least 2 years following a successful oncological treatment is recommended; in cases of tumors with a higher risk of late recurrence and/or metastases (breast cancer, kidney cancer, melanoma), this interval should be extended to 5 years. In patients with a history of cancer, the use of drugs known to have reduced oncological risk (ustekinumab, vedolizumab) is recommended. Exclusion of latent infections should include tuberculosis (IGRA and chest X-ray tests), hepatitis B (HBs antigen, total anti-HBc antibodies, anti-HBs antibodies in vaccinated individuals), hepatitis C (anti-HCV antibodies), and HIV (Combo test).

13. Infliximab and adalimumab show similar efficacy in the induction and maintenance of CD remission. In the light of current knowledge, the efficacy and safety of anti-TNF biosimilars are not significantly different from the original medications.

(Evidence: moderate; recommendation: strong)

Recommendation \#13 - Approval rating (Likert scale)

\begin{tabular}{|c|c|c|c|c|c|}
\hline $\begin{array}{l}1 \text {-Com- } \\
\text { plete dis- } \\
\text { approval }\end{array}$ & $\begin{array}{c}2 \text { - Disap- } \\
\text { proval }\end{array}$ & $\begin{array}{c}3 \text { - Partial } \\
\text { disap- } \\
\text { proval }\end{array}$ & $\begin{array}{c}4 \text { - Partial } \\
\text { approval }\end{array}$ & $\begin{array}{l}5-A p- \\
\text { proval }\end{array}$ & $\begin{array}{c}6- \\
\text { Complete } \\
\text { approval }\end{array}$ \\
\hline & & & & $11 \%$ & $89 \%$ \\
\hline
\end{tabular}

Biosimilars are biological agents similar to an approved biological drug, showing no significant differences in efficacy, safety and physicochemical properties, for which efficacy and safety have been found to be comparable with those of the original medicine for at least one registered indication. Biosimilars to infliximab and adalimumab are currently available on the market. Introduction of biosimilar medicines has contributed to a significant decrease in the price of biological drugs. In the light of the available studies, the replacement of the original medicine with a biosimilar drug does not entail an increased risk of loss of response or adverse reactions. However, such a decision should always be discussed with the patient and made after their consent is obtained [90, 91, 107-117].

\section{In the case of primary nonresponse to a biological drug, a switch to a drug with another mechanism of action should be considered.}

(Evidence: low; recommendation: weak)

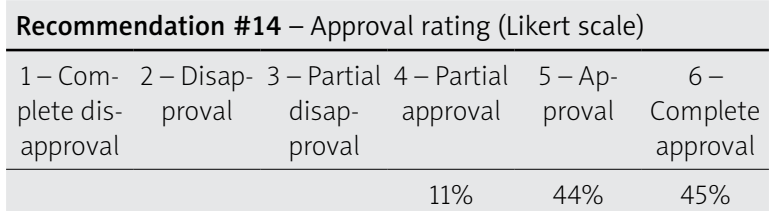

The lack of efficacy of the first line biological agent requires a thorough reassessment of the reported complaints as being potentially caused by factors other than CD exacerbation and exclusion of any CD complications (abscesses, strictures, fistulas). The complete lack of response as observed clinically and in additional investigations (in particular in relation to the reduced levels of biochemical inflammatory markers, e.g. (RP) is an indication that the biological drug should be switched to a drug with another mechanism of action.

If a clinical response is obtained (as confirmed by an improvement in the objective biochemical, radiological or endoscopic inflammatory markers) with no remission despite completion of the induction regimen, a dose increase (preferably based on the drug and antibody levels) or extension of the induction treatment period should be considered [118-127]. 
More information on the usefulness of drug and antibody level determinations can be found in Recommendation 20.

\section{VII.3. Maintenance treatment}

Maintenance treatment is intended to ensure that the state of remission as achieved by induction treatment is maintained. It is a long-term treatment which frequently lasts many years, and therefore the safety profile of the medication use is one of the basic criteria for the selection of treatment regimen. Immunosuppressants and biological agents are the main types of medications used for maintenance treatment of CD. No corticosteroids should be administered as part of the maintenance treatment.

15. The objective of maintenance treatment is to maintain the remission without the use of corticosteroids, to minimize the rates of exacerbations and to reduce the risk of complications.

(Evidence: moderate; recommendation: strong)

\begin{tabular}{|c|c|c|c|c|c|}
\hline $\begin{array}{l}1 \text {-Com- } \\
\text { plete dis- } \\
\text { approval }\end{array}$ & $\begin{array}{c}2 \text { - Disap- } \\
\text { proval }\end{array}$ & $\begin{array}{c}\text { 3- Partial } \\
\text { disap- } \\
\text { proval }\end{array}$ & $\begin{array}{c}4 \text { - Partial } \\
\text { approval }\end{array}$ & $\begin{array}{l}5-\mathrm{Ap}- \\
\text { proval }\end{array}$ & $\begin{array}{c}6- \\
\text { Complete } \\
\text { approval }\end{array}$ \\
\hline & & & & $11 \%$ & $89 \%$ \\
\hline
\end{tabular}

The aim of the maintenance treatment is to maintain clinical and endoscopic remission and to restore the patient's quality of life to pre-disease levels.

Endoscopic remission is defined as a score of $\leq 2$ on the SES-CD scale or $<3$ points on the CDEIS scale, with no ulcerations. Endoscopy is not recommended for routine use in the monitoring of treatment. Calprotectin levels are well correlated with the presence of endoscopic lesions; thus, calprotectin is a sufficient marker for endoscopic remission. Radiological examinations may be helpful in the assessment of resolving inflammation; however, an unremarkable outcome of radiological examination is not the goal of the treatment.

Histological remission, i.e. resolution of even the microscopic features of inflammation, is not the goal of CD treatment. The strive towards an unremarkable microscopic presentation would require long, extensive treatment of most patients, most frequently involving the use of biological agents. Although histological remission was shown to entail a lower risk of subsequent exacerbations, the high likelihood of adverse reactions to intensive treatment and secondary loss of response outweigh the potential benefits of biological therapy in all patients $[65,66,73-75$, 85, 87-89].
16. Initiation of maintenance treatment should depend on the results of disease recurrence risk assessment.

(Evidence: moderate; recommendation: strong)

Recommendation \#16 - Approval rating (Likert scale)

\begin{tabular}{|c|c|c|c|c|c|}
\hline $\begin{array}{l}1 \text {-Com- } \\
\text { plete dis- } \\
\text { approval }\end{array}$ & $\begin{array}{c}2 \text { - Disap- } \\
\text { proval }\end{array}$ & $\begin{array}{c}3 \text { - Partial } \\
\text { disap- } \\
\text { proval }\end{array}$ & $\begin{array}{c}4 \text { - Partial } \\
\text { approval }\end{array}$ & $\begin{array}{l}5 \text {-Ap- } \\
\text { proval }\end{array}$ & $\begin{array}{c}6- \\
\text { Complete } \\
\text { approval }\end{array}$ \\
\hline & & & $11 \%$ & $67 \%$ & $22 \%$ \\
\hline
\end{tabular}

In patients with mild disease, particularly within ileocecal locations, short history and no severe course risk factors, maintenance treatment may be skipped if early remission is achieved. In such patients, clinical signs, calprotectin levels, and radiological presentation should be monitored.

Further exacerbation is an indication for the inclusion of maintenance therapy and reinduction of remission using corticosteroids [73, 74, 85, 128].

17. Corticosteroids (either budesonide or systemic corticosteroids) should not be used in maintenance therapy.

17a: (Evidence: moderate; recommendation: strong) No good evidence is available regarding the usefulness of mesalazine in $C D$ treatment.

17b: (Evidence: moderate; recommendation: weak)

Recommendation \#17a - Approval rating (Likert scale)

1-Com- 2-Disap- 3-Partial 4-Partial 5-Ap- 6-

plete dis- proval disap- approval proval Complete

approval proval approval

$100 \%$

Recommendation \#17b - Approval rating (Likert scale)

1-Com- 2-Disap- 3-Partial 4-Partial 5-Ap- 6-

plete dis- proval disap- approval proval Complete

approval proval approval

$22 \% \quad 45 \% \quad 33 \%$

Corticosteroids are essential for the induction of $C D$ remission. However, no efficacy has been demonstrated for corticosteroids, either systemic corticosteroids or budesonide, in maintenance therapy [128-134]. Due to the numerous and serious side effects, the use of corticosteroids should be limited to the absolute minimum. Any steroid treatment lasting longer than 3 months should result in the existing treatment plan being subjected to verification and other therapeutic options such as inclusion of immunosuppressants or biological treatments as well as potential surgery should be considered.

Mesalazine is commonly used in the treatment of mild to moderate $C D$. In many countries, including 
Poland, such treatment is administered to more than one half of patients $[135,136]$. However, no positive effect of oral mesalazine has been observed in the numerous available clinical studies and meta-analyses with regard to inducing remission and providing maintenance treatment of CD irrespective of the location of inflammatory lesions [137-149]. Although individual studies suggested that mesalazine had a slight advantage over placebo $[142,148]$, these results were not confirmed by other studies and meta-analyses. Data on topical use of mesalazine in CD are insufficient. Based on these data, the recommendations of international scientific societies published in recent years do not advocate the use of mesalazine in the treatment of CD.

In addition to the potential anti-inflammatory effect, the use of mesalazine may be justified by its chemopreventive effect. For this reason, mesalazine should be considered in patients with CD within the large intestine.

18. If clinical remission has been achieved with corticosteroids, immunosuppressive agents such as thiopurine or methotrexate are recommended for maintenance treatment.

(Evidence: moderate; recommendation: strong)

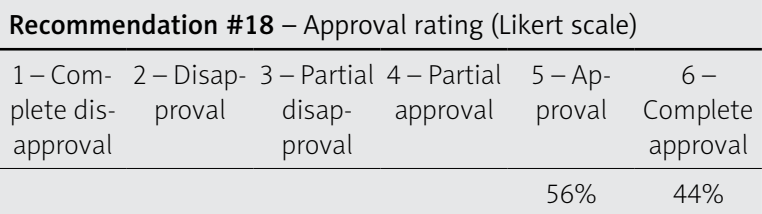

Immunosuppressants are the main agents for use in the maintenance treatment if remission has been achieved using corticosteroids. Biological agents should be considered in the presence of risk factors for severe course of the disease.

The first line of maintenance treatment consists of thiopurines (azathioprine at a dose of $2-2.5 \mathrm{mg} / \mathrm{kg}$ bw or 6-mercaptopurine at a dose of $1-1.5 \mathrm{mg} / \mathrm{kg}$ bw). The efficacy and safety profiles of both medicines are comparable [85, 150-157].

The metabolism of thiopurines depends on the activity of several enzymes, including thiopurine methyltransferase (TPMT). Measuring TPMT activity before the treatment is helpful in selecting patients with a higher risk of side effects (low TPMT activity).

The most common side effects of thiopurines include bone marrow suppression (usually reversible, dose-dependent, manifested by leukopenia as the first sign), liver and/or kidney damage, and acute pancreatitis. The risk of infection, including opportunistic infections, and tumors (cervical cancer, non-mel- anoma skin cancer, and lymphoid neoplasms) is also higher. One of these neoplasms is the lymphoma in the course of first Epstein-Barr virus (EBV) infection in young males. For this reason, immunosuppressants other than thiopurines (methotrexate, biological agents) are recommended in EBV-seronegative males below the age of 30 years. All patients treated with thiopurines should be followed up by a dermatologist; female patients should also participate in cervical cancer screening programs. Treatment with thiopurines requires continuous monitoring of peripheral blood count, aminotransferase activity, and kidney function (every 2 weeks during the first 2 months of treatment and at least every 3 months thereafter). Mild leukopenia (white blood cell counts above $3500 / \mu$ ) requires no drug dose adjustment. If the number of leukocytes is reduced and maintained below 3.5 thousand, the dose of thiopurine must be reduced; in the event of severe leukopenia (less than 2.5 thousand with lymphocytopenia of $<1$ thousand), the drug should be discontinued. The increase in aminotransferase activity exceeding three times the upper limit of normal requires monitoring and potentially dose adjustment, whereas a 5-fold increase above the upper limit of normal requires withdrawal of the drug. The efficacy of thiopurine treatment can be evaluated after at least 6 weeks of stable dosing. The optimum therapeutic effect is achieved after 12 weeks of treatment. Therefore, thiopurines should not be used in monotherapy to induce $C D$ remission.

Thiopurine treatment can be monitored by determining the erythrocytic levels of 6-thioguanine (6TG) and 6-methylmercaptopurine (6MMP). Determinations should be made no earlier than 3 months after the initiation of treatment. Determination of the levels of 6TG, which is the active metabolite of thiopurine, is particularly useful in cases of nonresponse or adverse effects (the target level of 6TG is $230-400 \mathrm{pmol} / 8 \times 10^{8}$ erythrocytes). The absence of the therapeutic effect at reduced 6-thioguanine levels suggests that the dose of the drug should be increased, whereas the absence of the therapeutic effect at high 6-thioguanine levels indicates the lack of efficacy - further dose increases would not produce therapeutic effects but increase the risk of side effects. However, only a few studies are available on the usefulness of treatment monitoring by means of 6TG level determination.

On the other hand, increased 6MMP levels are associated with a higher risk of side effects, particularly hepatotoxicity (limit concentration of 5000 pmol/ $8 \times 10^{8}$ erythrocytes).

Monitoring the effects of thiopurine treatment using 6TG and 6MMP does not abrogate the need to perform 
biochemical follow-up checks according to the aforementioned regimen.

In some patients, methylation of thiopurines is the predominant metabolic pathway. This group is characterized by low levels of 6TG and high levels of 6MMP. This leads to low efficacy of thiopurine treatment and high risk of side effects. It is acceptable to include allopurinol (100 mg/day) and reduce the dose of thiopurine to $25 \%$ of the initial dose under the control of laboratory investigations.

In cases of thiopurine intolerance, methotrexate at $25 \mathrm{mg}$ subcutaneously once a week for 12 weeks, followed by $15 \mathrm{mg}$ subcutaneously or in some cases orally, is an alternative immunosuppressive agent. Methotrexate was shown to be effective in the induction of remission and maintenance treatment of $\operatorname{CD}[88,158,159]$. The efficacy of thiopurines and methotrexate is comparable. However, if thiopurines are not effective, biological medicines should be used instead as the chance for remission following the use of methotrexate is low and the effective therapy would thus be delayed. The indication for the use of methotrexate is intolerance or contraindications to the use of thiopurines.

Peripheral blood count and aminotransferase activity should be monitored in the course of methotrexate treatment (an increase above the double upper limit of normal is an indication for the treatment being discontinued until the levels normalize). Supplementation with folic acid (1 mg daily or $5 \mathrm{mg}$ once a week 1-2 days after the dose of methotrexate) $[160,161]$ is indicated during methotrexate therapy. Methotrexate is teratogenic and should not be used in patients (both male and female) who plan on having children. The use of contraception is recommended during the treatment and for up to 6 months after the treatment. Methotrexate treatment does not involve an increased risk of cancer.

19. If clinical remission has been obtained using biological agents, the same agents should be used in maintenance therapy.

(Evidence: high; recommendation: strong)

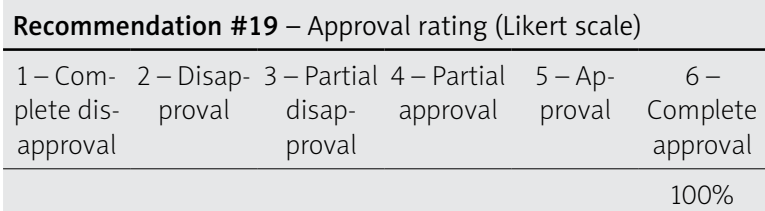

Maintenance treatment consists in continuation of the induction treatment. The biological agent used for achieving remission should be continued in maintenance therapy $[90,102,105,162]$. It is acceptable to change the administration route from intravenous (induction treatment) to subcutaneous (maintenance treatment). This is possible in the case of vedolizumab. Ustekinumab is always given intravenously in the first dose, and subcutaneously in the following doses.

\section{Maintenance therapy based on the monitoring of inflammatory activity (calprotectin) and drug pharmacokinetics (drug and neutralizing antibody levels) can improve the efficacy of treatment.}

(Evidence: low; recommendation: weak)

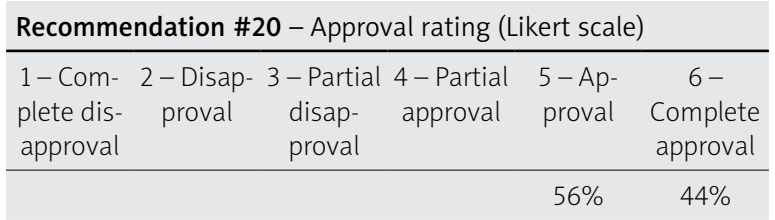

Effective maintenance treatment should ensure long-term remission. Evaluation of the efficacy of treatment on the basis of clinical signs alone is insufficient in the light of current knowledge. As mentioned above, the aim of maintenance treatment also consists in reducing and, ideally, completely suppressing local inflammation [81, 82, 99, 163]. Routine endoscopic evaluation of treatment efficacy is not recommended (except for endoscopic evaluation following resectional surgery).

Despite its limitations, determination of fecal calprotectin levels is a good method for indirect assessment of mucosal healing $[164,165]$. Observing the trend rather than absolute values of single measurements is particularly useful in treatment monitoring. An increase in calprotectin levels may precede the onset of clinical symptoms in a patient who remains in remission $[77,166]$. If clinical signs are observed, determination of calprotectin levels can be helpful in differentiating disease exacerbation from other causes of symptoms $[38,40,167]$. Therefore, periodic determination of calprotectin levels in patients in remission in the course of maintenance treatment as well as upon the onset of exacerbation symptoms may contribute to increased efficacy of treatment. The frequency of calprotectin determinations in asymptomatic patients should reflect the history of the disease; for example, patients in stable remission with no risk factors for severe course of the disease should have their calprotectin levels checked every 6-12 months.

Achievement and maintenance of therapeutic levels of biological drugs increase the chance for achievement and long-term maintenance of clinical and endoscopic remission [168-171]. The main reason for the secondary loss of response to biological drugs consists in the development of neutralizing antibodies, although non-immune mechanisms also play an important role. Determination of drug and antibody levels is helpful in 
assessing the cause and determining further actions in the event of a secondary loss of response [118-120, 172]. Low drug levels and the absence of antibodies are indications for dose increase. Low drug levels and the presence of antibodies suggest initiation or optimization of immunosuppressant treatment and/or biological drug dose increase. On the other hand, the appropriate concentration of the drug may be indicative of the need for switching to a biological agent characterized by another mechanism of action.

For infliximab, treatment may be intensified by either increasing the typical dose of $5 \mathrm{mg} / \mathrm{kg}$ bw delivered every 8 weeks to $10 \mathrm{mg} / \mathrm{kg}$ bw delivered as before, or by administering the previous dose of $5 \mathrm{mg} / \mathrm{kg}$ bw at shorter, 4-week intervals. Although the data comparing the two strategies are limited, they are suggestive of the superiority of the first strategy [122]. A dosage increase to $10 \mathrm{mg} / \mathrm{kg}$ bw administered every 4 weeks may be required in some isolated cases. In such events, the treatment should be adjusted to the monitored drug levels. In the case of adalimumab, treatment intensification is achieved by shortening the interval between doses from two weeks to one week.

A few studies have focused on the strategies for the monitoring of drug and antibody levels in all patients, including patients in remission, and for the optimization of the dosing of the biological drug on the basis of the obtained results (the proactive strategy) $[173,174]$. The strategy was found to be cost-effective yet failed to increase the percentage of patients remaining in remission while reducing the exacerbation rates. Currently, this strategy is recommended in selected patients.

\section{Other etiology than disease exacerbation should be taken into account in the case of symptoms recurring during maintenance therapy.}

(Evidence: low; recommendation: strong)

\begin{tabular}{|c|c|c|c|c|c|}
\hline $\begin{array}{l}1 \text {-Com- } \\
\text { plete dis- } \\
\text { approval }\end{array}$ & $\begin{array}{c}2 \text { - Disap- } \\
\text { proval }\end{array}$ & $\begin{array}{c}3 \text { - Partial } \\
\text { disap- } \\
\text { proval }\end{array}$ & $\begin{array}{l}4 \text { - Partial } \\
\text { approval }\end{array}$ & $\begin{array}{l}5-\mathrm{Ap}- \\
\text { proval }\end{array}$ & $\begin{array}{c}6- \\
\text { Complete } \\
\text { approval }\end{array}$ \\
\hline & & & & $33 \%$ & $67 \%$ \\
\hline
\end{tabular}

The recurrence of gastrointestinal symptoms during the course of the maintenance treatment may be related to progression of the underlying disease, its complications, as well as to causes other than CD (e.g. infections, including opportunistic microbial infections, functional disorders). Therefore, in the event of recurrence of clinical symptoms, other causes of exacerbation should always be excluded by means of laboratory, imaging and microbial tests before the existing treatment is intensified or changed. Determination of fecal calprotectin levels is particularly useful among all inflammatory markers. In cases of doubt, endoscopic verification is required $[17,56-59,61-64]$.

\section{In the case of secondary loss of response to the maintenance treatment, the first consideration should be to intensify the current treatment, or possibly switch to a drug with a different mech- anism of action. Re-induction therapy should be based on general principles.}

(Evidence: high; recommendation: strong)

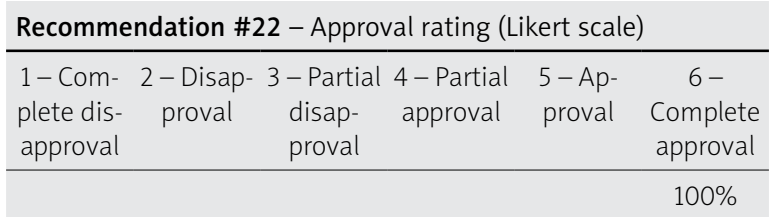

The secondary loss of response consists in exacerbation developing in the course of hitherto effective maintenance treatment. The secondary loss of response may be diagnosed only after causes other than exacerbation are excluded for the recurring clinical signs. Loss of response may be due to disease progression or to other mechanisms affecting drug concentration or efficacy. These include, for example, the development of neutralizing antibodies against the biological agent or non-immunological causes of increased elimination of the drug (both immunosuppressive and biological).

Secondary loss of response constitutes a failure of the treatment administered so far and requires optimization of the dose of the hitherto administered drug or switching to another drug [84-97, 100].

Determination of thiopurine metabolites - 6-thioguanine and 6-methylmercaptopurine - is helpful in cases of immunosuppressants being used in the treatment. The principles for determination of these metabolites and optimization of thiopurine doses have been discussed above. Administration of corticosteroids may be advisable until the desired effect of the optimized dose is achieved.

For biological medicines, the optimal decision can be made following determination of the drug trough level (drug concentration just before the next dose) and level of drug neutralizing antibodies. The efficacy of this approach is best documented for anti-TNF medicines and is outlined in detail in recommendation 20. In treatment with vedolizumab and ustekinumab, the decision to intensify treatment is based on clinical criteria and involves shortening the dosing interval (from 8 to 4 weeks for vedolizumab and from 12 to 8 weeks for ustekinumab). 
Switching a biological agent to another drug is tantamount to re-initiation of induction treatment, which should be conducted in accordance with the principles set out in the induction treatment section.

23. At the moment, it is not possible to clearly define the duration of treatment with biological agents. Long-term treatment should be considered in cases with severe symptoms, complications, and/or inefficacy or intolerance to immunosuppressive agents. (Evidence: low; recommendation: weak)

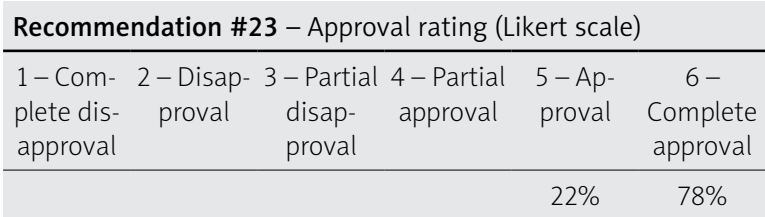

Based on the available studies, it is not possible to clearly determine the optimum duration of maintenance treatment with both immunosuppressive and biological agents. The risk of disease recurrence is greater in patients with severe forms of disease, complications, and intensified extraintestinal manifestations in whom second and subsequent lines of treatment, intensification of maintenance treatment, or surgical treatment were required to achieve remission [175-186]. In such cases, it is recommended that the maintenance treatment be administered long term until loss of response. The risk of disease progression and disability aggravation should also be taken into account in the event of recurrent exacerbation.

Episodic treatment, i.e. periodic treatment with a biological drug and discontinuation of the drug after the remission is achieved or after a short period of maintenance treatment despite the high risk of recurrent exacerbation, is not recommended. Such treatment is insufficient to alter the natural course of the disease and to prevent future complications while simultaneously increasing the risk of loss of response to the treatment.

In the case of long-term maintenance treatment, validity of further treatment should be assessed at least every 12 months, with the efficacy of the drug as well as the risk of adverse reactions being taken into account. Safety evaluation should include the exclusion of latent infections (just as before the induction treatment), and screening for cancer (both related and non-related to the gastrointestinal tract) according to current guidelines.

After completion of the maintenance treatment, the maintenance of remission should be monitored by biochemical tests (morphology, CRP, calprotectin) repeated at least every 3 months [187]. In cases of doubt, radiological and/or endoscopic examinations may be advisable.

\section{Differences in treatment depending on the location and phenotype of lesions}

\section{VIII.1. Ileocecal location}

The ileocecal region is one of the most common locations of inflammatory lesions. As the clinical signs of this form are most closely associated with CD, it is sometimes referred to as the "classical" form. The extent of inflammatory changes is usually limited, without any other sections of the gastrointestinal tract being affected. Because of the frequent symptoms of subileus or ileus, surgical treatment plays a greater role in the management of this form of the disease.

\section{Budesonide should be used to induce remission in mild to moderate disease.}

(Evidence: high; recommendation: strong)

\begin{tabular}{|c|c|c|c|c|}
\hline \multirow[t]{2}{*}{$\begin{array}{l}1 \text {-Com- } \\
\text { plete dis- } \\
\text { approval }\end{array}$} & $\begin{array}{l}2 \text { - Disap- } \\
\text { proval }\end{array}$ & $\begin{array}{c}\text { 3-Partial } \\
\text { disap- } \\
\text { proval }\end{array}$ & $\begin{array}{l}5-\mathrm{Ap}- \\
\text { proval }\end{array}$ & $\begin{array}{c}6- \\
\text { Complete } \\
\text { approval }\end{array}$ \\
\hline & & & $11 \%$ & $89 \%$ \\
\hline
\end{tabular}

Budesonide is the drug of choice in cases of exacerbated CD within the ileum and/or the ascending colon characterized by mild to moderate activity. The drug is characterized by strong local anti-inflammatory activity due to its high affinity to the corticosteroid receptor and its use in the form of capsules releasing the active substance in a $\mathrm{pH}$-dependent manner within the ileum and the ascending colon (controlled ileal release (CIR) capsules). The drug is also characterized by a large first liver passage effect, with approximately $90 \%$ of the dose being metabolized at that stage. This results in systemic side effects of budesonide being less frequent than those of systemic corticosteroids [143, 188-190].

The efficacy of budesonide treatment at the dose of $9 \mathrm{mg} /$ day for 8 weeks with respect to inducing the remission of ileocecal $C D$ with mild to moderate activity has been confirmed in three randomized studies (379 patients). However, it should be stressed that CIR budesonide showed worse therapeutic effects in moderately severe exacerbations of CD and in cases when inflammatory lesions were also located outside the ileum or ascending colon $[143,191]$. A single daily dose of $9 \mathrm{mg}$ was as effective as three doses of $3 \mathrm{mg} /$ day [189, 192]. CIR capsules of budesonide may be taken with or without meals [193]. Like any steroid, budesonide is used to induce the remission of $C D$ and not to maintain it once it is achieved. The use of budesonide for more than 4-6 months is not justified [194]. The drug should be administered at an initial dose of $9 \mathrm{mg} /$ day, which is 
then gradually reduced for 4-8 weeks [17]. Immediate termination of treatment, without gradual dose reduction, is also acceptable.

In the light of the results of the available studies, there is no evidence of the efficacy of mesalazine in ileocecal CD, regardless of its activity [17, 18, 153, 195, 196].

Despite numerous studies on the use of ciprofloxacin, metronidazole and antimycobacterial antibiotics, no evidence is also available on the efficacy of these antibiotics in the induction or maintenance of remission in the management of CD in ileocecal locations. These are indicated for concomitant infections or septic complications according to general principles [16-18, 197, 198]. In recent years, numerous studies have been published regarding the use of rifaximin in the treatment of $C D$. A positive effect was observed in particular in relation to reduction of certain disease symptoms, and therefore rifaximin can be used in the management of $C D$ as an adjuvant drug.

Surgical treatment plays a greater role in management of the ileocecal form of the disease as compared to forms with inflammatory lesions in other locations. Surgical treatment is discussed in Recommendation 29.

\section{VIII.2. Lesions within the upper gastrointestinal tract}

25. Proton pump inhibitors (PPI) are the first line treatment in cases of esophageal, gastric, or duodenal location. PPIs can be used in monotherapy in mild disease or in combination with systemic steroids, immunosuppressive and/or biological agents (especially anti-TNF) according to general principles in moderate to severe disease.

(Evidence: low; recommendation: weak)

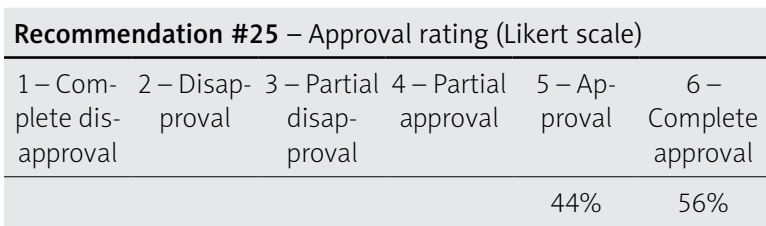

$C D$ with lesions located within the upper gastrointestinal tract (UGIT) is challenging in both diagnostic and therapeutic terms [199-201].

Any patient diagnosed with $C D$ and presenting with non-specific inflammatory lesions within the esophagus, stomach, or duodenum should be suspected of a primary disease manifestation. Identification of isolated inflammatory lesions (i.e. without concomitant lesions in locations more common to $C D$ ) with non-characteristic endoscopic presentation, especially in the form of multiple erosions or ulcerations, should also give rise to the suspicion of $C D$, particularly when involving a young person. In any case, differential diagnosis is advisable, particularly towards neoplasm, viral infections (CMV, HSV, HIV), sarcoidosis, or tuberculosis.

UGIT lesions are estimated to occur in $13.1 \%$ of patients with CD, with $6.5 \%$ of patients presenting with such lesions at the time of diagnosis. This value is probably underestimated, as esophagogastroduodenoscopy (EGD) is not routinely performed in asymptomatic patients. Male sex, $C D$, being diagnosed at the age of $<16$, and smoking were found to be predictors of UGIT lesions. UGIT location of lesions was not found to be related to worse course of the disease [202, 203].

\section{VIII.2.1. Esophagus}

Esophageal lesions occur in $3.3 \%$ to $6.8 \%$ of patients with CD [204]. Up to $95 \%$ of these patients present with concomitant intestinal lesions while about $33 \%$ present with concomitant mouth ulcerations [205]. Cases of isolated esophageal lesions in the course of CD have also been reported. The most common symptoms of CD in esophageal location include dysphagia (54\%), odynophagia (33\%), and epigastric pain (33\%); other symptoms include heartburn, regurgitation, and chest pains. The most common complications include esophageal stenosis (17\%), fistula and perforation.

No endoscopic esophageal lesions are typical for CD; the most common findings include scattered erosions or ulcerations with a tendency to longitudinal alignment, strictures and fistulas; less frequent findings include redness, fragility, granulation and cobblestone appearance of the esophageal mucosa or the presence of pseudopolyps [202]. Lesions within the upper part of the esophagus are the least common (4\%) [199].

\section{VIII.2.2. Stomach and duodenum}

Gastroduodenal changes are observed mainly within the antrum, pylorus, and proximal duodenum; they are present in $0.5 \%$ to $4 \%$ of patients with CD, with isolated gastroduodenal disease being very rare $(0.07 \%$ of all CD patients). Symptoms include epigastric pain, nausea, vomiting, malnutrition, fever and, less frequently, iron deficiency anemia or bleeding. The disease may be asymptomatic. The onset of postprandial vomiting, early fullness and body weight loss is indicative for stenosis [199]. Stenosis in the vicinity of the pylorus may present as a "ram's horn" or "pseudo-Billroth I" sign in the radiological image. Formation of fistulas is rare and usually associated with inflammatory changes occurring within the transverse colon and the ileocecal region; fistulas originating from gastroduodenal lesions 
may open into abdominal integuments and skin. Helicobacter pylori co-infection was observed in about $25 \%$ of patients [206]. Screening and eradication of this infection is recommended in patients with CD and UGIT symptoms [17].

Despite the lack of pathognomonic endoscopic lesions, CD may be manifested within the stomach as swollen rugae with bamboo joint-like appearance, scattered erosions within the peripyloric region, and ulcerations, particularly longitudinal ulcerations in the absence of $H$. pylori infection. Within the duodenum, $C D$ is manifested by the presence of longitudinal and irregular erosions and ulcerations, notch-like appearance or Buddhist rosary-like protruding lesions. In the histopathological examinations of UGIT lesion specimens, granulomas typical for CD are found with varying frequency (up to $25 \%$ for esophageal lesions, from $7 \%$ to $87 \%$ in the stomach, and up to $49 \%$ in the duodenum) [202, 207].

\section{VIII.2.3.Treatment}

Due to the absence of randomized studies, the treatment of $C D$ with upper gastrointestinal tract location is based only on clinical experience and recommendations of expert groups.

Proton pump inhibitors used to alleviate symptoms are the first line of pharmacotherapy. In cases of mild disease with non-severe lesions within the UGIT, monotherapy with PPIs may be considered. Corticosteroids are used as second line treatment (in the case of esophageal lesions, topical budesonide is one of the therapeutic options) while thiopurines and infliximab are used as the third line of treatment. In patients with symptomatic stenosis within the UGIT, balloon dilatation of stenosis should be considered prior to pharmacotherapy $[17,199,208]$.

26. In the case of symptomatic stenosis within the esophagus, pylorus, or duodenum, endoscopic dilatation may be considered, with surgical treatment being advisable in the event of other therapy's failure.

(Evidence: very low; recommendation: weak)

\begin{tabular}{|c|c|c|c|c|c|}
\hline $\begin{array}{l}1 \text {-Com- } \\
\text { plete dis- } \\
\text { approval }\end{array}$ & $\begin{array}{l}2 \text { - Disap- } \\
\text { proval }\end{array}$ & $\begin{array}{c}\text { 3- Partial } \\
\text { disap- } \\
\text { proval }\end{array}$ & $\begin{array}{l}\text { 4-Partial } \\
\text { approval }\end{array}$ & $\begin{array}{l}5-\text { Ap- } \\
\text { proval }\end{array}$ & $\begin{array}{c}6- \\
\text { Complete } \\
\text { approval }\end{array}$ \\
\hline & & & & $67 \%$ & $33 \%$ \\
\hline
\end{tabular}

Stenoses may develop in the course of the CD within the esophagus (particularly within the middle segment), the stomach (particularly within the pylorus and pyloric region) or the duodenum. In the case of symptomatic stenoses, expert groups (ECCO, British Society of Gastroenterology (BSG)) they recommend balloon dilatation being considered first (with repeated procedures being frequently required) followed by continued pharmacotherapy (immunosuppressants, anti-TNF agents).

Short $(<4 \mathrm{~cm})$ strictures of the pylorus and duodenum may also be successfully dilated using balloons (with perforation risk in the range of $1-2 \%$ ). However, symptoms of stenosis tend to recur and several procedure sessions are required to achieve efficacy and avoid surgical treatment. The absence of recurrence and the lack of need for subsequent intervention within the first month after dilatation is the main predictor of longterm efficacy [199, 204].

Surgical treatment of UGIT stenoses developing in the course of CD is considered in the event of other forms of therapy having failed. Surgical treatment was shown to be associated with a higher risk of post-surgical complications and longer hospitalizations as compared to surgical treatments of CD in other locations [203].

Surgery should be preceded by a thorough assessment of the disease activity, including in other sections of the gastrointestinal tract. Surgical treatment of UGIT stenoses may include the formation of bypass anastomosis, resection, or stricturoplasty, with bypass anastomosis being the most frequent choice. In the study by Moon et al., bypass anastomoses (gastrojejunostomy or jejunojejunostomy) were performed in all patients undergoing surgery due to gastric or duodenal stenosis. In other studies, the preferred method of surgical treatment for duodenal stenosis consisted in bypass anastomosis with or without vagotomy or stricturoplasty, as the resection procedure was shown to be more burdensome for patients [203].

Despite the increased importance of laparoscopic surgery in the treatment of CD in recent years, the approach is rarely chosen in the treatment of disease located within the UGIT.

\section{VIII.2.4. Perianal disease}

27. The first line of treatment should consist of local management (surgical drainage of abscesses and fistulas with antibiotic therapy). Anti-TNF agents should be considered as the first line systemic therapy, particularly in cases of complex fistulas. (Evidence: moderate; recommendation: strong)

Recommendation \#27 - Approval rating (Likert scale)

\begin{tabular}{|c|c|c|c|c|c|}
\hline $\begin{array}{l}1 \text {-Com- } \\
\text { plete dis- } \\
\text { approval }\end{array}$ & $\begin{array}{c}2 \text { - Disap- } \\
\text { proval }\end{array}$ & $\begin{array}{c}3 \text { - Partial } \\
\text { disap- } \\
\text { proval }\end{array}$ & $\begin{array}{c}4 \text { - Partial } \\
\text { approval }\end{array}$ & $\begin{array}{l}\text { 5-Ap- } \\
\text { proval }\end{array}$ & $\begin{array}{c}6- \\
\text { Complete } \\
\text { approval }\end{array}$ \\
\hline & & & $11 \%$ & & $89 \%$ \\
\hline
\end{tabular}




\section{VIII.2.4.1. Nomenclature, classification, and surgical treatment}

In the case of perianal lesions, particularly infected lesions, lesions with concomitant abscesses, multichannel, bifurcated, or recurrent fistulas, surgical treatment must be undertaken first [16, 17, 209-211].

Surgical treatment may consist in the incision and drainage of the abscess, seton placement, fistulotomy, fistulectomy, Hippocrates surgery, ligation of intersphincteric fistula tract, endoscopic procedures, vacuum-assisted closure, or the use of tissue glues or plugs. The optimum procedural treatment is decided upon by the surgeon depending on the type of fistula, the presence and course of bifurcations, internal and external orifices, the status of anal sphincters or the concomitant presence of abscesses. Surgical treatment is aimed at elimination of concomitant tissue inflammation.

Numerous classifications of perianal fistulas are available; although it seems easiest to divide the fistulas into simple and complex ones, definitions of these terms vary within the literature, leading to difficulties with interpretation of study results and recommendations [212].

The most common classifications include that proposed by Parks, who categorized the lesions as intersphincteric, transsphincteric, suprasphincteric and extrasphincteric fistulas depending on the course of the fistular lumen and fistular location relative to the anal sphincter and levator muscles, and that proposed by Milligan and Morgan, who categorized the lesions as low anal, high anal, and anorectal depending on the fistular location relative to the anorectal ring (the peripheral margin of the rectal bulb). Gruk's classification of fistulas into low (fistular tract below the pectinate line and internal opening on or below the pectinate line) and high fistulas is also known.

In 1962, the first classification of fistulas into complex fistulas (fistulas with the primary opening above the anorectal ring or fistulas involving 3/4 of the cross-section of the internal sphincter) and simple fistulas (i.e. other fistulas) was introduced by Thompson [213].

Since then, numerous definitions of simple and complex fistulas have been proposed. For example, a single-channel fistula may be referred to as "simple" with all the remaining types of fistulas (multichannel, multitype) being referred to as "complex".

The 2017 ECCO guidelines propose using the term "simple fistulas" when referring to superficial (subcutaneous) and intersphincteric fistulas, and the term "complex fistulas" referring to transsphincteric, extrasphincteric, and suprasphincteric fistulas [212, 214].

A widely used and established classification of simple and complex fistulas has also been proposed by the American Gastroenterological Association, who defined simple fistulas as those that are low, without abscesses or strictures, with single internal openings, and non-anovaginal fistulas with or without concomitant rectal inflammation, and complex fistulas as high fistulas with single or multiple external openings, with or without concomitant abscesses, strictures, or rectal inflammation $[209,215]$.

At this moment, the classification proposed by the American Society of Colorectal Surgeons appears to be most practical in light of its clinical implications. According to this classification, only intersphincteric or low transsphincteric fistulas involving less than $30 \%$ of the sphincter are defined as "simple" fistulas. Fistulas with other locations relative to anal sphincters, as well as recurrent fistulas, fistulas associated with stool incontinence, radiotherapy, or IBD, are referred to as "complex" fistulas. Therefore, all perianal fistulas developing in CD patients are considered complex fistulas [216, 217].

\section{VIII.2.4.2. Antibiotic therapy}

Antibiotic therapy concomitant to surgical and other methods of treatment is widely accepted as it may increase the efficacy of treatment despite limited data being available in the literature. Metronidazole and/or ciprofloxacin are characterized by the best safety and efficacy profiles [218-220].

The main objective of antibiotic therapy consists in the management of perianal tissue infections. Antibiotics are used in bridging therapy when the infection has to be cured prior to initiation of immunosuppressive or biological treatment. Antibiotic monotherapy is not recommended in cases of perianal lesions $[16,17]$.

\section{VIII.2.4.3. Immunosuppressive therapy}

No evidence from randomized controlled trials is available with regard to the efficacy of immunosuppressants in monotherapy of CD with perianal lesions [16].

Early onset of immunosuppressive therapy (using thiopurines) has been accepted by experts in this group of patients [221, 222].

A retrospective assessment of 156 patients receiving infliximab and azathioprine for CD with perianal fistulas revealed that combined treatment, long-term use of infliximab, and the duration of fistular drainage ( $<34$ weeks) translated to better long-term treatment outcomes [223].

\section{VIII.2.4.4. Biological treatment}

In the treatment of perianal fistulas, treatment with anti-TNF biological agents should be considered as first line systemic therapy after the local inflammation has been controlled.

Based on the available data, it is advisable to use infliximab as the first line of treatment; in the event of intolerance or inefficacy, particularly in relation to the 
drug's immunogenicity, it should be replaced by adalimumab [224-229].

The efficacy of treatment and the timing of perianal lesion healing are increased by the biological drug being combined with ciprofloxacin [230, 231].

Evidence is available on the efficacy and safety of adalimumab in the treatment of perianal fistulas after infliximab therapy failure. This was demonstrated in the CHOICE trial (with fistula healing observed in $39 \%$ of subjects) [232].

For optimum efficacy, anti-TNF treatment may need to be adjusted on a case-by-case basis.

Higher serum levels of infliximab $(\geq 5 \mu \mathrm{g} / \mathrm{ml}$ ) and adalimumab ( $\geq 5.9 \mu \mathrm{g} / \mathrm{ml}$ ) have been shown to be associated with the maintenance of fistular closure during the treatment, suggesting that an increase in the dose may be considered in the course of the treatment in certain clinical situations [233-236].

At present, no strong evidence is available regarding the efficacy of vedolizumab and ustekinumab in the treatment of perianal lesions in CD patients. The beneficial effects of these drugs with respect to fistular healing are shown by the analyses of the results of GEMINI 2, CERTIFI, and UNITI trials as well as case reports pertaining to patients receiving ustekinumab due to infliximab intolerance; however, further research is required on this subject $[16,17]$.

At present, vedolizumab and ustekinumab appear to be a valid option for second line treatment of perianal lesions in CD following the failure of anti-TNF therapy, particularly in patients with active gastrointestinal mucosal lesions [215].

\section{VIII.2.4.5. Stem cells}

Allogeneic (donor-derived) or autologous (patient-derived) stem cells administered locally into the perifistular region following appropriate surgical preparation are the most recent and a very promising method for the treatment of perianal fistular in CD.

The efficacy and safety of allogeneic stem cells in the treatment of perianal fistulas in the course of $C D$ were demonstrated in a meta-analysis of 11 studies, including three randomized, placebo-controlled trials [237].

The largest of these trials was the ADMIRE CD trial (212 patients) [238, 239].

As part of the trial, all patients were subjected to surgical debridement and closure of the internal fistular opening; after the procedure, subjects were randomized into groups receiving stem cells or placebo in the form of injections administered into the internal opening region and the fistula channel. Patients with more than two internal fistular openings, enterovaginal fistulas, and stenosis or active inflammatory lesions within the rectum were excluded from the trial. After 1 year, remission was observed in $56.3 \%$ of patients receiving the study treatment as compared to $38.6 \%$ of patients in the placebo group $(p=0.010)$. Darvadstrocel has become the first drug containing allogeneic stem cells to be approved for use in Europe (2017).

Evidence on the efficacy of autologous stem cells in the treatment of perianal lesions in CD originates from several studies conducted in small groups of patients. In one of these studies, Lee et al. administered a preparation containing stem cells and fibrin glue into the perifistular lesion after appropriate surgical preparation (one or two administrations). After 12 months, $88.5 \%$ of the treated fistulas remained inactive. The use of autologous cells requires the cells to be collected from the patient during liposuction, which gives rise to concerns regarding additional procedure-related complications [240].

Further studies are needed on the efficacy, safety and applicability of stem cell preparations being combined with other treatments for $C D$, particularly in relation to the treatment of perianal lesions.

Asymptomatic perianal fistulas developing in the course of $C D$ require no targeted treatment. In the case of symptomatic fistulas, even those referred to as "simple" (according to ECCO or AGA guidelines), treatment should include surgical preparation and pharmacotherapy, although simple fistulotomy or seton placement combined with antibiotic therapy may be sufficient in low symptomatic, non-recurrent fistulas [200, 212].

\section{VIII.2.4.6. Team treatment}

The treatment of perianal lesions in the course of $C D$ presents a major challenge, and experts agree in their opinion that it should be conducted by a team consisting of a gastroenterologist and a surgeon [16, 17, 241].

\section{Diverting stoma formation is suggested in cases of severe perianal lesions resistant to local surgical and pharmacological management.}

(Evidence: low; recommendation: weak)

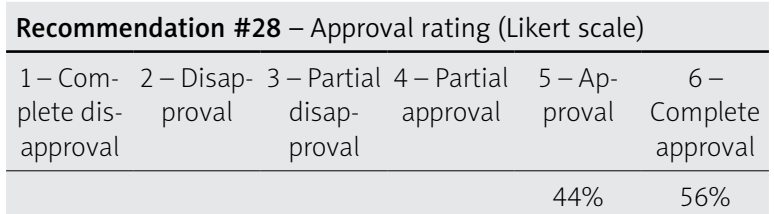

In cases of failure of conventional and biological pharmacotherapy as well as local surgical treatment of fistulas, formation of a temporary diverting stoma may be considered in patients with severe perianal $\mathrm{CD}$. This approach is aimed at reducing the quantity 
of stool leaking through the fistular channels to reduce their contamination and mechanical irritation and thus facilitate the healing of perianal lesions [17, 200, 211, 212].

The approach is unanimously approved in experts' recommendations despite the low quality of evidence due to the lack of randomized controlled trials. A meta-analysis of the available literature covering a total of 16 studies (556 patients) was published in 2015 . Indications for temporal stoma formations included perianal fistulas and abscesses as well as rectal inflammation. Temporary ileostomy was formed in most studies, with temporary colostomy being less frequent. A clinical response was achieved in a total of $63.8 \%$ of patients (within 3-6 months of surgery). No differences were observed in the percentage of clinical responses among patients subjected to surgery before the era of biological treatment (pre-1998 studies) and patients subjected to surgery after the biological drugs had been introduced into therapeutic regimens. No differences in clinical responses to surgery were also observed between patients who had not responded to biological treatment and patients who had not received this treatment. Gastrointestinal tract continuity was restored in a total of $34.5 \%$ of the operated patients (on average 1-1.5 years after stoma formation); however, the overall success rate was only $16.6 \%$ of patients in whom no recurrence or perianal lesions was observed and no repeated surgical treatment was required.

Overall, proctectomy was required in a total of $41.6 \%$ of patients due to the lack of clinical response following the stoma formation or symptom recurrence following the restoration of GI continuity [242].

Notably, temporary diverting stoma may provide an alternative to extensive resections or proctocolectomy procedures as well as facilitating the patient's adaptation to and acceptance of the permanent stoma [211].

\section{Other recommendations}

\section{IX.1. Surgical treatment}

29. Surgical treatment is recommended in cases of isolated changes within the ileocecal region presenting with recurrent subileus symptoms. Surgical treatment of ileocecal CD may also be considered in the absence of subileus symptoms.

(Evidence: low; recommendation: strong)

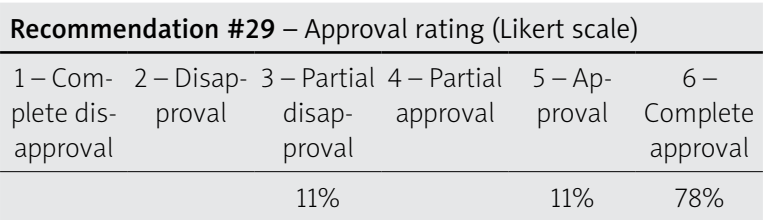

Surgical treatment is required in cases of the narrowing of the gastrointestinal tract leading to ileus or recurrent subileus symptoms [17, 200, 211, 212]. This also applies to patients with isolated location of lesions within the ileocecal segment. However, if subileus is not accompanied by intestinal perforation or peritoneal inflammation, if the disease presents with high inflammatory activity and the patient's condition is stable enough, surgical treatment may be postponed and conservative treatment may be initiated with the aim of improving the nutritional status along with possible anti-inflammatory treatment. However, this approach should not lead to a delay in the decision regarding the surgical treatment if it is necessary.

According to some evidence, surgical treatment applied at the early stage of therapeutic management may also be beneficial for patients with isolated ileocecal lesions and no history of subileus episodes. Retrospective observations revealed that such a strategy may reduce the need for resurgery, steroid therapy or biological treatment, and may translate into longer remission periods as compared to patients who had initially received conservative treatment [243-246]. A prospective, randomized, multi-center trial (the LIR!C trial) was also conducted to compare the efficacy and costs of conservative infliximab treatment and laparoscopic resection in patients with ileocecal CD without subileus symptoms following failure of short-term steroid and immunomodulatory treatment [247]. In the about 4 years of follow-up, surgical intervention was required in $1 / 3$ of patients who had received infliximab whereas about $25 \%$ of patients who had received the initial surgical treatment required the administration of anti-TNF antibodies. At the same time, early surgical treatment was shown to be potentially more cost-effective than early biological therapy [247].

30. Surgical treatment should be considered in cases of small intestinal lesions with abscess complications. In some cases, preliminary treatment may involve percutaneous drainage.

(Evidence: low; recommendation: weak)

\begin{tabular}{lcccc}
\multicolumn{4}{l}{ Recommendation \#30 - Approval rating (Likert scale) } & \\
\hline $\begin{array}{l}1 \text {-Com- } \\
\text { plete dis- } \\
\text { approval }\end{array}$ & $\begin{array}{l}\text { proval } \\
\text { provaltial }\end{array}$ & $\begin{array}{c}\text { 4-Partial } \\
\text { disap- } \\
\text { proval }\end{array}$ & $\begin{array}{c}5 \text {-Approval } \\
\text { proval }\end{array}$ & $\begin{array}{c}6- \\
\text { Complete } \\
\text { approval }\end{array}$ \\
\hline & $22 \%$ & $45 \%$ & $33 \%$
\end{tabular}

Intraabdominal abscesses usually develop in the course of $C D$ as the consequence of intense transmural inflammation leading to intestinal microperforation. In many cases, peritonitis does not develop and emergency surgery potentially burdened by a high risk of complications is not required [17, 211, 212, 248]. On the other hand, antibiotic 
therapy alone is usually inefficient and immunosuppressive therapy is quite risky. Data from retrospective analyses are available showing that percutaneous abscess drainage may in some cases be the most advantageous approach. A meta-analysis on this subject revealed that such a strategy provides an opportunity for resection treatment being avoided in about $30 \%$ of patients [249]. However, only well-visible, easily accessible, single-compartment collections can be qualified for ultrasound- or CT-guided drainage. The efficacy of this approach at experienced centers can be as high as 74-100\% [211]. However, constant follow-up is required after drainage procedures as the risk of abscess recurrence is estimated to be about 6.5 times higher than in patients who had undergone resection of the lesioned segment of the GI tract adjacent to the abscess [250]. Thus, intra-abdominal drainage should be considered primarily an ad hoc procedure ensuring time for optimization of conservative treatment and improvement in patient's nutritional status prior to the scheduled resection procedure. This multistage strategy may improve the long-term outcomes of surgical treatment.

In patients with intraabdominal as well as enteroatmospheric fistulas, surgical treatment is particularly recommended in cases of fistulas opening to the urinary tract, fistulas with concomitant disturbances in the enteral passage and/or purulent complications as well as lesions causing diarrhea and/or malnutrition [212].

31. Laparoscopic technique is particularly preferred in ileocecal CD. Surgery should be carried out at centers with appropriate experience in minimally invasive surgery.

(Evidence: moderate; recommendation: strong)

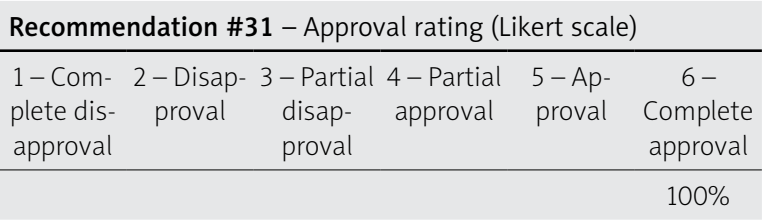

Laparoscopic technique has an advantage over the conventional surgical access since it entails shorter postsurgical recovery, is less invasive and burdened by lower risk of postsurgical scar hernias, and provides a better cosmetic effect $[17,211,212]$. This knowledge comes from a meta-analysis of studies including multicenter randomized trials [251]. Dasari et al. carried out a meta-analysis including two randomized studies which demonstrated that laparoscopic technique is as safe as the open technique and does not differ from the latter in the rate of subsequent resurgery [252]. The laparoscopic approach may be particularly useful in patients with short-segment lesions within the ileocecal section of the bowel; in such cases, the efficacy of the treatment was shown to the similar to that of infliximab [246]. The approach can also be used in patients with severe recurrent forms of $C D$; however, the risk of conversion to an open procedure is higher in such cases [253].

32. Endoscopic dilatation is preferred in cases of short ileal strictures $(<5 \mathrm{~cm})$. Stricturoplasty is an alternative technique which should be taken into account in particular in patients with multiple small intestinal strictures and/or in cases when a resectional surgery should be avoided. Some patients with stenosis and an inflammatory component may benefit from the optimization of anti-inflammatory treatment.

(Evidence: low; recommendation: weak)

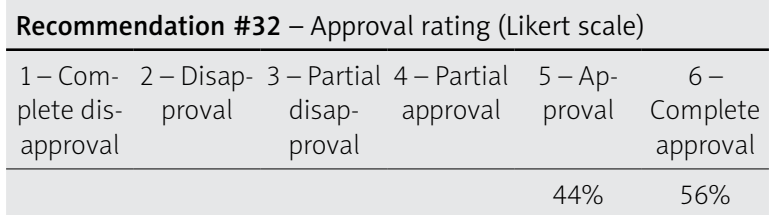

The strictures of the gastrointestinal tract developing in the course of CD are characterized by complex etiopathogenesis. As a simplification, one may say that they can develop as the result of both active inflammation and the fibrosis of the intestinal wall. Strictures may develop in any segment of the digestive tract; they are also quite common in the vicinity of anastomoses following previous resectional surgery $[211,212]$. Optimization of anti-inflammatory treatment may be beneficial, particularly in cases of the inflammatory component being predominant in the etiology of gastrointestinal stenosis. Some evidence is available to suggest that effective management of selected patients with symptomatic Gl stenosis may consist in anti-TNF agents, with independent predictors of therapeutic success including concomitant use of immunomodulators, high severity and short duration of symptoms, stenosis length of $<12 \mathrm{~cm}$ with moderate prestenotic bowel dilatation as observed MRI enterography, and absence of a fistula at the stricture site [254]. It is worth mentioning, however, about one half of the patients included in this analysis finally underwent surgery within 4 years of follow-up.

In the case of short-segment stenosis (usually defined as stenosis $<5 \mathrm{~cm}$ in length, particularly in the case of stenosis at anastomoses following previous resectional surgery), endoscopic dilatation may be preferred [211, 255]. Bettenworth et al. carried out a meta-analysis including a group of 1493 patients who had undergone a total of 3213 endoscopic dilatation procedures [256]. They found that the clinical efficacy of such treatment was as high as $80 \%$ and complications developed in about $3 \%$ of the patients. However, more than $2 / 3$ of pa- 
tients had to undergo subsequent dilatation procedures, while nearly one half were also subjected to surgical treatment. Another meta-analysis revealed that up to $75 \%$ of patients previously treated with endoscopic dilatation required surgical intervention within 5 years [257].

Surgical stricturoplasty may provide an alternative to endoscopic dilatation and resectional surgery, particularly in the case of strictures with predominance of the fibrotic component. Yamamoto et al. carried out a meta-analysis to assess the efficacy of stricturoplasty in the period preceding the widespread use of biological therapeutic agents [258]. According to the authors, stricture recurrence within 5 years from the treatment was observed in $30 \%$ of patients; however, most cases involved locations different than that treated by stricturoplasty. In another study with a follow-up period of about 10 years, stricturoplasty was found to be associated with a significantly lower risk of resurgery than primary resection of the strictured segment of the gastrointestinal tract [259].

Of note, the above data pertain mainly to treatment within the ileal segment. Data on strictures in other segments of the gastrointestinal tract, particularly the duodenum and colon, are very limited. In addition, exclusion of neoplastic transformation is required in all cases of chronic gastrointestinal tract stenoses in the natural history of CD.

33. Prior to surgical treatment, it is advisable to properly prepare the patient by improving the nutritional status, treating potential anemia, and reducing the dose of steroid therapy. Thiopurines and anti-TNF agents appear to have no adverse effect on the perioperative period.

(Evidence: low; recommendation: strong)

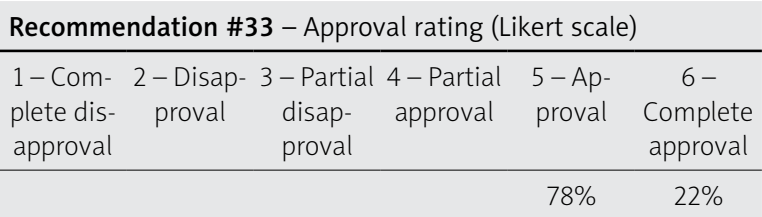

If possible, surgical treatment of $C D$ should be delivered in an elective setting. This strategy facilitates the opportunity to adequately prepare the patient for the surgical treatment; preparation should include a detailed assessment of the extent and activity of the disease, the possibility of preliminary abscess drainage (if feasible), and the control of any septic condition, anemia, or malnutrition [211, 212].

Malnutrition, which is a very common finding in CD patients, may be responsible for a several-fold increase in the risk of peri- and postoperative complications. Assessment of the nutrition status is mandatory in all CD patients prepared for surgical treatment. Evidence is available, mainly from observational studies, that initiation of preoperative enteral and/or parenteral nutrition in patients with nutritional deficiencies increases the safety of surgical treatment [260].

In 2015, a meta-analysis was published which summarized the available knowledge in this respect and showed that preoperative nutritional intervention improved the outcomes of surgical treatment despite numerous limitations of studies included in the meta-analysis [261].

The elements of such intervention should be adapted to the clinical situation. In adults, supplementation of a balanced oral diet with ready-made pharmaceutical formulas (complementary enteral nutrition) may be preferred. Partial and complete enteral nutrition is also acceptable, if clinically necessary; parenteral nutrition may also be used if no other option is possible. According to ESPEN (European Society for Clinical Nutrition and Metabolism) recommendations, nutritional interventions of this type should last about 7 to 10 days or longer in cases of particularly severe malnutrition [262]. Anemia ( $\mathrm{Hb}$ of $<13 \mathrm{~g} / \mathrm{dl}$ in men and $\mathrm{Hb}$ of $<12 \mathrm{~g} / \mathrm{dl}$ in women) also contributes to worse results of surgical treatment. The management of iron deficiency anemia in the context of scheduled surgical treatment should be provided primarily by means of intravenous (less commonly oral) iron supply [263].

Steroids are the group of drugs of the highest importance for the outcomes of surgical treatment as their use contributes to increased risk of infectious complications and anastomotic leaks. Two meta-analyses of retrospective and prospective studies are available showing that this risk is increased at least by a factor of two $[264,265]$. The safe dose of steroids has not been well defined. Therefore, whenever possible, surgical treatment of CD should be delayed until maximum dose reduction or total withdrawal of steroid therapy has been reached. No convincing evidence is available to support perioperative administration of an additional "stress dose" of steroids in patients receiving these medicines and undergoing scheduled surgery [266]. In the case of chronic use of steroids ( $>4$ weeks) and discontinuation of treatment prior to surgery being impossible, treatment should be continued after the procedure treatment (usually intravenously in the perioperative period if the patient remains fasting and then orally) with continuous dose tapering - the faster, the shorter the steroid therapy preceding surgery.

There is no evidence that thiopurines increase the risk of peri- and postoperative complications. Most scientific evidence also suggests that anti-TNF medications may be safely administered to patients subjected to 
surgical treatment, although the first reviews and meta-analyses were not clear in this respect $[267,268]$. The most recent analysis of 18 non-randomized, controlled trials revealed no significant differences in the rates of complications and rehospitalizations in patients receiving infliximab in the perioperative period $(n=1407)$ compared to patients not receiving anti-TNF agents $(n=4589)$ [269]. However, while no unambiguous evidence is available to provide a rationale for such actions, the UK recommendations continue to call for surgical treatment being deferred by up to 6-8 weeks from the last dose of infliximab and up to 4 weeks from the last dose of adalimumab, if possible [17].

The data on the safety of vedolizumab and ustekinumab are very limited in this context, but it appears that none of these drugs increases the risk of perioperative complications [211].

34. Thiopurines and anti-TNF agents reduce the risk of recurrence after surgical treatment. The use of these medications should depend on the presence of risk factors for disease recurrence and the results of the endoscopic evaluation as carried out 6-12 months after the surgery.

(Evidence: moderate; recommendation: weak)

\begin{tabular}{lcccc}
\multicolumn{4}{l}{ Recommendation \#34-Approval rating (Likert scale) } \\
\hline $\begin{array}{l}\text { 1-Com- } \\
\text { plete dis- } \\
\text { approval }\end{array}$ & $\begin{array}{l}\text { proval } \\
\text { disap- } \\
\text { proval }\end{array}$ & $\begin{array}{c}\text { 3-Partial } \\
\text { disproval }\end{array}$ & $\begin{array}{c}\text { 5-Ap- } \\
\text { proval }\end{array}$ & $\begin{array}{c}6- \\
\text { Complete } \\
\text { approval }\end{array}$ \\
\hline & & $56 \%$ & $44 \%$
\end{tabular}

Recurrence of the inflammatory process following surgical resection is common in CD. Endoscopic lesions are estimated to occur in up to $40-80 \%$ of patients 6 months after surgical treatment. The risk factors for disease recurrence include smoking, presence of fistulas, active perianal lesions, and extensive involvement of the small bowel [17, 212].

The risk of symptomatic exacerbation following intestinal resection was shown to increase with the severity of endoscopic lesions detected within the anastomotic region (particularly within the neoterminal ileum) in follow-up colonoscopy, which should be performed 6-12 months after the surgery. The Rutgeerts score is the most common tool used for this purpose.

Available data suggest that certain drugs may reduce the likelihood of disease recurrence following the surgery; however, most studies discuss the risk of recurrence of endoscopic lesions rather than of clinical symptoms [270]. For example, the post-hoc analysis of the TOPPIC study revealed that 6-mercaptopurine increases the likelihood of complete mucosal remission (Rutgeerts score of i0) in smoking patients [271].
The research on the use of anti-TNF agents led to mostly unambiguous conclusions regarding the positive impact on endoscopic recurrence rates; however, data on clinical recurrence were not so homogeneous. For example, Yoshida et al. observed a significantly higher rate of CD symptom remission in the third year of follow-up in the group of patients receiving infliximab as compared to no therapy [272]. In another RCT, no significant difference was found between the rates of clinical recurrence of $C D$ at 76 weeks after the surgery in patients receiving infliximab and placebo [273].

In another randomized trial which compared the efficacy of adalimumab, azathioprine, and mesalazine, patients treated with anti-TNF had lower endoscopic as well as recurrence rates [274]. A systematic review carried out in 2019 revealed that thiopurines may be useful in maintenance of $C D$ remission following surgical resection; however, the quality of evidence to support this claim is moderate [275].

Data on the practical applicability of other medications in the prevention of postoperative CD recurrence are limited (mesalazine), or investigational drugs are poorly tolerated (metronidazole) [276]. No evidence is currently available on the usefulness of ustekinumab or vedolizumab in this indication.

\section{IX.2. Pregnancy}

35. Female fertility is not reduced in CD remission periods. Both male and female fertility may be reduced in disease activity periods. History of abdominal surgery in females may result in difficulties in becoming pregnant.

(Evidence: moderate; recommendation: strong)

Recommendation \#35 - Approval rating (Likert scale)

1-Com- 2-Disap- 3-Partial 4-Partial 5-Ap- 6-

plete dis- proval disap- approval proval Complete

approval proval approval

$22 \% \quad 11 \% \quad 67 \%$

36. Sulfasalazine may cause a reversible reduction in the number and motility of male sperm. At the same time, no evidence is available on any adverse effects of steroids, mesalazine, thiopurines, and anti-TNF drugs on male fertility or increased risk of congenital defects in children.

(Evidence: moderate; recommendation: strong)

Recommendation \#36 - Approval rating (Likert scale)

\begin{tabular}{|c|c|c|c|c|}
\hline $\begin{array}{l}1 \text {-Com- } \\
\text { plete dis- } \\
\text { approval }\end{array}$ & $\begin{array}{c}2 \text { - Disap- } \\
\text { proval }\end{array}$ & $\begin{array}{ll}\text { 3-Partial } & 4 \text {-Partial } \\
\text { disap- } & \text { approval } \\
\text { proval } & \end{array}$ & $\begin{array}{l}\text { 5-Ap- } \\
\text { proval }\end{array}$ & $\begin{array}{c}6- \\
\text { Complete } \\
\text { approval }\end{array}$ \\
\hline & & & $11 \%$ & $89 \%$ \\
\hline
\end{tabular}


37. In the case of pregnancy in a woman in clinical remission of $C D$, previous treatment should be continued (except for methotrexate treatment). The risk of failed pregnancy due to disease exacerbation is much higher than the risk associated with the potential adverse effects of the treatment.

(Evidence: low; recommendation: weak)

\begin{tabular}{lcccc}
\multicolumn{4}{l}{ Recommendation \#37 - Approval rating (Likert scale) } \\
\hline $\begin{array}{l}\text { 1-Com- } \\
\text { plete dis- } \\
\text { approval }\end{array}$ & $\begin{array}{c}\text { proval } \\
\text { disap- } \\
\text { proval }\end{array}$ & approval & $\begin{array}{c}\text { p-Ap- } \\
\text { proval }\end{array}$ & $\begin{array}{c}\text { Complete } \\
\text { approval }\end{array}$ \\
\hline & & $100 \%$
\end{tabular}

There is no evidence of reduced fertility in patients with CD in remission [277]. Reduced natality, as reported in many analyses, results mainly from the decisions of patients who are afraid of pregnancy complications, the risk of fetal defects, and the risk of IBD in children. However, we have reasons to believe that active, uncontrolled disease with high systemic activity may affect fertility in both female and male patients [278]. This may be due to the direct impact of inflammatory mediators on a number of fertility-related processes (e.g. ovulation disorders, erectile dysfunction, impact on semen quality). Evidence is also available that a history of major surgery within the abdominal cavity and/ or pelvis may contribute to increased risk of problems with becoming pregnant [277]. In men, surgery within the pelvis region may result in erectile and ejaculation disorders. However, it should be stressed that data in this respect are very limited. With regard to pharmaceutical agents, only sulfasalazine was shown to have a reversible, negative impact on the quality of male sperm. Methotrexate is absolutely contraindicated during the periconceptual period, pregnancy, and lactation [279]. The drug had been shown to increase the risk of miscarriage and a number of congenital defects (particularly in cases of fetal exposure within the first trimester). It is therefore recommended to discontinue methotrexate (in women as well as in men) about 6 months before the planned conception. Other medications have no negative impact on fertility.

$C D$ remission is crucial for the maintenance of reproductive potential as well as for the safe course of pregnancy and childbirth. Potential risks associated with the treatment are significantly lower than those resulting from uncontrolled CD. Therefore, previous treatment effective in achieving remission should be continued in case of pregnancy (with the exception of methotrexate treatment) [280]. Numerous registries (e.g. PIANO Registry) and observational studies reveal no increased rates of obstetric failures or congenital malformations in children born to mothers treated with aminosalicy- lates, thiopurines, or anti-TNF agents [277, 281]. The existing data on vedolizumab and ustekinumab, although very limited, also do not contain any alarming signals in this regard.

Anti-TNF agents are known to cross the placental barrier, particularly within the third trimester of gestation. These antibodies were detectable in children born to mothers receiving biological IBD treatment during pregnancy up to the age of 6 months. Therefore, if possible (i.e. in cases of lasting remission of the disease), discontinuation of treatment at gestational weeks 24-26 should be considered to limit the fetal exposure to the drug. Live vaccinations should be postponed in children of mothers suffering from IBD and treated with anti-TNF while pregnant (usually, it is suggested that they be given after the child has reached 6-9 months old) $[277,281]$.

CD treatment can also be continued during lactation. Aminosalicylates, thiopurines, steroids and antiTNF agents are considered safe in this respect. Data on the use of vedolizumab and ustekinumab are scarce, but no adverse findings have been reported to date [282].

\section{Systemic steroids are the treatment of choice if CD is diagnosed or exacerbated in pregnancy.}

(Evidence: low; recommendation: weak)

\begin{tabular}{lcccc}
\multicolumn{4}{l}{ Recommendation \#38 - Approval rating (Likert scale) } \\
\hline $\begin{array}{l}\text { 1-Com- } \\
\text { plete dis- } \\
\text { approval }\end{array}$ & $\begin{array}{c}\text { proval } \\
\text { disap- } \\
\text { proval }\end{array}$ & $\begin{array}{c}\text { approval } \\
\text { proval }\end{array}$ & $\begin{array}{c}\text { 5-Ap- } \\
\text { pomplete } \\
\text { approval }\end{array}$ \\
\hline
\end{tabular}

The principles for the management of $C D$ exacerbations in pregnancy are similar to the general standard of care. However, the assessment of disease activity should be based mainly on non-invasive parameters. Gastroscopy, sigmoidoscopy, or even endoscopic retrograde cholangiopancreatography is not contraindicated if absolutely necessary; however, every effort should be made to minimize maternal and fetal exposure to ionizing radiation in the latter case. With regard to imaging studies, ultrasound and magnetic resonance imaging are the modalities of choice [277, 281].

Systemic steroids are the treatment of choice in cases of disease exacerbation. According to some reports, the drugs may increase the risk of cleft palate in the fetus when administered during the first trimester of pregnancy; however, the supporting evidence is of very poor quality [283]. No confirmation of this finding was provided in one of the largest analyses on the subject, encompassing a total of more than 51,000 pregnancies [284]. Nonetheless, it is suggested 
that short-acting steroids, such as prednisone, prednisolone, or methylprednisolone, are used in the treatment. No adverse data are also available on the safety of oral budesonide in CD. Anti-TNF agents [277, 281] should be used in the treatment of CD exacerbations if steroids are ineffective or not tolerated. Data on other biological drugs are limited. If antibiotic therapy is necessary, metronidazole and ciprofloxacin should be avoided, especially in the first trimester of pregnancy and during lactation. Indications for surgical treatment in pregnant women with CD are not different from those in non-pregnant women.

39. In CD with perianal lesions, cesarean section is the recommended method of delivery. No contraindications to vaginal delivery exist in other cases (including patients with ileo- or colostomy).

(Evidence: low; recommendation: weak)

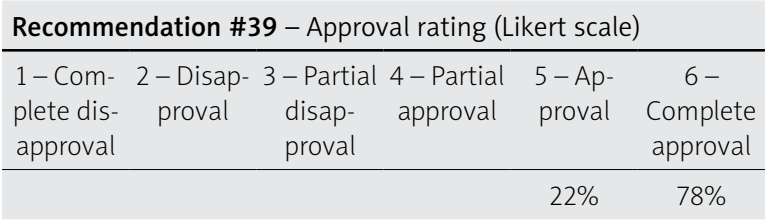

The decision on the delivery route depends primarily on obstetric indications. Despite the significant percentage of cesarean sections being performed in females with $C D$, literature data suggest that this approach is substantiated only in cases of perianal lesions [277]. Retrospective analyses demonstrated that vaginal delivery in women with the perianal form of CD is associated with a risk of damage to the crotch and vaginal tissues [285]. In the remaining cases, no unambiguous evidence was provided to suggest any increase in the risk of de novo perianal lesions or impaired sphincter function in cases of vaginal birth. Nonetheless, it is suggested that the frequency of episiotomy be kept to a minimum while, at the same time, the decision regarding vaginal delivery be determined mainly by obstetric considerations [277].

\section{IX.3. Osteoporosis and osteopenia}

40. Patients with osteopenia and patients treated with systemic steroids should receive calcium and vitamin D supplementation. Bisphosphonates are suggested if osteoporosis is diagnosed.

(Evidence: moderate; recommendation: weak)

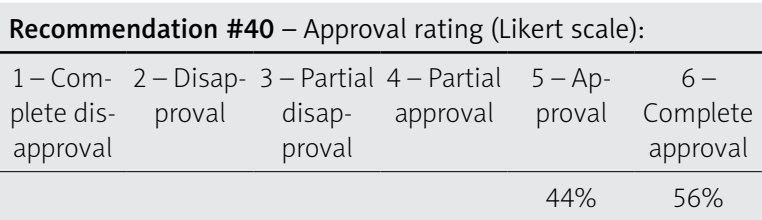

Osteopenia and osteoporosis are among the most common extraintestinal complications of CD [286]. Their development is promoted by the inflammatory activity and the deficiencies of vitamin D, calcium, and other micro- and macronutrients, malnutrition and lack of physical activity. Osteopenia and osteoporosis may be the result of treatment, particularly steroid therapy. These diseases should therefore be actively screened for in any person with an active form of CD, in individuals with a long medical history, patients with additional risk factors for reduced bone mineral density, and patients undergoing steroid therapy (especially if the treatment lasts > 3 months). Dual energy X-ray absorptiometry (DEXA) of the femoral neck and/or lumbar spine is the method of choice [287]. In individuals subjected to long-term exposure to steroids and in patients with osteopenia, calcium preparations should be given at the dose of 500-1000 mg/day and vitamin D should be given at the dose of 1000-2000 IU/day (with higher doses of vitamin D being recommended in some guidelines) [287-290]. Physical activity should be promoted in all patients. Smoking is contraindicated. Of key importance, however, is the optimized treatment of the primary disease (particularly in young patients). In the event of pathological fractures in individuals with osteoporosis, bisphosphonate treatment should be initiated [286]. Bisphosphonates are not recommended in prevention of fractures in individuals with reduced bone mineral density by ECCO experts. However, one should keep in mind that studies on the subject are still under way. The risk of osteoporosis-related complications in patients with reduced bone mineral density should therefore be assessed on a case-by-case basis, with appropriate treatment being chosen accordingly.

\section{IX.4. Nutritional treatment}

41. Adequate nutritional status improves CD treatment results. Adequate nutritional treatment (both enteral and parenteral) should be an integral part of CD treatment. Consultation of a clinical dietitian with appropriate experience in providing care to $C D$ patients should also be considered. (Evidence: high; recommendation: strong)

Recommendation \#41 - Approval rating (Likert scale)

\begin{tabular}{|c|c|c|c|c|c|}
\hline $\begin{array}{l}1 \text { - Com- } \\
\text { plete dis- } \\
\text { approval }\end{array}$ & $\begin{array}{c}2 \text { - Disap- } \\
\text { proval }\end{array}$ & $\begin{array}{c}3 \text { - Partia } \\
\text { disap- } \\
\text { proval }\end{array}$ & $\begin{array}{l}4 \text { - Partial } \\
\text { approval }\end{array}$ & $\begin{array}{l}\text { 5-Ap- } \\
\text { proval }\end{array}$ & $\begin{array}{c}6- \\
\text { Complete } \\
\text { approval }\end{array}$ \\
\hline & & & & $33 \%$ & $67 \%$ \\
\hline
\end{tabular}

Malnutrition is a frequent complication of CD. Among various factors, it can be due to increased catabolism in patients with active, uncontrolled disease, 
nutritional deficiencies, and the applied treatment [17, 291]. Therefore, nutritional status should be assessed in each patient separately using commonly available scales. Adequate nutrition improves long-term prognosis of CD treatment. It also promotes optimization of pharmacotherapy and affects the efficacy and safety of surgical treatment [292]. Complete enteral nutrition is the modality of choice in the management of CD exacerbations in children and adolescents; however, no similar evidence is available with regard to the adult population [17]. Nonetheless, according to the 2019 Guidelines of the British Society of Gastroenterology, such treatment may also be considered in the management of mild to moderate exacerbations of CD in selected motivated patients not consenting to take up pharmacotherapy. On the other hand, nutritional treatment (preferably enteral treatment and, in the absence of other possibilities, parenteral treatment) should be taken into account as part of supportive therapy in each adult patient on a case-by-case basis [292]. At present, no high quality evidence is available with regard to efficacy of any diet in the treatment of active CD. Although data on the so-called CD Exclusion Diet are available only for the pediatric population, growing interest is observed with regard to the potential use of this diet in the adult population [293]. At present, dietary treatment cannot be recommended as an alternative to conventional pharmacotherapy. However, given the importance of diet as an important environmental factor in the pathogenesis of IBD, and taking into account the high interest of patients in the importance of diet, the option to consult a professional clinical dietitian having appropriate qualifications and experience is an important element in the holistic approach to the management of IBD patients [291, 294].

\section{IX.5. Anemia}

42. If anemia is observed, the type of anemia should be determined followed by implementation of the adequate treatment.

(Evidence: moderate; recommendation: strong)

\begin{tabular}{|c|c|c|c|c|}
\hline \multicolumn{5}{|c|}{ Recommendation \#42 - Approval rating (Likert scale) } \\
\hline \multirow[t]{2}{*}{$\begin{array}{l}1-\text { Com- } \\
\text { plete dis- } \\
\text { approval }\end{array}$} & $\begin{array}{c}2 \text { - Disap- } \\
\text { proval }\end{array}$ & $\begin{array}{cc}\text { 3-Partial } & 4 \text { - Partial } \\
\text { disap- } & \text { approval } \\
\text { proval } & \end{array}$ & $\begin{array}{l}5-\text { Ap- } \\
\text { proval }\end{array}$ & $\begin{array}{c}6- \\
\text { Complete } \\
\text { approval }\end{array}$ \\
\hline & & & $33 \%$ & $67 \%$ \\
\hline
\end{tabular}

It is estimated that anemia develops in about $1 / 3$ of IBD patients [17]. Its etiology is usually complex, the most common factors including iron deficiency and the so-called anemia of chronic disease (anemia of inflammation). Sometimes, other contributing factors include vitamin B12 deficiency and, less frequently, folic acid deficiency. Anemia significantly affects the course of CD; in addition to typical symptoms (such as fatigue, tachycardia), it may lead to impaired tissue healing, reducing the effectiveness of conventional pharmacotherapy [17].

Hemoglobin levels should be determined in all CD patients; evaluation of the ferritin levels, and possibly transferrin saturation, is also helpful. Anemia is defined as hemoglobin levels of $<12 \mathrm{~g} / \mathrm{dl}$ in women (< $11 \mathrm{~g} / \mathrm{dl}$ in pregnant women) or $<13 \mathrm{~g} / \mathrm{dl}$ in men. In an IBD patient with no active inflammatory processes, the iron deficiency can usually be recognized if ferritin concentration is $<30 \mathrm{~g} / \mathrm{l}$ (or if transferrin saturation is $<16 \%$ ); in patients with an active inflammatory process, iron deficiency is defined if ferritin concentration is lower than $100 \mathrm{~g} / \mathrm{l}$ [295]. Other investigations (e.g. assessment of vitamin $B_{12}$ levels) should be performed as required.

The treatment of anemia in CD consists in augmentation of anti-inflammatory therapy (in active disease) and iron supplementation [296]. For hemoglobin levels of less than $10 \mathrm{~g} / \mathrm{dl}$, intravenous compensation of iron deficiency is necessary. The most commonly used preparations include ferric derisomaltose and ferric carboxymaltose. The total iron dose to be administered can be calculated using the Ganzoni formula or in a simplified way - using the hemoglobin value and the patient's body weight (the usual dose is 1000-2000 mg) (Table VII). In the case of mild anemia with a hemoglobin values of above $10 \mathrm{~g} / \mathrm{dl}$, oral supplementation of iron at doses not exceeding $100 \mathrm{mg} /$ day is acceptable [296]. However, in the event of intolerance to oral supplementation as well as in the event of active disease, intravenous infusion of iron preparations is necessary, as it is considered to be the optimal method of treatment of anemia due to iron deficiency. A positive response to treatment is defined as hemoglobin concentration increasing by at least $2 \mathrm{~g} / \mathrm{dl}$ in approximately 4 weeks [297]. In the absence of a response, treatment verification is required; erythropoietin administration with intravenous iron supply may be considered in some patients. Blood transfers are indicated only in

Table VII. The total dose of iron supplementation using the example of ferric carboxymaltose [297]

\begin{tabular}{ccc} 
Hemoglobin level $[\mathrm{g} / \mathrm{dl}]$ & Body weight $<70 \mathrm{~kg}$ & Body weight $>70 \mathrm{~kg}$ \\
\hline$\geq 10$ & $1000 \mathrm{mg}$ & $1500 \mathrm{mg}$ \\
\hline $7-10$ & $1500 \mathrm{mg}$ & $2000 \mathrm{mg}$
\end{tabular}


patients with deep, symptomatic anemia (usually with hemoglobin levels of $<7 \mathrm{~g} / \mathrm{dl}$ ).

\section{IX.6. Skin lesions}

43. Systemic steroids should be used in the case of skin lesions of the type of pyoderma gangrenosum or erythema nodosum; in cases of treatment failure, anti-TNF agents should be used. The efficacy of other biologicals in this indication has not been studied in detail.

(Evidence: moderate; recommendation: weak)

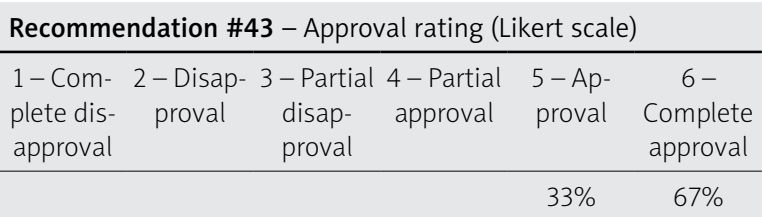

The most common skin lesions that may accompany $C D$ include erythema nodosum and pyoderma gangrenosum [1]. The diagnosis of these parenteral manifestations of CD should be based mainly on clinical presentation. In ambiguous cases with atypical natural history, histopathological evaluation of skin lesion biopsy specimens should be sought.

Erythema nodosum is manifested by painful subcutaneous tissue lumps or nodules sized 1 to $5 \mathrm{~cm}$, usually red/violet in color, most frequently occurring on the surfaces of the thighs. The incidence of erythema nodosum is closely correlated with the clinical activity of CD, and therefore its treatment should involve intensification of CD therapy. Systemic steroids are the treatment of choice. In the absence of therapeutic effects or in the case of recurrent lesions, immunosuppressive therapy should be implemented, with anti-TNF antibodies also being effective [286, 298].

Pyoderma gangrenosum may affect any area of skin. Most frequently, however, dermatosis is observed within the thighs as well as in the vicinity of the stoma opening in patients subjected to enterostomy formation [286]. Initially, pyoderma gangrenosum is manifested as isolated inflammatory nodules similar to abscesses or blemishes. These are followed by dermal necrosis leading to painful ulceration frequently covered by necrotic scabs. Pyoderma gangrenosum may also occur in patients in clinical remission of $C D$. The first-line treatment of this dermal manifestation of CD consists in administration of systemic steroids. In the absence of a timely response to this treatment, infliximab or adalimumab is the drug of choice [298]. Calcineurin inhibitors (cyclosporine, tacrolimus) are an alternative therapeutic approach. Stoma closure should be considered, if possible, upon the development of skin lesions typical for pyoderma gangrenosum in the vicinity of the opening.
IX.7. Arthropathy associated with CD

44. In cases of arthropathy associated with CD, the first step should involve the intensification of primary disease treatment. Supportive treatment with sulfasalazine, short-term NSAIDs and topical steroids, and physiotherapy may be helpful in patients with peripheral articular involvement. In cases of axial lesions, anti-TNF agents are suggested in addition to physiotherapy. The efficacy of other biologicals in this indication has not been studied in detail.

(Evidence: moderate; recommendation: weak)

Recommendation \#44 - Approval rating (Likert scale)

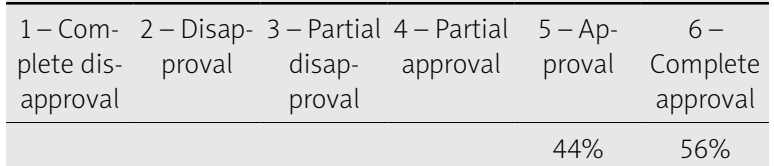

Arthropathies accompanying CD can be of peripheral and axial type $[1,286]$. Peripheral arthropathy is usually associated with involvement of large joints (subtype 1). A characteristic trait of this subtype consists in the asymmetry of pathological lesions. Subtype 1 is usually acute and correlated with the activity of CD. The less common subtype 2 of peripheral arthropathy involves the small joints of the hands and is not dependent on the activity of CD. In both cases, the diagnosis is based on the clinical presentation (joint pain) and physical examination (painful swelling of joint areas). The treatment of peripheral arthropathies should involve intensification of CD therapy (steroids, immunosuppression, anti-TNF agents). Short-term use of NSAIDs, preferably those belonging the group of cyclooxygenase-2 inhibitors (coxibs), is acceptable. Local steroid injections and physiotherapy are also recommended in selected cases. Sulfasalazine may be used particularly in peripheral arthritis of subtype 1 [1].

Axial arthropathy consists in inflammation of sacroiliac and spinal joints [1, 286]. Typical symptoms include chronic back pain decreasing after physical exercise, and morning stiffness. Recommended diagnostic procedures include an MRI scan of the osteoarticular system. Axial arthropathy in the course of CD may be treated with NSAIDs; however, minimum effective doses should be used for the shortest possible periods, with selective cyclooxygenase-2 inhibitors being the preferred subgroup of these drugs. Physiotherapy also plays an important role in the management of axial arthropathy. No satisfactory activity is observed for medications such as thiopurines, sulfasalazine, methotrexate, or steroids. Since the use of NSAIDs should be kept to a minimum in patients with $C D$, an alternative with proven efficacy is provided by anti-TNF drugs. To date, no unambiguous 
evidence is available regarding the usefulness of other biological drugs in arthropathies accompanying CD. The available data on vedolizumab do not support its efficacy in this indication. With regard to ustekinumab, some premises exist to suggest its efficacy, although evidence of higher scientific value is still to be obtained [298-300].

\section{IX.8. Vaccination}

45. Vaccination and infection history should be collected in all patients with CD. A full schedule of preventive vaccinations is recommended.

(Evidence: low; recommendation: strong)

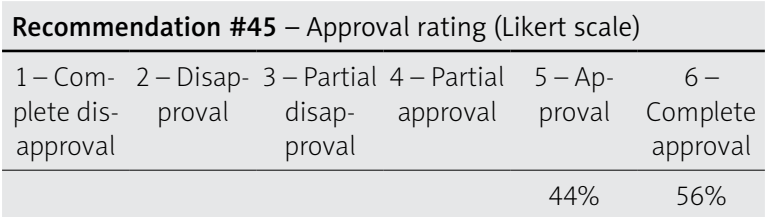

Upon the diagnosis of CD, a complete medical history should be collected including information on the history of infectious diseases and protective vaccinations. The drugs used in the treatment of CD and the disease itself may contribute to increased risk of a number of infectious diseases. Atypical course of an infectious disease and lack of response to the applied treatment may be another problem in immunosuppressed CD patients [1,301]

Evaluation of systemic protection against individual infectious diseases prior to initiation of immunosuppressive treatment provides an opportunity for safe and effective completion of the protective vaccination schedule. Immunosuppressed patients are defined as patients receiving steroids at daily doses of more than $20 \mathrm{mg}$ prednisone equivalent for $>2$ weeks and patients treated with effective doses of thiopurines, methotrexate, biological agents as well as malnourished patients [302]. In these cases, live vaccines may be delivered no later than 3 weeks before initiating these treatments and no earlier than 3 months after the completion of these treatments. Live vaccines include tuberculosis vaccine (BCG), measles, mumps, and rubella vaccine (MMR), chickenpox vaccine, oral polio vaccine, yellow fever vaccine, and oral anti-rotavirus vaccine. Dead vaccines can be used safely in immunocompromised patients; however, the efficacy of immunization may be lower than in healthy individuals.

The following supplementary vaccinations should be considered in adults not immunized against individual infectious diseases (either by protective vaccination or by recovery from the infectious disease resulting in permanent immunity) [1, 303]:

- hepatitis $B$ vaccination,

- chickenpox vaccination;
- seasonal influenza vaccination;

- anti-human papilloma virus vaccination (girls aged 11-12 years prior to initiation of sexual activity being the main target group),

- pneumococcal and meningococcal vaccination.

Vaccination against COVID-19 should also be considered in all CD patients [304, 305].

\section{IX.9. Psychological support}

\section{Psychological support should be made available to each CD patient.}

(Evidence: very low; recommendation: strong)

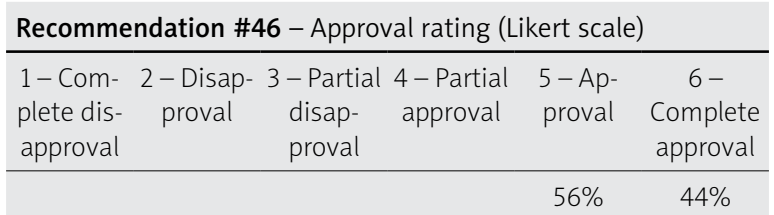

The quality of life of patients is seriously affected by $C D$. Due to the prospect of living with an incurable disease, the fear of adverse reactions to medications, surgical treatment, and disability caused by the disease, as well as the painful symptoms, patients frequently experience depression and anxiety [306]. Few studies have been carried out to date on the efficacy of various psychological interventions against these symptoms as well as on the course of the IBD itself. So far, no data are available to show that any psychological intervention (such as behavioral and cognitive therapy) has any impact on CD remission rates $[307,308]$. Sparse evidence is available, however, to suggest that such interventions may improve the overall health of patients. For example, as shown in a randomized study by Wynne et al., acceptance and commitment therapy (ACT) significantly reduces the severity of anxiety or stress in IBD [309]. Therefore, it appears that the possibility to obtain psychological support, as well as consideration being paid to the impact of CD on the patient's emotional condition, should constitute an integral part of holistic care to IBD patients.

\section{References}

1. Łodyga M, Eder P, Bartnik W, et al. Guidelines for the management of Crohn's disease. Recommendations of the Working Group of the Polish National Consultant in Gastroenterology and the Polish Society of Gastroenterology. Gastroenterology Rev 2012; 7: 317-38.

2. Łodyga M, Eder P, Bartnik W, et al. New pharmaceuticals in inflammatory bowel disease. Gastroenterology Rev 2015; 10: 57-60.

3. Mularczyk A, Gonciarz M, Bartnik W, et al. Biosimilar medicines - their use in the treatment of inflammatory bowel diseases. Position statement of the Working Group of the Polish National Consultant in Gastroenterology. Gastroenterology Rev 2014; 9: 1-3. 
4. Loftus EV Jr. Clinical epidemiology of inflammatory bowel disease: Incidence, prevalence, and environmental influences Gastroenterology 2004; 126: 1504-17.

5. Pasvol TJ, Horsfall L, Bloom S, et al. Incidence and prevalence of inflammatory bowel disease in UK primary care: a population-based cohort study. BMJ Open 2020; 10: e036584.

6. Feuerstein JD, Cheifetz AS. Crohn disease: epidemiology, diagnosis, and management. Mayo Clin Proc 2017; 92: 1088-103.

7. GBD 2017 Inflammatory Bowel Disease Collaborators. The global, regional, and national burden of inflammatory bowel disease in 195 countries and territories, 1990-2017: a systematic analysis for the Global Burden of Disease Study 2017. Lancet Gastroenterol Hepatol 2020; 5: 17-30.

8. Best WR, Becktel JM, Singleton JW, Kern F Jr. Development of a Crohn's disease activity index. National Cooperative Crohn's Disease Study. Gastroenterology 1976; 70: 439-44

9. Harvey RF, Bradshaw JM. A simple index of Crohn's-disease activity. Lancet 1980; 1: 514.

10. Mary JY, Modigliani R. Development and validation of an endoscopic index of the severity for Crohn's disease: a prospective multicentre study. Groupe d'Etudes Thérapeutiques des Affections Inflammatoires du Tube Digestif (GETAID). Gut 1989; 30: 983-9.

11. Daperno M, D’Haens G, Van Assche G, et al. Development and validation of a new, simplified endoscopic activity score for Crohn's disease: the SES-CD. Gastrointest Endosc 2004; 60: 505-12.

12. Silverberg MS, Satsangi J, Ahmad T, et al. Toward an integrated clinical, molecular and serological classification of inflammatory bowel disease: report of a Working Party of the 2005 Montreal World Congress of Gastroenterology. Can J Gastroenterol 2005; 19 Suppl A: 5A-36A.

13. Roda G, Jharap B, Neeraj N, Colombel JF. Loss of response to anti-TNFs: definition, epidemiology, and management. Clin Transl Gastroenterol 2016; 7: e135.

14. Sprakes MB, Ford AC, Warren L, et al. Efficacy, tolerability, and predictors of response to infliximab therapy for Crohn's disease: a large single centre experience. J Crohns Colitis 2012; 6: 143-53.

15. Allez M, Karmiris K, Louis E, et al. Report of the ECCO pathogenesis workshop on anti-TNF therapy failures in inflammatory bowel diseases: definitions, frequency and pharmacological aspects. J Crohns Colitis 2010; 4: 355-66.

16. Torres J, Bonovas S, Doherty G, et al. ECCO guidelines on therapeutics in Crohn's disease: medical treatment. J Crohns Colitis 2020; 14: 4-22.

17. Lamb CA, Kennedy NA, Raine T, et al. British Society of Gas troenterology consensus guidelines on the management of inflammatory bowel disease in adults [published correction appears in Gut. 2021 Apr;70(4):1]. Gut 2019; 68 (Suppl 3): s1-106.

18. Lichtenstein GR, Loftus EV, Isaacs KL, et al. ACG clinical guideline: management of Crohn's disease in adults [published correction appears in Am J Gastroenterol. 2018 Jul;113(7):1101] Am J Gastroenterol 2018; 113: 481-517.

19. Romberg-Camps MJ, Dagnelie PC, Kester AD, et al. Influence of phenotype at diagnosis and of other potential prognostic factors on the course of inflammatory bowel disease. Am J Gastroenterol 2009; 104: 371-83.

20. Moum B, Ekbom A, Vatn MH, et al. Inflammatory bowel disease: re-evaluation of the diagnosis in a prospective population based study in south eastern Norway. Gut 1997; 40: 328-32.

21. Sands BE. From symptom to diagnosis: clinical distinctions among various forms of intestinal inflammation. Gastroenterology 2004; 126: 1518-32.

22. Coremans G, Rutgeerts P, Geboes K, et al. The value of ileoscopy with biopsy in the diagnosis of intestinal Crohn's disease. Gastrointest Endosc 1984; 30: 167-72.

23. Geboes K, Ectors N, D'Haens G, Rutgeerts P. Is ileoscopy with biopsy worthwhile in patients presenting with symptoms of inflammatory bowel disease? Am J Gastroenterol 1998; 93: 201-6.

24. Witte AM, Veenendaal RA, Van Hogezand RA, et al. Crohn's disease of the upper gastrointestinal tract: the value of endoscopic examination. Scand J Gastroenterol Suppl 1998; 225: 100-5.

25. Annunziata ML, Caviglia R, Papparella LG, Cicala M. Upper gastrointestinal involvement of Crohn's disease: a prospective study on the role of upper endoscopy in the diagnostic work-up. Dig Dis Sci 2012; 57: 1618-23.

26. Taylor SA, Avni F, Cronin CG, et al. The first joint ESGAR/ ESPR consensus statement on the technical performance of cross-sectional small bowel and colonic imaging. Eur Radiol 2017; 27: 2570-82.

27. Masselli G, Casciani E, Polettini E, Gualdi G. Comparison of $M R$ enteroclysis with MR enterography and conventional enteroclysis in patients with Crohn's disease. Eur Radiol 2008; 18: 438-47.

28. Liu W, Liu J, Xiao W, Luo G. A Diagnostic accuracy meta-analysis of CT and MRI for the evaluation of small bowel Crohn disease. Acad Radiol 2017; 24: 1216-25.

29. Horsthuis K, Bipat S, Stokkers PC, Stoker J. Magnetic resonance imaging for evaluation of disease activity in Crohn's disease: a systematic review. Eur Radiol 2009; 19: 1450-60.

30. Horsthuis K, Bipat S, Bennink RJ, Stoker J. Inflammatory bowel disease diagnosed with US, MR, scintigraphy, and CT: meta-analysis of prospective studies. Radiology 2008; 247 : 64-79.

31. Dong J, Wang H, Zhao J, et al. Ultrasound as a diagnostic tool in detecting active Crohn's disease: a meta-analysis of prospective studies. Eur Radiol 2014; 24: 26-33.

32. Panés J, Bouzas R, Chaparro $M$, et al. Systematic review: the use of ultrasonography, computed tomography and magnetic resonance imaging for the diagnosis, assessment of activity and abdominal complications of Crohn's disease. Aliment Pharmacol Ther 2011; 34: 125-45.

33. Puylaert CA, Tielbeek JA, Bipat S, et al. Grading of Crohn's disease activity using CT, MRI, US and scintigraphy: a meta-analysis. Eur Radiol 2015; 25: 3295-313.

34. Bossuyt $X$. Serologic markers in inflammatory bowel disease. Clin Chem 2006; 52: 171-81.

35. Reese GE, Constantinides VA, Simillis C, et al. Diagnostic precision of anti-Saccharomyces cerevisiae antibodies and perinuclear antineutrophil cytoplasmic antibodies in inflammatory bowel disease. Am J Gastroenterol 2006; 101: 2410-22. 
36. Magro F, Sousa P, Ministro P. C-reactive protein in Crohn's disease: how informative is it? Expert Rev Gastroenterol Hepato 2014; 8: 393-408.

37. Vermeire S, Van Assche G, Rutgeerts P. C-reactive protein as a marker for inflammatory bowel disease. Inflamm Bowel Dis 2004; 10: 661-5.

38. Menees SB, Powell C, Kurlander J, et al. A meta-analysis of the utility of C-reactive protein, erythrocyte sedimentation rate, fecal calprotectin, and fecal lactoferrin to exclude inflammatory bowel disease in adults with IBS. Am J Gastroenterol 2015; 110: 444-54

39. Chang MH, Chou JW, Chen SM, et al. Faecal calprotectin as a novel biomarker for differentiating between inflammatory bowel disease and irritable bowel syndrome. Mol Med Rep 2014; 10: 522-6.

40. Kennedy NA, Clark A, Walkden A, et al. Clinical utility and diagnostic accuracy of faecal calprotectin for IBD at first presentation to gastroenterology services in adults aged 16-50 years. J Crohns Colitis 2015; 9: 41-9.

41. Yang Z, Clark N, Park KT. Effectiveness and cost-effectiveness of measuring fecal calprotectin in diagnosis of inflammatory bowel disease in adults and children. Clin Gastroentero Hepatol 2014; 12: 253-62.e2.

42. Henderson P, Casey A, Lawrence SJ, et al. The diagnostic accu racy of fecal calprotectin during the investigation of suspected pediatric inflammatory bowel disease. Am J Gastroenterol 2012; 107: 941-9.

43. Gasche C, Lomer MC, Cavill I, Weiss G. Iron, anaemia, and inflammatory bowel diseases. Gut 2004; 53: 1190-7.

44. Voudoukis E, Karmiris K, Oustamanolakis P, et al. Association between thrombocytosis and iron deficiency anemia in inflammatory bowel disease. Eur J Gastroenterol Hepatol 2013; 25: $1212-6$

45. Orsoni P, Barthet M, Portier F, et al. Prospective comparison of endosonography, magnetic resonance imaging and surgical findings in anorectal fistula and abscess complicating Crohn's disease. Br J Surg 1999; 86: 360-4.

46. Schwartz DA, Wiersema MJ, Dudiak KM, et al. A comparison of endoscopic ultrasound, magnetic resonance imaging, and exam under anesthesia for evaluation of Crohn's perianal fistulas. Gastroenterology 2001; 121: 1064-72.

47. Buchanan GN, Halligan S, Bartram Cl, et al. Clinical examination, endosonography, and MR imaging in preoperative assessment of fistula in ano: comparison with outcome-based reference standard. Radiology 2004; 233: 674-81.

48. Garros A, Siproudhis L, Tchoundjeu B, et al. Magnetic resonance imaging and clinical assessments for perianal Crohn's disease: gain and limits. Dig Liver Dis 2014; 46: 1072-6.

49. Schwartz DA, Pemberton JH, Sandborn WJ. Diagnosis and treatment of perianal fistulas in Crohn disease. Ann Intern Med 2001; 135: 906-18.

50. Chidi VN, Schwartz DA. Imaging of perianal fistulizing Crohn's disease. Expert Rev Gastroenterol Hepatol 2015; 9: 797-806.

51. Wise PE, Schwartz DA. The evaluation and treatment of Crohn perianal fistulae: EUA, EUS, MRI, and other imaging modalities. Gastroenterol Clin North Am 2012; 41: 379-91.

52. Schwartz DA, White CM, Wise PE, Herline AJ. Use of endoscopic ultrasound to guide combination medical and surgical therapy for patients with Crohn's perianal fistulas. Inflamm Bowel Dis 2005; 11: 727-32.

53. Spradlin NM, Wise PE, Herline AJ, et al. A randomized prospective trial of endoscopic ultrasound to guide combination medical and surgical treatment for Crohn's perianal fistulas. Am J Gastroenterol 2008; 103: 2527-35.

54. Villa C, Pompili G, Franceschelli G, et al. Role of magnetic resonance imaging in evaluation of the activity of perianal Crohn's disease. Eur J Radiol 2012; 81: 616-22.

55. Pinto-Sanchez MI, Seiler CL, Santesso N, et al. Association between inflammatory bowel diseases and celiac disease: a systematic review and meta-analysis. Gastroenterology 2020; 159: 884-903.e31.

56. Rodemann JF, Dubberke ER, Reske KA, et al. Incidence of Clostridium difficile infection in inflammatory bowel disease. Clin Gastroenterol Hepatol 2007; 5: 339-44.

57. Monaghan TM, Cockayne A, Mahida YR. Pathogenesis of Clostridium difficile infection and its potential role in inflammatory bowel disease. Inflamm Bowel Dis 2015; 21: 1957-66.

58. Pascual V, Dieli-Crimi R, López-Palacios N, et al. Inflammatory bowel disease and celiac disease: overlaps and differences. World J Gastroenterol 2014; 20: 4846-56.

59. Bar Yehuda S, Axlerod R, Toker O, et al. The association of inflammatory bowel diseases with autoimmune disorders: a report from the epi-IIRN. J Crohns Colitis 2019; 13: 324-9.

60. Leeds JS, Höroldt BS, Sidhu R, et al. Is there an association between coeliac disease and inflammatory bowel diseases? A study of relative prevalence in comparison with population controls. Scand J Gastroenterol 2007; 42: 1214-20.

61. Le Baut G, O’Brien C, Pavli P, et al. Prevalence of Yersinia species in the ileum of crohn's disease patients and controls. Front Cell Infect Microbiol 2018; 8: 336.

62. Hanada Y, Khanna S, Loftus EV Jr, et al. Non-Clostridium difficile bacterial infections are rare in patients with flares of inflammatory bowel disease. Clin Gastroenterol Hepatol 2018; 16: 528-33.

63. Limsrivilai J, Lee CK, Prueksapanich P, et al. Validation of models using basic parameters to differentiate intestinal tuberculosis from Crohn's disease: a multicenter study from Asia. PLoS One 2020; 15: e0242879.

64. Dyson JK, Rutter MD. Colorectal cancer in inflammatory bowel disease: what is the real magnitude of the risk? World J Gastroenterol 2012; 18: 3839-48.

65. Peyrin-Biroulet L, Sandborn W, Sands BE, et al. Selecting therapeutic targets in inflammatory bowel disease (STRIDE): determining therapeutic goals for treat-to-target. Am J Gastroenterol 2015; 110: 1324-38.

66. Turner D, Ricciuto A, Lewis A, et al. STRIDE-II: an update on the selecting therapeutic targets in inflammatory bowel disease (STRIDE) Initiative of the International Organization for the Study of IBD (IOIBD): Determining Therapeutic Goals for Treat-to-Target strategies in IBD. Gastroenterology 2021; 160: 1570-83.

67. Schoepfer AM, Beglinger C, Straumann A, et al. Fecal calprotectin correlates more closely with the Simple Endoscopic Score for Crohn's disease (SES-CD) than CRP, blood leukocytes, and the CDAI. Am J Gastroenterol 2010; 105: 162-9. 
68. Boschetti G, Laidet M, Moussata D, et al. Levels of fecal calprotectin are associated with the severity of postoperative endoscopic recurrence in asymptomatic patients with Crohn's disease. Am J Gastroenterol 2015; 110: 865-72.

69. Klimczak K, Lykowska-Szuber L, Eder P, et al. The diagnostic usefulness of fecal lactoferrin in the assessment of Crohn's disease activity. Eur J Intern Med 2015; 26: 623-7.

70. Wright EK, Kamm MA, De Cruz P, et al. Measurement of fecal calprotectin improves monitoring and detection of recurrence of Crohn's disease after surgery. Gastroenterology 2015; 148 938-47.e1.

71. Ferrante M, Colombel JF, Sandborn WJ, et al. Validation of endoscopic activity scores in patients with Crohn's disease based on a post hoc analysis of data from SONIC. Gastroenterology 2013; 145: 978-86.e5.

72. Nahon S, Lahmek P, Lesgourgues B, et al. Diagnostic delay in a French cohort of Crohn's disease patients. J Crohns Colitis 2014; 8: 964-9.

73. Schoepfer AM, Dehlavi MA, Fournier N, et al. Diagnostic delay in Crohn's disease is associated with a complicated disease course and increased operation rate. Am J Gastroenterol 2013; 108: 1744-54.

74. Thia KT, Sandborn WJ, Harmsen WS, et al. Risk factors associated with progression to intestinal complications of Crohn's disease in a population-based cohort. Gastroenterology 2010; 139: 1147-55.

75. Vavricka SR, Spigaglia SM, Rogler G, et al. Systematic evaluation of risk factors for diagnostic delay in inflammatory bowe disease. Inflamm Bowel Dis 2012; 18: 496-505.

76. Khanna R, Bressler B, Levesque BG, et al. Early combined im munosuppression for the management of Crohn's disease (REACT): a cluster randomised controlled trial. Lancet 2015 386: 1825-34.

77. Colombel JF, Panaccione R, Bossuyt P, et al. Effect of tight control management on Crohn's disease (CALM): a multicentre, randomised, controlled phase 3 trial [published correction appears in Lancet. 2018 Dec 23;390(10114):2768]. Lancet 2017; 390: 2779-89.

78. Maaser C, Sturm A, Vavricka SR, et al. ECCO-ESGAR Guideline for Diagnostic Assessment in IBD Part 1: Initial diagnosis, monitoring of known IBD, detection of complications. J Crohns Colitis 2019; 13: 144-64.

79. Sandborn WJ, Hanauer S, Van Assche G, et al. Treating beyond symptoms with a view to improving patient outcomes in inflammatory bowel diseases. J Crohns Colitis 2014; 8: 927-35.

80. Zallot C, Peyrin-Biroulet L. Deep remission in inflammatory bowel disease: looking beyond symptoms. Curr Gastroenterol Rep 2013; 15: 315.

81. Baert F, Moortgat L, Van Assche G, et al. Mucosal healing predicts sustained clinical remission in patients with early-stage Crohn's disease. Gastroenterology 2010; 138: 463-e11.

82. Frøslie KF, Jahnsen J, Moum BA, Vatn MH; IBSEN Group. Mucosal healing in inflammatory bowel disease: results from a Norwegian population-based cohort. Gastroenterology 2007; 133: 412-22.

83. Nuti F, Civitelli F, Bloise S, et al. Prospective evaluation of the achievement of mucosal healing with anti-TNF- $\alpha$ therapy in a paediatric Crohn's disease cohort. J Crohns Colitis 2016; 10: 5-12.

84. Benchimol El, Seow CH, Steinhart AH, Griffiths AM. Traditional corticosteroids for induction of remission in Crohn's disease. Cochrane Database Syst Rev 2008; 2008: CD006792.

85. Summers RW, Switz DM, Sessions JT Jr, et al. National Cooperative Crohn's Disease Study: results of drug treatment. Gastroenterology 1979; 77: 847-69.

86. Malchow H, Ewe K, Brandes JW, et al. European Cooperative Crohn's Disease Study (ECCDS): results of drug treatment. Gastroenterology 1984; 86: 249-66.

87. Chande N, Townsend CM, Parker CE, et al. Azathioprine or 6-mercaptopurine for induction of remission in Crohn's disease. Cochrane Database Syst Rev 2016; 10: CD000545.

88. Feagan BG, Rochon J, Fedorak RN, et al. Methotrexate for the treatment of Crohn's disease. The North American Crohn's Study Group Investigators. N Engl J Med 1995; 332: 292-7.

89. McDonald JWD, Wang Y, Tsoulis DJ, et al. Methotrexate for induction of remission in refractory Crohn's disease. Cochrane Database Syst Rev 2014; 8: CD003459.

90. Stidham R, Lee T, Higgins P, et al. Systematic review with network meta-analysis: the efficacy of anti-TNF agents for the treatment of Crohn's disease. Aliment Pharmacol Ther 2014; 39: 1349-62.

91. Cholapranee A, Hazlewood G, Kaplan G, et al. Systematic review with meta-analysis: comparative efficacy of biologics for induction and maintenance of mucosal healing in Crohn's disease and ulcerative colitis controlled trials. Aliment Pharmacol Ther 2017; 45: 1291-302.

92. Ford A, Sandborn W, Khan K, et al. Efficacy of biological therapies in inflammatory bowel disease: systematic review and meta-analysis. Am J Gastroenterol 2011; 106: 644-59.

93. Matsumoto T, Motoya S, Watanabe K et al. Adalimumab monotherapy and a combination with azathioprine for Crohn's disease: a prospective, randomized trial. J Crohn's Colitis 2016; 10: 1259-66.

94. Colombel JF, Sandborn WJ, Reinisch W, et al. Infliximab, azathioprine, or combination therapy for Crohn's disease. N Engl J Med 2010; 362: 1383-95.

95. MacDonald JK, Nguyen TM, Khanna R, et al. Anti-IL-12/23p40 antibodies for induction of remission in Crohn's disease. Cochrane Database Syst Rev 2016; 11: CD007572.

96. Rutgeerts P, Gasink C, Chan D, et al. Efficacy of ustekinumab for inducing endoscopic healing in patients with Crohn's disease. Gastroenterology 2018; 155: 1045-58.

97. Chandar AK, Singh S, Murad MH, et al. Efficacy and safety of natalizumab and vedolizumab for the management of Crohn's disease: a systematic review and meta-analysis. Inflam Bowel Dis 2015; 21: 1695-708.

98. Targan SR, Hanauer SB, van Deventer SJ, et al. A short-term study of chimeric monoclonal antibody CA2 to tumor necrosis factor alpha for Crohn's disease. Crohn's Disease cA2 Study Group. N Engl J Med 1997; 337: 1029-35.

99. Schnitzler F, Fidder H, Ferrante $M$, et al. Long-term outcome of treatment with infliximab in 614 patients with Crohn's disease: results from a single-centre cohort. Gut 2009; 58 : 492-500. 
100. Hanauer SB, Sandborn WJ, Rutgeerts P, et al. Human anti-tumor necrosis factor monoclonal antibody (adalimumab) in Crohn's disease: the CLASSIC-I trial. Gastroenterology 2006; 130: 323-33.

101. Sandborn WJ, Rutgeerts P, Enns R, et al. Adalimumab induction therapy for Crohn disease previously treated with infliximab: a randomized trial. Ann Intern Med 2007; 146: 829-38.

102. Sandborn WJ, Feagan BG, Rutgeerts P, et al. Vedolizumab as induction and maintenance therapy for Crohn's disease. N Engl J Med 2013; 369: 711-21.

103. Sands BE, Sandborn WJ, Van Assche G, et al. Vedolizumab as induction and maintenance therapy for Crohn's disease in patients naïve to or who have failed tumor necrosis factor antagonist therapy. Inflamm Bowel Dis 2017; 23: 97-106.

104. Vermeire S, Loftus EV Jr, Colombel JF, et al. Long-term efficacy of vedolizumab for Crohn's disease. J Crohns Colitis 2017; 11: 412-24.

105. Feagan BG, Sandborn WJ, Gasink C, et al. Ustekinumab as induction and maintenance therapy for Crohn's disease. N Engl J Med 2016; 375: 1946-60.

106. Wils P, Bouhnik Y, Michetti P, et al. Subcutaneous ustekinumab provides clinical benefit for two-thirds of patients with Crohn's disease refractory to anti-tumor necrosis factor agents. Clin Gastroenterol Hepatol 2016; 14: 242-50.e502.

107. Mao EJ, Hazlewood GS, Kaplan GG, et al. Systematic review with meta-analysis: comparative efficacy of immunosuppressants and biologics for reducing hospitalisation and surgery in Crohn's disease and ulcerative colitis. Aliment Pharmacol Ther 2017; 45: 3-13.

108. European Medicines Agency. Biosimilars in the EU: Information guide for healthcare professionals. 2017. https://www. ema.europa.eu/documents/leaflet/ biosimilars-eu-information-guide-healthcare-professionals_en.pdf [Accessed $14 \mathrm{Dec}$ 2018].

109. Association of the British Pharmaceutical Industry. ABPI position on biologic medicines, including biosimilar medicines. 2015. https://www.abpi.org.uk/media/4568/abpi-position-on-biosimilar-medicines.pdf [Accessed 14 Dec 2018].

110. Moots R, Azevedo V, Coindreau JL, et al. Switching between reference biologics and biosimilars for the treatment of rheumatology, gastroenterology, and dermatology inflammatory conditions: considerations for the clinician. Curr Rheumato Rep 2017; 19: 37.

111. Danese S, Fiorino G, Raine T, et al. ECCO position statement on the use of biosimilars for inflammatory bowel disease-an update. J Crohns Colitis 2017; 11: 26-34.

112. Jørgensen KK, Olsen IC, Goll GL, et al. Switching from originator infliximab to biosimilar CT-P13 compared with maintained treatment with originator infliximab (NORSWITCH): a 52-week, randomised, double-blind, non-inferiority trial [published correction appears in Lancet. 2017 Jun 10;389(10086):2286]. Lancet 2017; 389: 2304-16.

113. Buer LC, Moum BA, Cvancarova M, et al. Switching from Remicade ${ }^{\circledR}$ to $\operatorname{Remsima}^{\circledR}$ is well tolerated and feasible: a prospective, open-label study. J Crohns Colitis 2017; 11: 297-304.

114. Smits LJ, Derikx LA, de Jong DJ, et al. Clinical outcomes following a switch from Remicade ${ }^{\circledR}$ to the Biosimilar CTP13 in inflammatory bowel disease patients: a prospec- tive observational cohort study. J Crohns Colitis 2016; 10: 1287-93.

115. Dapavo P, Vujic I, Fierro MT, et al. The infliximab biosimilar in the treatment of moderate to severe plaque psoriasis. J Am Acad Dermatol 2016; 75: 736-9.

116. Park W, Yoo DH, Miranda P, et al. Efficacy and safety of switching from reference infliximab to CT-P13 compared with maintenance of CT-P13 in ankylosing spondylitis: 102-week data from the PLANETAS extension study. Ann Rheum Dis 2017; 76: 346-54.

117. Yoo DH, Prodanovic N, Jaworski J, et al. Efficacy and safety of CT-P13 (biosimilar infliximab) in patients with rheumatoid arthritis: comparison between switching from reference infliximab to CT-P13 and continuing CT-P13 in the PLANETRA extension study. Ann Rheum Dis 2017; 76: 355-63.

118. Yanai H, Lichtenstein L, Assa A, et al. Levels of drug and antidrug antibodies are associated with outcome of interventions after loss of response to infliximab or adalimumab. Clin Gastroenterol Hepatol 2015; 13: 522-30.e2.

119. Velayos FS, Kahn JG, Sandborn WJ, Feagan BG. A test-based strategy is more cost effective than empiric dose escalation for patients with Crohn's disease who lose responsiveness to infliximab. Clin Gastroenterol Hepatol 2013; 11: 654-66.

120. Paul S, Del Tedesco E, Marotte H, et al. Therapeutic drug monitoring of infliximab and mucosal healing in inflammatory bowel disease: a prospective study. Inflamm Bowel Dis 2013; 19: 2568-76.

121. Kopylov U, Mantzaris GJ, Katsanos KH, et al. The efficacy of shortening the dosing interval to once every six weeks in Crohn's patients losing response to maintenance dose of infliximab. Aliment Pharmacol Ther 2011; 33: 349-57.

122. Katz L, Gisbert JP, Manoogian B, et al. Doubling the infliximab dose versus halving the infusion intervals in Crohn's disease patients with loss of response. Inflamm Bowel Dis 2012; 18: 2026-33.

123. Vande Casteele N, Gils A, Singh S, et al. Antibody response to infliximab and its impact on pharmacokinetics can be transient. Am J Gastroenterol 2013; 108: 962-71.

124. Van Stappen T, Vande Casteele N, Van Assche G, et al. Clinical relevance of detecting anti-infliximab antibodies with a drug-tolerant assay: post hoc analysis of the TAXIT trial. Gut 2018; 67: 818-26.

125. Ben-Horin S, Waterman M, Kopylov U, et al. Addition of an immunomodulator to infliximab therapy eliminates antidrug antibodies in serum and restores clinical response of patients with inflammatory bowel disease. Clin Gastroenterol Hepatol 2013; 11: 444-7.

126. Bartelds GM, Wijbrandts CA, Nurmohamed MT, et al. Anti-infliximab and anti-adalimumab antibodies in relation to response to adalimumab in infliximab switchers and anti-tumour necrosis factor naive patients: a cohort study. Ann Rheum Dis 2010; 69: 817-21.

127. Kawalec P, Moćko P. An indirect comparison of ustekinumab and vedolizumab in the therapy of TNF-failure Crohn's disease patients. J Comp Eff Res 2018; 7: 101-11.

128. Steinhart AH, Ewe K, Griffiths AM, et al. Corticosteroids for maintenance of remission in Crohn's disease. Cochrane Database Syst Rev 2003; 4: CD000301. 
129. Ford AC, Bernstein CN, Khan KJ, et al. Glucocorticosteroid therapy in inflammatory bowel disease: systematic review and meta-analysis. Am J Gastroenterol 2011; 106: 590-600.

130. Greenberg GR, Feagan BG, Martin F, et al. Oral budesonide as maintenance treatment for Crohn's disease: a placebo-controlled, dose-ranging study. Canadian Inflammatory Bowe Disease Study Group. Gastroenterology 1996; 110: 45-51.

131. Ferguson A, Campieri M, Doe W, et al. Oral budesonide as maintenance therapy in Crohn's disease--results of a 12-month study. Global Budesonide Study Group. Aliment Pharmacol Ther 1998; 12: 175-83.

132. Gross V, Andus T, Ecker KW, et al. Low dose oral pH modified release budesonide for maintenance of steroid induced remission in Crohn's disease. The Budesonide Study Group Gut 1998; 42: 493-6.

133. Cortot A, Colombel JF, Rutgeerts P, et al. Switch from systemic steroids to budesonide in steroid dependent patients with inactive Crohn's disease. Gut 2001; 48: 186-90.

134. Lewis JD, Scott FI, Brensinger CM, et al. Increased mortality rates with prolonged corticosteroid therapy when compared with antitumor necrosis factor- $\alpha$-directed therapy for inflammatory bowel disease. Am J Gastroenterol 2018; 113: 405-17.

135. Chhaya V, Saxena S, Cecil E, et al. Steroid dependency and trends in prescribing for inflammatory bowel disease - a 20year national population-based study. Aliment Pharmacol Ther 2016; 44: 482-94.

136. Schoepfer AM, Bortolotti M, Pittet V, et al. The gap between scientific evidence and clinical practice: 5-aminosalicylates are frequently used for the treatment of Crohn's disease. Aliment Pharmacol Ther 2014; 40: 930-7.

137. Ford AC, Kane SV, Khan KJ, et al. Efficacy of 5-aminosalicylates in Crohn's disease: systematic review and meta-analysis. Am J Gastroenterol 2011; 106: 617-29.

138. Rasmussen SN, Lauritsen K, Tage-Jensen U, et al. 5-Aminosalicylic acid in the treatment of Crohn's disease. A 16-week double-blind, placebo-controlled, multicentre study with Pentasa. Scand J Gastroenterol 1987; 22: 877-83.

139. Singleton JW, Hanauer SB, Gitnick GL, et al. Mesalamine capsules for the treatment of active Crohn's disease: results of a 16-week trial. Pentasa Crohn's Disease Study Group. Gastroenterology 1993; 104: 1293-301.

140. Tremaine WJ, Schroeder KW, Harrison JM, Zinsmeister AR. A randomized, double-blind, placebo-controlled trial of the oral mesalamine (5-ASA) preparation, Asacol, in the treatment of symptomatic Crohn's colitis and ileocolitis. J Clin Gastroenterol 1994; 19: 278-82.

141. Ferring Pharmaceuticals. PEACE study: a study with Pentasa in patients with active Crohn's disease. 2012. https://clinicaltrials.gov/ct2/show/NCT00862121 Accessed Sep 16, 2019.

142. Moja L, Danese S, Fiorino G, et al. Systematic review with network meta-analysis: comparative efficacy and safety of budesonide and mesalazine (mesalamine) for Crohn's dis ease. Aliment Pharmacol Ther 2015; 41: 1055-65.

143. Rezaie A, Kuenzig ME, Benchimol El, et al. Budesonide for induction of remission in Crohn's disease. Cochrane Database Syst Rev 2015; 6: CD000296.

144. Akobeng AK, Zhang D, Gordon M, MacDonald JK. Oral 5-aminosalicylic acid for maintenance of medically-induced remis- sion in Crohn's disease. Cochrane Database Syst Rev 2016; 9: CD003715.

145. Lim WC, Hanauer S. Aminosalicylates for induction of remission or response in Crohn's disease. Cochrane Database Syst Rev 2010; 12: CD008870.

146. Lim WC, Wang Y, MacDonald JK, Hanauer S. Aminosalicylates for induction of remission or response in Crohn's disease. Cochrane Database Syst Rev 2016; 7: CD008870.

147. Subramanian S, Ekbom A, Rhodes JM. Recent advances in clinical practice: a systematic review of isolated colonic Crohn's disease: the third IBD? Gut 2017; 66: 362-81.

148. Hanauer SB, Strömberg U. Oral pentasa in the treatment of active Crohn's disease: a meta-analysis of double-blind, placebo-controlled trials. Clin Gastroenterol Hepatol 2004; 2 : 379-88.

149. Coward S, Kuenzig ME, Hazlewood G, et al. Comparative effectiveness of mesalamine, sulfasalazine, corticosteroids, and budesonide for the induction of remission in Crohn's disease: a bayesian network meta-analysis: republished. Inflamm Bowel Dis 2017; 23: E26-37.

150. Present DH, Korelitz BI, Wisch N, et al. Treatment of Crohn's disease with 6-mercaptopurine. A long-term, randomized, double-blind study. N Engl J Med 1980; 302: 981-7.

151. Candy S, Wright J, Gerber M, et al. A controlled double blind study of azathioprine in the management of Crohn's disease. Gut 1995; 37: 674-8.

152. Willoughby JM, Beckett J, Kumar PJ, Dawson AM. Controlled trial of azathioprine in Crohn's disease. Lancet 1971; 2: 944-7.

153. Chande N, Patton PH, Tsoulis DJ, et al. Azathioprine or 6-mercaptopurine for maintenance of remission in Crohn's disease. Cochrane Database Syst Rev 2015; 10: CD000067.

154. Lémann M, Mary JY, Colombel JF, et al. A randomized, double-blind, controlled withdrawal trial in Crohn's disease patients in long-term remission on azathioprine. Gastroenterology 2005; 128: 1812-8.

155. O'Donoghue DP, Dawson AM, Powell-Tuck J, et al. Double-blind withdrawal trial of azathioprine as maintenance treatment for Crohn's disease. Lancet 1978; 2: 955-7.

156. Panés J, López-Sanromán A, Bermejo F, et al. Early azathioprine therapy is no more effective than placebo for newly diagnosed Crohn's disease. Gastroenterology 2013; 145: 766-74.e1.

157. Rosenberg JL, Levin B, Wall AJ, Kirsner JB. A controlled trial of azathioprine in Crohn's disease. Am J Dig Dis 1975; 20 : 721-6.

158. Hazlewood GS, Rezaie A, Borman M, et al. Comparative effectiveness of immunosuppressants and biologics for inducing and maintaining remission in Crohn's disease: a network meta-analysis. Gastroenterology 2015; 148: 344-e15.

159. Patel V, Wang Y, MacDonald JK, et al. Methotrexate for maintenance of remission in Crohn's disease. Cochrane Database Syst Rev 2014; 2014: CD006884.

160. Herfarth $\mathrm{HH}$, Kappelman MD, Long MD, Isaacs KL. Use of methotrexate in the treatment of inflammatory bowel diseases. Inflamm Bowel Dis 2016; 22: 224-33.

161. González-Lama Y, Taxonera C, López-Sanromán A, et al. Methotrexate in inflammatory bowel disease: a multicenter ret- 
rospective study focused on long-term efficacy and safety. The Madrid experience. Eur J Gastroenterol Hepatol 2012; 24: 1086-91.

162. Singh S, Fumery M, Sandborn WJ, Murad MH. Systematic review and network meta-analysis: first- and second-line biologic therapies for moderate-severe Crohn's disease. Aliment Pharmacol Ther 2018; 48: 394-409.

163. Ardizzone S, Cassinotti A, Duca P, et al. Mucosal healing predicts late outcomes after the first course of corticosteroids for newly diagnosed ulcerative colitis. Clin Gastroenterol Hepatol 2011; 9: 483-9.e3.

164. Sipponen T, Kolho KL. Fecal calprotectin in diagnosis and clinical assessment of inflammatory bowel disease. Scand J Gastroenterol 2015; 50: 74-80.

165. Sipponen T, Kärkkäinen P, Savilahti E, et al. Correlation of faecal calprotectin and lactoferrin with an endoscopic score for Crohn's disease and histological findings. Aliment Pharmaco Ther 2008; 28: 1221-9.

166. Osterman MT, Aberra FN, Cross R, et al. Mesalamine dose escalation reduces fecal calprotectin in patients with quiescent ulcerative colitis. Clin Gastroenterol Hepatol 2014; 12 1887-93.e3.

167. Walker GJ, Moore L, Heerasing N, et al. Faecal calprotectin effectively excludes inflammatory bowel disease in 789 symptomatic young adults with/without alarm symptoms: a prospective UK primary care cohort study [published correction appears in Aliment Pharmacol Ther. 2020 Jan;51(1):196] Aliment Pharmacol Ther 2018; 47: 1103-16.

168. Ding NS, Hart A, De Cruz P. Systematic review: predicting and optimising response to anti-TNF therapy in Crohn's disease algorithm for practical management. Aliment Pharmacol Ther 2016; 43: 30-51.

169. Papamichael K, Cheifetz AS. Therapeutic drug monitoring in IBD: the new standard-of-care for anti-TNF therapy. Am J Gastroenterol 2017; 112: 673-6.

170. Yarur AJ, Rubin DT. Therapeutic drug monitoring of anti-tumor necrosis factor agents in patients with inflammatory bowe diseases. Inflamm Bowel Dis 2015; 21: 1709-18.

171. Vaughn BP, Sandborn WJ, Cheifetz AS. Biologic concentration testing in inflammatory bowel disease. Inflamm Bowel Dis 2015; 21: 1435-42.

172. Steenholdt C, Brynskov J, Thomsen $O \emptyset$, et al. Individualised therapy is more cost-effective than dose intensification in patients with Crohn's disease who lose response to anti-TNF treatment: a randomised, controlled trial. Gut 2014; 63: 919-27.

173. Vande Casteele N, Ferrante M, Van Assche G, et al. Trough concentrations of infliximab guide dosing for patients with inflammatory bowel disease. Gastroenterology 2015; 148 1320-9.e3.

174. D'Haens G, Vermeire S, Lambrecht G, et al. Increasing infliximab dose based on symptoms, biomarkers, and serum drug concentrations does not increase clinical, endoscopic, and corticosteroid-free remission in patients with active luminal Crohn's disease. Gastroenterology 2018; 154: 1343-51.e1.

175. Torres J, Boyapati RK, Kennedy NA, et al. Systematic review of effects of withdrawal of immunomodulators or biologic agents from patients with inflammatory bowel disease. Gastroenterology 2015; 149: 1716-30.
176. Gisbert JP, Marín AC, Chaparro M. The risk of relapse after anti-TNF discontinuation in inflammatory bowel disease: systematic review and meta-analysis. Am J Gastroenterol 2016; 111: 632-47.

177. Kennedy NA, Warner B, Johnston EL, et al. Relapse after withdrawal from anti-TNF therapy for inflammatory bowel disease: an observational study, plus systematic review and meta-analysis. Aliment Pharmacol Ther 2016; 43: 910-23.

178. Casanova MJ, Chaparro M, García-Sánchez V, et al. Evolution after anti-TNF discontinuation in patients with inflammatory bowel disease: a multicenter long-term follow-up study. Am J Gastroenterol 2017; 112: 120-31.

179. Helwig U, Lutter F, Koppka N, Schreiber S. Proposal for an anti-TNF-exit strategy based on trough serum level. Biologicals 2017; 47: 81-5.

180. Papamichael K, Rivals-Lerebours O, Billiet T, et al. Long-term outcome of patients with ulcerative colitis and primary non-response to infliximab. J Crohns Colitis 2016; 10: 1015-23.

181. Hlavaty T, Krajcovicova A, Letkovsky J, et al. Relapse rates of inflammatory bowel disease patients in deep and clinical remission after discontinuing anti-tumor necrosis factor alpha therapy. Bratisl Lek Listy 2016; 117: 205-11.

182. Bortlik M, Duricova D, Machkova N, et al. Discontinuation of anti-tumor necrosis factor therapy in inflammatory bowel disease patients: a prospective observation. Scand J Gastroenterol 2016; 51: 196-202.

183. Molander P, Färkkilä $M$, Kemppainen $\mathrm{H}$, et al. Long-term outcome of inflammatory bowel disease patients with deep remission after discontinuation of TNF $\alpha$-blocking agents. Scand J Gastroenterol 2017; 52: 284-90.

184. Reenaers C, Mary JY, Nachury M, et al. Outcomes 7 years after infliximab withdrawal for patients with Crohn's disease in sustained remission. Clin Gastroenterol Hepatol 2018; 16: 234-43.e2.

185. Hu H, Xiang C, Qiu C, et al. Discontinuation of scheduled infliximab in crohn's patients with clinical remission: a retrospective single-center study. Gastroenterology Res 2017; 10: 92-9.

186. Ampuero J, Rojas-Feria M, Castro-Fernández M, et al. Remission maintained by monotherapy after biological + immunosuppressive combination for Crohn's disease in clinical practice. J Gastroenterol Hepatol 2016; 31: 112-8.

187. Doherty G, Katsanos KH, Burisch J, et al. European Crohn's and Colitis Organisation topical review on treatment withdrawal ['Exit Strategies'] in inflammatory bowel disease. J Crohns Colitis 2018; 12: 17-31.

188. Edsbäcker S, Jönsson S, Lindberg C, et al. Metabolic pathways of the topical glucocorticoid budesonide in man. Drug Metab Dispos 1983; 11: 590-6.

189. Tromm A, Bunganič I, Tomsová E, et al. Budesonide $9 \mathrm{mg}$ is at least as effective as mesalamine $4.5 \mathrm{~g}$ in patients with mildly to moderately active Crohn's disease. Gastroenterology 2011; 140: 425-e14.

190. Yokoyama T, Ohta A, Motoya S, et al. Efficacy and safety of oral budesonide in patients with active Crohn's disease in Japan: a multicenter, double-blind, randomized, parallel-group phase 3 study. Inflamm Intest Dis 2018; 2: 154-62.

191. Bar-Meir S, Chowers Y, Lavy A, et al. Budesonide versus prednisone in the treatment of active Crohn's disease. The Is- 
raeli Budesonide Study Group. Gastroenterology 1998; 115 835-40.

192. Dignass A, Stoynov S, Dorofeyev AE, et al. Once versus three times daily dosing of oral budesonide for active Crohn's disease: a double-blind, double-dummy, randomised trial. J Crohns Colitis 2014; 8: 970-80.

193. Lundin P, Naber T, Nilsson M, Edsbäcker S. Effect of food on the pharmacokinetics of budesonide controlled ileal release capsules in patients with active Crohn's disease. Aliment Pharmacol Ther 2001; 15: 45-51.

194. Radwan P. Leczenie farmakologiczne choroby Leśniowskiego-Crohna. In: Choroba Leśniowskiego-Crohna - 100 lat diagnostyki i terapii. Rydzewska G, Małecka-Panas E (eds.). Termedia, Poznan 2008; 113-30.

195. Feagan BG. 5-ASA therapy for active Crohn's disease: old friends, old data, and a new conclusion. Clin Gastroentero Hepatol 2004; 2: 376-8.

196. Thomsen OO, Cortot A, Jewell D, et al. A comparison of budesonide and mesalamine for active Crohn's disease. International Budesonide-Mesalamine Study Group [published correction appears in N Engl J Med 2001 Nov 29;345(22):1652]. N Engl J Med 1998; 339: 370-4.

197. Selby W, Pavli P, Crotty B, et al. Two-year combination antibiotic therapy with clarithromycin, rifabutin, and clofazimine for Crohn's disease. Gastroenterology 2007; 132: 2313-9.

198. Khan KJ, Ullman TA, Ford AC, et al. Antibiotic therapy in inflammatory bowel disease: a systematic review and meta-analysis [published correction appears in Am J Gastroenterol. 2011 May;106(5):1014. Abadir, A [corrected to Abadir Amir]]. Am J Gastroenterol 2011; 106: 661-73.

199. Pimentel AM, Rocha R, Santana GO. Crohn's disease of esophagus, stomach and duodenum. World I Gastrointest Pharmacol Ther 2019; 10: 35-49.

200. Van Assche G, Dignass A, Reinisch W, et al. The second European evidence-based Consensus on the diagnosis and management of Crohn's disease: special situations. J Crohns Colitis 2010; 4: 63-101.

201. Turner D, Griffiths AM. Esophageal, gastric, and duodenal manifestations of IBD and the role of upper endoscopy in IBD diagnosis. Curr Gastroenterol Rep 2007; 9: 475-8.

202. Greuter T, Piller A, Fournier N, et al. Upper gastrointestinal tract involvement in Crohn's disease: frequency, risk factors, and disease course. J Crohns Colitis 2018; 12: 1399-409.

203. Moon JS, Lee JL, Yu CS, et al. Clinical characteristics and postoperative outcomes of patients presenting with upper gastrointestinal tract Crohn disease. Ann Coloproctol 2020; 36: 243-8.

204. De Felice KM, Katzka DA, Raffals LE. Crohn's disease of the esophagus: clinical features and treatment outcomes in the biologic era. Inflamm Bowel Dis 2015; 21: 2106-13.

205. Decker GA, Loftus EV Jr, Pasha TM, et al. Crohn's disease of the esophagus: clinical features and outcomes. Inflamm Bowel Dis 2001; 7: 113-9.

206. Wu XW, Ji HZ, Yang MF, et al. Helicobacter pylori infection and inflammatory bowel disease in Asians: a meta-analysis. World J Gastroenterol 2015; 21: 4750-6.

207. Nomura Y, Moriichi K, Fujiya M, Okumura T. The endoscopic findings of the upper gastrointestinal tract in patients with Crohn's disease. Clin J Gastroenterol 2017; 10: 289-96.
208. Mottet C, Vader JP, Felley C, et al. Appropriate management of special situations in Crohn's disease (upper gastro-intestinal; extra-intestinal manifestations; drug safety during pregnancy and breastfeeding): results of a multidisciplinary international expert panel-EPACT II. J Crohns Colitis 2009; 3: 257-63.

209. Sandborn WJ, Fazio VW, Feagan BG, Hanauer SB; American Gastroenterological Association Clinical Practice Committee. AGA technical review on perianal Crohn's disease. Gastroenterology 2003; 125: 1508-30.

210. Schwartz DA, Loftus EV Jr, Tremaine WJ, et al. The natural history of fistulizing Crohn's disease in Olmsted County, Minnesota. Gastroenterology 2002; 122: 875-80.

211. Adamina M, Bonovas S, Raine T, et al. ECCO guidelines on therapeutics in Crohn's disease: surgical treatment. J Crohns Colitis 2020; 14: 155-68

212. Gionchetti P, Dignass A, Danese S, et al. 3rd European Evidence-based Consensus on the Diagnosis and Management of Crohn's Disease 2016: Part 2: Surgical Management and Special Situations. J Crohns Colitis 2017; 11: 135-49.

213. Arentd J, Trompeta J, Podwiński A, Rdes J. Przetoka okołoodobytnicza - problemy rozpoznawcze, leczenie. Chirur Pol 2002; 4: $73-80$

214. Bell SJ, Williams AB, Wiesel P, et al. The clinical course of fistulating Crohn's disease. Aliment Pharmacol Ther 2003; 17: 1145-51.

215. Kotze PG, Shen B, Lightner A, et al. Modern management of perianal fistulas in Crohn's disease: future directions. Gut 2018; 67: 1181-94.

216. Vogel JD, Johnson EK, Morris AM, et al. Clinical practice guideline for the management of anorectal abscess, fistula-in-ano, and rectovaginal fistula. Dis Colon Rectum 2016; 59: 1117-33.

217. Steele SR, Kumar R, Feingold DL, et al.; Standards Practice Task Force of the American Society of Colon and Rectal Surgeons. Practice parameters for the management of perianal abscess and fistula-in-ano. Dis Colon Rectum 2011; 54: 1465-74.

218. Solomon MJ, McLeod RS, O'Connor BI, et al. Combination ciprofloxacin and metronidazole in severe perianal Crohn's disease. Can J Gastroenterol 1993; 7: 571-3.

219. Thia KT, Mahadevan U, Feagan BG, et al. Ciprofloxacin or metronidazole for the treatment of perianal fistulas in patients with Crohn's disease: a randomized, double-blind, placebo-controlled pilot study. Inflamm Bowel Dis 2009; 15: 17-24.

220. Marzo M, Felice C, Pugliese D, et al. Management of perianal fistulas in Crohn's disease: an up-to-date review. World J Gastroenterol 2015; 21: 1394-403.

221. Ghosh S, lacucci M. Role of immunosuppressives in special situations: perianal disease and postoperative period. Dig Dis 2014; 32 Suppl 1: 92-5.

222. Chhaya V, Saxena S, Cecil E, et al. Impact of timing and duration of thiopurine treatment on first perianal surgery in Crohn's disease: UK population-based study (1995-2009). Inflamm Bowel Dis 2015; 21: 385-91.

223. Bouguen G, Siproudhis L, Gizard E, et al. Long-term outcome of perianal fistulizing Crohn's disease treated with infliximab. Clin Gastroenterol Hepatol 2013; 11: 975-81.e814.

224. Present DH, Rutgeerts $P$, Targan S, et al. Infliximab for the treatment of fistulas in patients with Crohn's disease. N Engl I Med 1999; 340: 1398-405. 
225. Sands BE, Anderson FH, Bernstein CN, et al. Infliximab maintenance therapy for fistulizing Crohn's disease. N Engl J Med 2004; 350: 876-85.

226. Sands BE, Blank MA, Diamond RH, et al. Maintenance inflix imab does not result in increased abscess development in fistulizing Crohn's disease: results from the ACCENT II study. Aliment Pharmacol Ther 2006; 23: 1127-36.

227. Lichtenstein GR, Yan S, Bala M, et al. Infliximab maintenance treatment reduces hospitalizations, surgeries, and procedures in fistulizing Crohn's disease. Gastroenterology 2005; 128: 862-9.

228. Colombel JF, Sandborn WJ, Rutgeerts P, et al. Adalimumab for maintenance of clinical response and remission in patients with Crohn's disease: the CHARM trial. Gastroenterology 2007; 132: 52-65.

229. Colombel JF, Schwartz DA, Sandborn WJ, et al. Adalimumab for the treatment of fistulas in patients with Crohn's disease. Gut 2009; 58: 940-8.

230. West RL, van der Woude CJ, Hansen BE, et al. Clinical and endosonographic effect of ciprofloxacin on the treatment of perianal fistulae in Crohn's disease with infliximab: a double-blind placebo-controlled study. Aliment Pharmacol Ther 2004; 20: 1329-36

231. Dewint $P$, Hansen BE, Verhey E, et al. Adalimumab combined with ciprofloxacin is superior to adalimumab monotherapy in perianal fistula closure in Crohn's disease: a randomised, double-blind, placebo controlled trial (ADAFI). Gut 2014; 63: 292-9.

232. Lichtiger S, Binion DG, Wolf DC, et al. The CHOICE trial: adalimumab demonstrates safety, fistula healing, improved quality of life and increased work productivity in patients with Crohn's disease who failed prior infliximab therapy. Aliment Pharmacol Ther 2010; 32: 1228-39.

233. Echarri A, Castro J, Barreiro M, et al. Evaluation of adalimumab therapy in multidisciplinary strategy for perianal Crohn's disease patients with infliximab failure. J Crohns Colitis 2010, 4: 654-60.

234. Strik AS, Löwenberg M, Buskens CJ, et al. Higher anti-TNF serum levels are associated with perianal fistula closure in Crohn's disease patients. Scand J Gastroenterol 2019; 54 453-8.

235. Davidov Y, Ungar B, Bar-Yoseph H, et al. Association of induction infliximab levels with clinical response in perianal Crohn's disease. J Crohns Colitis 2017; 11: 549-55.

236. Yarur AJ, Kanagala V, Stein DJ, et al. Higher infliximab trough levels are associated with perianal fistula healing in patients with Crohn's disease. Aliment Pharmacol Ther 2017; 45: 933-40.

237. Lightner AL, Wang Z, Zubair AC, Dozois EJ. A systematic review and meta-analysis of mesenchymal stem cell injections for the treatment of perianal Crohn's disease: progress made and future directions. Dis Colon Rectum 2018; 61: 629-40.

238. Panés J, García-Olmo D, Van Assche G, et al. Long-term efficacy and safety of stem cell therapy (Cx601) for complex perianal fistulas in patients with Crohn's disease. Gastroenterology 2018; 154: 1334-42.e4.

239. Panés J, García-Olmo D, Van Assche G, et al. Expanded allogeneic adipose-derived mesenchymal stem cells (Cx601) for complex perianal fistulas in Crohn's disease: a phase 3 randomised, double-blind controlled trial. Lancet 2016; 388: 1281-90.

240. Lee WY, Park KJ, Cho YB, et al. Autologous adipose tissue-derived stem cells treatment demonstrated favorable and sustainable therapeutic effect for Crohn's fistula. Stem Cells 2013; 31: 2575-81.

241. Reguła J, Wallner G, Nowak S, et al. Stan obecny w rozpoznawaniu i leczeniu złożonych przetok odbytniczych (CPF) w chorobie Leśniowskiego-Crohna (chLC) w Polsce - na podstawie badania pt. „Schematy postępowania terapeutycznego u pacjentów ze złożonymi przetokami w przebiegu choroby Leśniowskiego-Crohna". Gastroenterol Klin 2018; 10: 135-47.

242. Singh S, Ding NS, Mathis KL, et al. Systematic review with meta-analysis: faecal diversion for management of perianal Crohn's disease. Aliment Pharmacol Ther 2015; 42: 783-92.

243. An V, Cohen L, Lawrence M, et al. Early surgery in Crohn's disease a benefit in selected cases. World J Gastrointest Surg 2016; 8: 492-500.

244. Lee JM, Lee KM, Kim JS, et al. Postoperative course of Crohn disease according to timing of bowel resection: results from the CONNECT Study. Medicine 2018; 97: e0459.

245. Aratari A, Papi C, Leandro G, et al. Early versus late surgery for ileo-caecal Crohn's disease. Aliment Pharmacol Ther 2007; 26: 1303-12.

246. Ponsioen CY, de Groof EJ, Eshuis EJ, et al. Laparoscopic ileocaecal resection versus infliximab for terminal ileitis in Crohn's disease: a randomised controlled, open-label, multicentre trial [published correction appears in Lancet Gastroenterol Hepatol. 2017 Nov;2(11):e7]. Lancet Gastroenterol Hepatol 2017; 2: 785-92.

247. de Groof EJ, Stevens TW, Eshuis EJ, et al. Cost-effectiveness of laparoscopic ileocaecal resection versus infliximab treatment of terminal ileitis in Crohn's disease: the LIR!C Trial. Gut 2019; 68: $1774-80$

248. de Groof EJ, Carbonnel F, Buskens CJ, Bemelman WA. Abdominal abscess in Crohn's disease: multidisciplinary management. Dig Dis 2014; 32 Suppl 1: 103-9.

249. Clancy C, Boland T, Deasy J, et al. A Meta-analysis of percutaneous drainage versus surgery as the initial treatment of Crohn's disease-related intra-abdominal abscess. J Crohns Colitis 2016; 10: 202-8.

250. He X, Lin X, Lian L, et al. Preoperative percutaneous drainage of spontaneous intra-abdominal abscess in patients with crohn's disease: a meta-analysis. J Clin Gastroenterol 2015; 49: e82-90.

251. Patel SV, Patel SV, Ramagopalan SV, Ott MC. Laparoscopic surgery for Crohn's disease: a meta-analysis of perioperative complications and long term outcomes compared with open surgery. BMC Surg 2013; 13: 14.

252. Dasari BV, McKay D, Gardiner K. Laparoscopic versus open surgery for small bowel Crohn's disease. Cochrane Database Syst Rev 2011; 1: CD006956.

253. Shigeta K, Okabayashi K, Hasegawa H, et al. Meta-analysis of laparoscopic surgery for recurrent Crohn's disease. Surg Today 2016; 46: 970-8.

254. Bouhnik Y, Carbonnel F, Laharie D, et al. Efficacy of adalimumab in patients with Crohn's disease and symptomatic small 
bowel stricture: a multicentre, prospective, observational cohort (CREOLE) study. Gut 2018; 67: 53-60.

255. Navaneethan U, Lourdusamy V, Njei B, Shen B. Endoscopic balloon dilation in the management of strictures in Crohn's disease: a systematic review and meta-analysis of non-randomized trials. Surg Endosc 2016; 30: 5434-43.

256. Bettenworth D, Gustavsson A, Atreja A, et al. A pooled analysis of efficacy, safety, and long-term outcome of endoscopic balloon dilation therapy for patients with stricturing Crohn's disease. Inflamm Bowel Dis 2017; 23: 133-42.

257. Morar PS, Faiz O, Warusavitarne J, et al. Systematic review with meta-analysis: endoscopic balloon dilatation for Crohn's disease strictures. Aliment Pharmacol Ther 2015; 42 1137-48.

258. Yamamoto T, Fazio VW, Tekkis PP. Safety and efficacy of strictureplasty for Crohn's disease: a systematic review and meta-analysis. Dis Colon Rectum 2007; 50: 1968-86.

259. Uchino M, Ikeuchi H, Matsuoka $H$, et al. Long-term efficacy of strictureplasty for Crohn's disease. Surg Today 2010; 40: 949-53.

260. Brennan GT, Ha I, Hogan C, et al. Does preoperative enteral or parenteral nutrition reduce postoperative complications in Crohn's disease patients: a meta-analysis. Eur J Gastroenterol Hepatol 2018; 30: 997-1002.

261. Grass F, Pache B, Martin D, et al. Preoperative nutritional conditioning of Crohn's patients-systematic review of current evidence and practice. Nutrients 2017; 9: 562.

262. Weimann A, Braga M, Carli F, et al. ESPEN guideline: clinical nutrition in surgery. Clin Nutr 2017; 36: 623-50.

263. Patel KV, Darakhshan AA, Griffin N, et al. Patient optimization for surgery relating to Crohn's disease. Nat Rev Gastroentero Hepatol 2016; 13: 707-19.

264. Subramanian V, Saxena S, Kang JY, Pollok RC. Preoperative steroid use and risk of postoperative complications in patients with inflammatory bowel disease undergoing abdominal surgery. Am J Gastroenterol 2008; 103: 2373-81.

265. Huang W, Tang Y, Nong L, Sun Y. Risk factors for postoperative intra-abdominal septic complications after surgery in Crohn's disease: a meta-analysis of observational studies. J Crohns Colitis 2015; 9: 293-301.

266. Zaghiyan K, Melmed GY, Berel D, et al. A prospective, randomized, noninferiority trial of steroid dosing after major colorectal surgery. Ann Surg 2014; 259: 32-7.

267. Kopylov U, Ben-Horin S, Zmora O, et al. Anti-tumor necrosis factor and postoperative complications in Crohn's disease: systematic review and meta-analysis. Inflamm Bowel Dis 2012; 18: 2404-13.

268. Narula N, Charleton D, Marshall JK. Meta-analysis: peri-operative anti-TNF treatment and post-operative complications in patients with inflammatory bowel disease. Aliment Pharmacol Ther 2013; 37: 1057-64

269. Xu Y, Yang L, An P, et al. Meta-analysis: the influence of preoperative infliximab use on postoperative complications of Crohn's disease. Inflamm Bowel Dis 2019; 25: 261-9.

270. Feng JS, Li JY, Chen XY, et al. Strategies for preventing endoscopic recurrence of Crohn's disease 1 year after surgery: a network meta-analysis. Gastroenterol Res Pract 2017; 2017: 7896160.
271. Mowat C, Arnott I, Cahill A, et al. Mercaptopurine versus placebo to prevent recurrence of Crohn's disease after surgical resection (TOPPIC): a multicentre, double-blind, randomised controlled trial. Lancet Gastroenterol Hepatol 2016; 1 : 273-82.

272. Yoshida K, Fukunaga K, Ikeuchi H, et al. Scheduled infliximab monotherapy to prevent recurrence of Crohn's disease following ileocolic or ileal resection: a 3-year prospective randomized open trial. Inflamm Bowel Dis 2012; 18: 1617-23.

273. Regueiro M, Feagan BG, Zou B, et al. Infliximab reduces endoscopic, but not clinical, recurrence of Crohn's disease after ileocolonic resection. Gastroenterology 2016; 150: 1568-78.

274. Savarino E, Bodini G, Dulbecco P, et al. Adalimumab is more effective than azathioprine and mesalamine at preventing postoperative recurrence of Crohn's disease: a randomized controlled trial. Am J Gastroenterol 2013; 108: 1731-42.

275. Gjuladin-Hellon T, Iheozor-Ejiofor Z, Gordon M, Akobeng AK. Azathioprine and 6-mercaptopurine for maintenance of surgically-induced remission in Crohn's disease. Cochrane Database Syst Rev 2019; 8: CD010233.

276. Gordon M, Naidoo K, Thomas AG, Akobeng AK. Oral 5-aminosalicylic acid for maintenance of surgically-induced remission in Crohn's disease. Cochrane Database Syst Rev 2011; 1: CD008414.

277. van der Woude CJ, Ardizzone S, Bengtson MB, et al. The second European evidenced-based consensus on reproduction and pregnancy in inflammatory bowel disease. J Crohns Colitis 2015; 9: 107-24.

278. Shin T, Okada H. Infertility in men with inflammatory bowel disease. World J Gastrointest Pharmacol Ther 2016; 7: 361-9.

279. Kozlowski RD, Steinbrunner JV, MacKenzie AH, et al. Outcome of first-trimester exposure to low-dose methotrexate in eight patients with rheumatic disease. Am J Med 1990; 88: 589-92.

280. Ban L, Tata LJ, Fiaschi L, Card T. Limited risks of major congenital anomalies in children of mothers with IBD and effects of medications. Gastroenterology 2014; 146: 76-84.

281. Shannahan SE, Erlich JM, Peppercorn MA. Insights into the treatment of inflammatory bowel disease in pregnancy. Therap Adv Gastroenterol 2019; 12: 1756284819852231.

282. Tavernier N, Fumery M, Peyrin-Biroulet L, et al. Systematic review: fertility in non-surgically treated inflammatory bowel disease. Aliment Pharmacol Ther 2013; 38: 847-53.

283. Carmichael SL, Shaw GM, Ma C, et al. Maternal corticosteroid use and orofacial clefts. Am J Obstet Gynecol 2007; 197: 585.e1-e7.

284. Hviid A, Mølgaard-Nielsen D. Corticosteroid use during pregnancy and risk of orofacial clefts. CMAJ 2011; 183: 796-804.

285. Hatch Q, Champagne BJ, Maykel JA, et al. Crohn's disease and pregnancy: the impact of perianal disease on delivery methods and complications. Dis Colon Rectum 2014; 57: 174-8.

286. Harbord M, Annese V, Vavricka SR, et al. The first European evidence-based consensus on extra-intestinal manifestations in inflammatory bowel disease. J Crohns Colitis 2016; 10: $239-54$

287. Zhao X, Zhou C, Chen H, et al. Efficacy and safety of medical therapy for low bone mineral density in patients with Crohn disease: a systematic review with network meta-analysis. Medicine 2017; 96: e6378. 
288. van Bodegraven AA, Bravenboer N, Witte BI, et al. Treatment of bone loss in osteopenic patients with Crohn's disease: a double-blind, randomised trial of oral risedronate $35 \mathrm{mg}$ once weekly or placebo, concomitant with calcium and vitamin D supplementation. Gut 2014; 63: 1424-30.

289. Li J, Chen N, Wang D, et al. Efficacy of vitamin D in treatment of inflammatory bowel disease: a meta-analysis. Medicine 2018; 97: e12662.

290. Fletcher J, Cooper SC, Ghosh S, Hewison M. The role of vitamin D in inflammatory bowel disease: mechanism to management. Nutrients 2019; 11: 1019.

291. Forbes A, Escher J, Hébuterne X, et al. ESPEN guideline: clinical nutrition in inflammatory bowel disease [published correction appears in Clin Nutr. 2019 Jun;38(3):1486] [published correction appears in Clin Nutr. 2019 Jun;38(3):1485]. Clin Nutr 2017; 36: 321-47.

292. Gomollón F, Dignass A, Annese V, et al. $3^{\text {rd }}$ European evidence-based consensus on the diagnosis and management of Crohn's disease 2016: Part 1: diagnosis and medical management. J Crohns Colitis 2017; 11: 3-25.

293. Levine A, Wine E, Assa A, et al. Crohn's disease exclusion diet plus partial enteral nutrition induces sustained remission in a randomized controlled trial. Gastroenterology 2019; 157 440-50.e8.

294. Levine A, Rhodes JM, Lindsay JO, et al. Dietary guidance from the International Organization for the Study of Inflammatory Bowel Diseases. Clin Gastroenterol Hepatol 2020; 18 1381-92.

295. Kaitha S, Bashir M, Ali T. Iron deficiency anemia in inflammatory bowel disease. World J Gastrointest Pathophysiol 2015 6: 62-72.

296. Patel D, Trivedi C, Khan N. Management of anemia in patients with inflammatory bowel disease (IBD). Curr Treat Options Gastroenterol 2018; 16: 112-28.

297. Evstatiev R, Marteau P, Iqbal T, et al. FERGIcor, a randomized controlled trial on ferric carboxymaltose for iron deficiency anemia in inflammatory bowel disease. Gastroenterology 2011; 141: 846-53.e8532.

298. Peyrin-Biroulet L, Van Assche G, Gómez-Ulloa D, et al. Systematic review of tumor necrosis factor antagonists in extraintestinal manifestations in inflammatory bowel disease. Clin Gastroenterol Hepatol 2017; 15: 25-36.e27.

299. Chateau T, Bonovas S, Le Berre C, et al. Vedolizumab treatment in extra-intestinal manifestations in inflammatory bowel disease: a systematic review. J Crohns Colitis 2019; 13: 1569-77.

300. Guillo L, D’Amico F, Danese S, Peyrin-Biroulet L. Ustekinumab for extra-intestinal manifestations of inflammatory bowe disease: a systematic literature review. J Crohns Colitis 2021; 15: $1236-43$

301. Rubin LG, Levin MJ, Ljungman P, et al. 2013 IDSA clinical practice guideline for vaccination of the immunocompromised host [published correction appears in Clin Infect Dis. 2014 Jul 1;59(1):144]. Clin Infect Dis 2014; 58: e44-e100.

302. Rahier JF, Magro F, Abreu C, et al. Second European evidence-based consensus on the prevention, diagnosis and management of opportunistic infections in inflammatory bowel disease. J Crohns Colitis 2014; 8: 443-68.
303. Farraye FA, Melmed GY, Lichtenstein GR, Kane SV. ACG clinical guideline: preventive care in inflammatory bowel disease [published correction appears in Am J Gastroenterol. 2017 Jul;112(7):1208]. Am J Gastroenterol 2017; 112: 241-58.

304. Siegel CA, Melmed GY, McGovern DP, et al. SARS-CoV-2 vaccination for patients with inflammatory bowel diseases: recommendations from an international consensus meeting. Gut 2021; 70: 635-40.

305. Eder P, Łodyga M, Dobrowolska A, et al. Position statement of the Polish Society of Gastroenterology and the National Gastroenterology Consultant on vaccination against COVID-19 among patients with inflammatory bowel diseases. Gastroenterology Rev 2021; 16: 2-4.

306. Bernstein CN, Hitchon CA, Walld R, et al. Increased burden of psychiatric disorders in inflammatory bowel disease. Inflamm Bowel Dis 2019; 25: 360-8.

307. Timmer A, Preiss JC, Motschall E, et al. Psychological interventions for treatment of inflammatory bowel disease. Cochrane Database Syst Rev 2011; 2: CD006913.

308. Mikocka-Walus A, Bampton P, Hetzel D, et al. Cognitive-behavioural therapy for inflammatory bowel disease: 24-month data from a randomised controlled trial. Int J Behav Med 2017; 24: 127-35

309. Wynne B, McHugh L, Gao W, et al. Acceptance and commitment therapy reduces psychological stress in patients with inflammatory bowel diseases. Gastroenterology 2019; 156: 935-45.e1.

Received: 1.10 .2021

Accepted: 25.10 .2021 